Universidade de São Paulo

Instituto de Física de São Carlos

Thiago Altair Ferreira

Ambientes radioativos naturais como fonte de desequilíbrio local em cenários planetários e prebióticos 

Thiago Altair Ferreira

\title{
Ambientes radioativos naturais como fonte de desequilíbrio local em cenários planetários e prebióticos
}

\author{
Dissertação apresentada ao Programa de Pós- \\ Graduação em Física do Instituto de Física de \\ São Carlos da Universidade de São Paulo, para \\ obtenção do título de Mestre em Ciências. \\ Área de concentração: Física Aplicada \\ Opção: Física Biomolecular \\ Orientador: Dr. Douglas Galante
}

\begin{abstract}
Versão Corrigida
(versão original disponível na Unidade que aloja o Programa)
\end{abstract}

São Carlos

2018 
AUTORIZO A REPRODUÇÃO E DIVULGAÇĂO TOTAL OU PARCIAL DESTE TRABALHO, POR QUALQUER MEIO CONVENCIONAL OU ELETRÓNICO PARA FINS DE ESTUDO E PESQUISA, DESDE QUE CITADA A FONTE.

Eerreira, Thiago Altair.

Ambientes radioativos naturais como fonte de

desequilibrio local em cenártos planetários e prebibticos / Thiago Altair Ferreiras orientador Douglas Galante -

versato corrigida -- Sao Carlos, 2018.

$103 \mathrm{P}$.

Dissertaça (Mestrado - Programa de PGs-Graduaçáo em Fisica hplicada Biomolecular) -- Instituto de Fisica de săo Carlos, Universidade de Sào Paulo, 2018.

1. Origem da vida. 2. Habitabilidade. 3. Transduçao. 4. Fadiolise aquosa. 5. Desequilibrio termodinamico. I. Galante, Douglas, orient. II. titulo. 


\section{AGRADECIMENTOS}

Agradeço, principalmente, ao orientador deste projeto, o Dr. Douglas Galante pela oportunidade concedida para realizar este trabalho e pelos auxílios em momentos de emergência durante o processo, principalmente com ideias um tanto quanto impressionantes.

Agradeço aos colaboradores, Dr. Marcio G. B. de Avellar, Larissa Sartori que auxiliaram em muitos momentos extremamente importantes deste trabalho que se consolidou; e agradeço, em especial, ao Prof. Dr. Fabio Rodrigues não apenas pelas ajudas e ideias, mas pela gentileza em oferecer espaço em seu laboratório para que se pudesse seguir com esse trabalho.

Agradeço aos velhos amigos em São Paulo e aos novos amigos em São Carlos por questões externas a esse trabalho. Mas sem os momentos que partilhamos, o valor pedagógico do processo que resultou nessa dissertação seria fortemente comprometido.

E agradeço às agências de fomento pelo financiamento deste projeto de pesquisa em nível de

Mestrado - especificamente CAPES/PROEX e processo $n^{\circ}$ 2016/08854-7, Fundação de Amparo à Pesquisa do Estado de São Paulo (FAPESP). 

“Onde quer que estejas, cava profundamente; Em baixo fica a fonte.

Deixa os homens sombrios a gritar: 'Em baixo fica sempre o inferno'” 



\section{RESUMO}

FERREIRA, T.A. Ambientes radioativos naturais como fonte de desequilíbrio local em cenários planetários e prebióticos. 2018. 103 p. Dissertação (Mestrado em Ciências) Instituto de Física de São Carlos, Universidade de São Paulo, São Carlos, 2018.

Certos ambientes subterrâneos da Terra possuem acumulados, naturalmente, compostos de radionuclídeos de longa vida, como ${ }^{238} \mathrm{U},{ }^{232} \mathrm{Th}{ }^{40} \mathrm{~K}$, próximo à presença de água líquida. $\mathrm{O}$ mesmo é esperado que aconteça em corpos planetários, no Sistema Solar, que possua quantidades apreciáveis de água. Nestes ambientes radioativos naturais, a radiólise da água produz espécies químicas e desequilíbrios químicos importantes para a vida. Apesar da proposta do decaimento radioativo como fonte alternativa de energia para sistemas vivos existir há mais de trinta anos, isto se mostrou realmente concreto após descoberta de um ecossistema peculiar cuja sobrevivência é dependente de espécies químicas produzidas por radiólise aquosa. Neste trabalho, avaliamos e quantificamos os desequilíbrios químicos gerados localmente pela radiólise aquosa e a possível contribuição destes para a emergência da vida, tendo como referência os estudos em ambientes de fontes hidrotermais alcalinas, consideradas promissores ambientes para esse evento. Também foram avaliados seus efeitos na habitabilidade de possíveis ambientes análogos na lua gelada Europa. Procuramos quantificar a diversidade química formada nessas condições e a associar aos desequilíbrios parâmetros termodinâmicos. As estimativas realizadas para ambientes radioativos na Terra primitiva apontaram para a similaridade entre o desequilíbrio causado por radiólise aquosa e o encontrado em fontes hidrotermais alcalinas. Confirmando e detalhando a análise preliminar que motivou o trabalho. Não obstante, considerando Europa, chegamos a valores de densidade de células do extremófilo Candidatus Desulforudis audaxviator que sobreviveriam em um conjunto de candidatos a análogos geológicos de possível ambiente radioativo na lua gelada. A partir deste estudo pudemos analisar o potencial para a emergência da vida e de protometabolismos nestes ambientes radioativos naturais na Terra primitiva, bem como levantar parâmetros mensuráveis para futuras missões espaciais que buscam vida ou habitabilidade em Europa.

Palavras-chave: Origem da vida. Habitabilidade. Transdução. Radiólise aquosa. Desequilíbrio termodinâmico. 



\begin{abstract}
FERREIRA, T.A. Natural radioactive environments as a source of local disequilibrium in planetary and prebiotic scenarios. 2018. 103 p. Dissertação (Mestrado em Ciências) Instituto de Física de São Carlos, Universidade de São Paulo, São Carlos, 2018.
\end{abstract}

Certain subterranean environments of the Earth has naturally accumulated compounds of longlived radionuclides, such as ${ }^{238} \mathrm{U},{ }^{232} \mathrm{Th}{ }^{40} \mathrm{~K}$, near the presence of liquid water. The same is estimated in wet planetary bodies in the Solar System. In these natural radioactive environments, water radiolysis produces chemical species and chemical disequilibria, which are important for life. Although the proposal of radioactive decay as an alternative source of energy for deep biospheres has existed for more than thirty years, this proved to be really feasible after the discovery of a peculiar ecosystem whose survivor is dependent on chemical species produced by water radiolysis. In this work, we evaluate and quantify the chemical disequilibria generated locally by water radiolysis and the possible contribution of these to the emergence of life, having as reference the studies alkaline hydrothermal vents, which is considered highly promising environment for this event. It is also evaluated their effects on the habitability of possible analogous environments on the Jupiter icy moon Europa. It was aimed to quantify the chemical diversity formed under these conditions and to calculate disequilibria using thermodynamic parameters. The estimates made for natural radioactive environments in early Earth pointed to the similarity between the disequilibrium caused by water radiolysis and those found in alkaline hydrothermal vents. What confirms and details the preliminary analysis that motivated this work. In addition, it was calculated values for cell density of the Candidatus Desulforudis audaxviator extremophile, that would survive in Europa comparable to the in situ analysis of some terrestrial radioactive environments, using a set of possible scenarios for possible local natural radioactive environments. From this study, we were able to analyze the potential for the emergence of life and protometabolisms in these natural radioactive environments in early Earth, as well as to provide measurable parameters for future space missions that seek for life or habitability in Europa.

Keywords: Origins of life. Habitability. Transduction. Water radiolysis. Thermodynamic disequilibrium. 



\section{LISTA DE FIGURAS}

FIGURA 1 - MODELO DA ESPÉCIE PROPOSTA SER A ÚNICA PRESENTE NO ECOSSISTEMA EXISTENTE NA SUBSUPERFÍCIE PROFUNDA NA FORMAÇÃO DE WITWATERSRAND. É REPRESENTADA UMA DAS PRINCIPAIS VIAS METABÓLICAS DO CA. D. AUDAXVIATOR, DE REDUÇÃO DE SULFATO PARA A PRODUÇÃO DE ATP. SÃO TAMBÉM REPRESENTADAS AS FONTES DE ENERGIA E NUTRIENTES A PARTIR DA RADIÓLISE AQUOSA.

FIGURA 2 - AMBIENTE DE FONTES HIDROTERMAIS NOS CAMPOS DE LOST CITY.A: IMAGEM CAPTURADA PELO VEÍCULO SUBMARINO ARGOLL DE UM MONTE INATIVO DE CARBONATO NA PARTE ORIENTAL DOS CAMPOS DE LOST CITY, POSSUINDO ALTURA DE 8M. B: FLANGE DA DIMENSÃO DE 1M COM COMUNIDADES BACTERIANAS DE FORMAÇÃO DE CARBONATO E BRUCITA CRESCENDO HORIZONTALMENTE A PARTIR DAS LATERAIS DA CHAMINÉ. C: IMAGEM DE MICROSCOPIA ELETRÔNICA DE VARRIMENTO DA FLANGE APRESENTADA EM B COLETADA PELO VEÍCULO ALVIN APRESENTANDO A MATRIZ CARBONÁTICA POROSA. D: IMAGEM DE FLUORESCÊNCIA DE COMUNIDADES BACTERIANAS DA FLANGE APRESENTADA EM B.

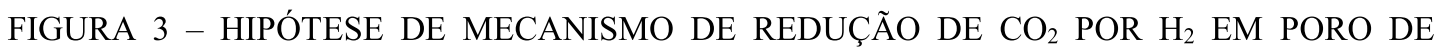
FONTES HIDROTERMAIS. NESTA, AS DUAS FASES ESTÃO JUSTAPOSTAS NO PORO DO PRECIPITADO CARBONÁTICOS, ONDE A BARREIRA DE MINERAL DO TIPO FE(NI)S SEPARA O FLUIDO HIDROTERMAL DO OCEANO. O ACÚMULO DE CARGA NA BARREIRA É EVITADA PELO FLUXO E POSSÍVEL MISTURA OS FLUIDOS EM OUTRA REGIÃO.

FIGURA 4 - DISTRIBUIÇÃO TÉRMICA NOS OCEANOS MODERNOS.

FIGURA 5 - MODELO DE EUROPA ILUSTRANDO O MATERIAL RADIOGÊNICO E A RADIÓLISE AQUOSA QUE OCORRE NA SUBSUPERFÍCIE. ASSUMIMOS A PRESENÇA DE ${ }^{238} \mathrm{U}$ E ${ }^{232} \mathrm{TH}$ PRESENTE EM ROCHAS DA LUA GELADA E ${ }^{40} \mathrm{~K}$ DISSOLVIDO NA ÁGUA.

FIGURA 6 - RESULTADO DO MODELO CINÉTICO PARA PRODUÇÃO DE ESPÉCIES QUÍMICAS A PARTIR DA RADIÓLISE AQUOSA. AS CONCENTRAÇÕES SÃO APRESENTADAS EM FUNÇÃO DO TEMPO. OS CÁLCULOS DA DIVERSIDADE QUÍMICA EFEITO DA RADIÓLISE AQUOSA FOI FEITA CONSIDERANDO A CONCENTRAÇÃO DE ${ }^{238} \mathrm{U},{ }^{232} \mathrm{TH}$ E ${ }^{40} \mathrm{~K}$ ASSOCIADAS A ESTRATOS MINERAIS MAIS CONCENTRADOS EM WITWATERSRAND - SENDO A CONCENTRAÇÃO E ATIVIDADE DE ${ }^{40} \mathrm{~K}$ RELATIVOS AO OCEANO PRIMITIVO, E CONSIDERANDO OCEANO PRIMITIVO MODERADAMENTE ÁCIDO (PH=5). 
FIGURA 7 - RESULTADO DO MODELO CINÉTICO PARA PRODUÇÃO DE ESPÉCIES QUÍMICAS A PARTIR DA RADIÓLISE AQUOSA. AS CONCENTRAÇÕES SÃO APRESENTADAS EM FUNÇÃO DO TEMPO. OS CÁLCULOS DA DIVERSIDADE QUÍMICA EFEITO DA RADIÓLISE AQUOSA FOI FEITA CONSIDERANDO A CONCENTRAÇÃO DE ${ }^{238} \mathrm{U},{ }^{232} \mathrm{TH} \mathrm{E}{ }^{40} \mathrm{~K}$ ASSOCIADAS A CONDRITOS E CONSIDERANDO OCEANO PRIMITIVO MODERADAMENTE ÁCIDO (PH=5) .......63

FIGURA 8 - GRADIENTE DE PH EM FUNÇÃO DO TEMPO E DO ESPAÇO NA INTERFACE ENTRE UM AMBIENTE RADIOATIVO EM X $=0$ (ORIGEM ESPACIAL) E O OCEANO PRIMITIVO DE $\mathrm{PH}=5$ E TEMPERATURA $\mathrm{T}=5^{\circ} \mathrm{C}$. PARA TAL GRADIENTE, FOI CONSIDERADO MODELO UNIDIMENSIONAL DE DIFUSÃO DOS ÍONS $\mathrm{H}^{+} \mathrm{E} \mathrm{OH}^{-}$PELA LEI DE FICK E DIFUSIVIDADE CONSTANTE. EM $\mathrm{X}=0$, TEMOS O PH RELATIVO AO AMBIENTE RADIOATIVO, UTILIZANDO AS CONCENTRAÇÕES APRESENTADAS NA TABELA 4 PARA REGIÃO EM WITWATERSRAND CORRIGIDAS PARA PERÍODO ANTERIOR A 4 GA.

FIGURA 9 - DISTRIBUIÇÃO DE $\mathrm{H}_{2}$ NO TEMPO E NO ESPAÇO A PARTIR DE MODELO DE DIFUSÃO UNIDIMENSIONAL PELA LEI DE FICK, CONSIDERANDO O COEFICIENTE DE DIFUSÃO CONSTANTE RELATIVO AO MEIO AQUOSO A $\mathrm{T}=5^{\circ} \mathrm{C}$. NESTE MODELO, EM X=0 ESTÁ A CONCENTRAÇÃO MÉDIA DO PERÍODO DE TEMPO EM QUE A CONCENTRAÇÃO DE $\mathrm{H}_{2}$, NA FIGURA 5 A), ENCERRA SUA OSCILAÇÃO -APROXIMADAMENTE EM T $=7,5.10^{5}$ ANOS.

FIGURA 10 - SUPERIOR: FORÇA ELETROMOTRIZ ASSOCIADA AO ESPAÇO E TEMPO EM DECORRÊNCIA AO GRADIENTE QUIMIOSMÓTICO ENTRE O AMBIENTE RADIOATIVO - EM X=0 (ORIGEM ESPACIAL) - E OCEANO PRIMITIVO. INFERIOR: POTENCIAL QUÍMICO ASSOCIADA AO ESPAÇO E TEMPO EM DECORRÊNCIA AO GRADIENTE QUIMIOSMÓTICO ENTRE O AMBIENTE RADIOATIVO - EM X=0 - E OCEANO PRIMITIVO. PARA AMBOS OS CASOS, CONSIDERAMOS QUE ESPÉCIES ESTÃO SE DIFUNDINDO EM OCEANO PRIMITIVO DE TEMPERATURA T $=5^{\circ} \mathrm{C}$ E $\mathrm{PH}=5$

FIGURA 11 - REGIÕES DE MAIOR PROBABILIDADE DE PRECIPITAÇÃO DE MINERAIS DE FERRO E ENXOFRE EM REGIÃO PRÓXIMA A AMBIENTE RADIOATIVO. APRESENTA A VARIAÇÃO DE PH E FORÇA ELETROMOTRIZ (F.E.M.) EM FUNÇÃO DA DISTÂNCIA EM REGIÃO DE AMBIENTE RADIOATIVO APÓS ESTABILIZAÇÃO DOS VALORES (APÓS $10^{4}$ SEGUNDOS DE DIFUSÃO DAS ESPÉCIES FORMADAS). AS BARRAS HORIZONTAIS APRESENTAM A REGIÃO ONDE CADA MINERAL SE MOSTRA ESTÁVEL, CONSIDERANDO SIMULTANEAMENTE O PH E O POTENCIAL ASSOCIADO À FAIXA DE DISTÂNCIA REPRESENTADA. AS ESTABILIDADES FORAM VERIFICADAS EM DUAS REFERÊNCIAS; LINHAS VERDES: ESTABILIDADES DE ÓXIDOS, SULFETOS E CARBONATOS DE FERRO EM ÁGUA A $25^{\circ} \mathrm{C}$ E 1 ATM DE PRESSÃO. CONSIDERANDO CONCENTRAÇÃO DE ENXOFRE DISSOLVIDO DE $10^{-6} \mathrm{M}, \quad \mathrm{E}$ DE $\sum \mathrm{CO}_{2}=1 \mathrm{M}$; LINHAS PRETAS: ESTABILIDADES DE CARBONATOS E PIRITA, CONSIDERANDO PRESSÃO DE ÁGUA COMO PRESSÃO TOTAL 
FIGURA 12 - RELAÇÃO ENTRE DENSIDADE CELULAR QUE SOBREVIVERIA POR MASSA DE ROCHA EM FUNÇÃO DA VARIAÇÃO DO TAMANHO DE GRÃO DE PIRITA PARA OS DIFERENTES CENÁRIOS. A ESPESSURA DAS FAIXAS REPRESENTA OS VALORES ENTRE O MÁXIMO DA DENSIDADE QUE SOBREVIVERIA, ENQUANTO OS DIFERENTES CENÁRIOS SÃO REPRESENTADOS NAS VARIAÇÕES DE CONCENTRAÇÃO DE ${ }^{238} \mathrm{U},{ }^{232} \mathrm{TH},{ }^{40} \mathrm{~K}$ EM MEIO AQUOSO E DE PIRITA NO MEIO ROCHOSO.

FIGURA C.1 - RESULTADO MODELO CINÉTICO PARA CONCENTRAÇÃO DE RADIONUCLÍDEO DE CONDRITOS. $\quad\left[{ }^{238} \mathrm{U}\right]=12 \quad \mathrm{PPB} ;\left[{ }^{232} \mathrm{TH}\right]=40$ PPB; $\left[{ }^{40} \mathrm{~K}\right]=105$ PPB. EM MODELOS DE OCEANOS PRIMITIVOS A) DE $\mathrm{PH}=5$; $\mathrm{B}) \mathrm{DE} \mathrm{PH}=7$.

FIGURA C.2 - RESULTADO MODELO CINÉTICO PARA CONCENTRAÇÃO DE RADIONUCLÍDEO DE WITWATERSRAND. $\left[{ }^{238} \mathrm{U}\right]=271 \quad \mathrm{PPM} ;\left[{ }^{232} \mathrm{TH}\right]=15$ PPM; $\left[{ }^{40} \mathrm{~K}\right]=380$ PPM. EM MODELOS DE OCEANOS PRIMITIVOS A) DE $\mathrm{PH}=5$; B) $\mathrm{DE} \mathrm{PH}=7$. 



\section{LISTA DE TABELAS}

TABELA 1 - EXEMPLOS DE REAÇÕES E CONSTANTES DE VELOCIDADES ASSOCIADAS QUE DESCREVEM O PROCESSO DE RADIÓLISE AQUOSA.

TABELA 2 - DIFERENTES CONCENTRAÇÕES PROPOSTAS PARA O OCEANO PRIMITIVO 35

TABELA 3 - CARACTERÍSTICAS DE AMOSTRAS DE ÁGUAS SUBTERRÂNEAS DE DIFERENTES REGIÕES E FORMAÇÕES GEOLÓGICAS NA BACIA DE WITWATERSRAND, ÁFRICA DO SUL

TABELA 4- VALORES ASSOCIADOS AO RADIONUCLÍDEOS UTILIZADOS PARA O MODELO DE PRODUÇÃO DE ESPÉCIES QUÍMICAS POR RADIÓLISE AQUOSA ........46

TABELA 5 - TAXA DE PRODUÇÃO DE DIVERSAS ESPÉCIES QUÍMICAS PARA RAIOS GAMA.

TABELA 6 - REAÇÕES ENVOLVENDO PRODUTOS DA RADIÓLISE E SUAS RESPECTIVAS CONSTANTES DE REAÇÃO.

TABELA 7 - RESULTADOS DO CÁLCULO DA ÁREA SUPERFICIAL DE PIRITA COM BASE EM DIFERENTES TIPOS DE AGREGADOS CONFORME A ESCALA DE WENTWORTH (97). 



\section{SUMÁRIO}

1 Introdução.

1.1 Origens da vida: perspectiva termodinâmica e bioenergética da emergência a partir de sistemas geológicos.

1.2 Fenômeno da radiólise e sua proposta prebiótica .....................................................29

1.3 Condições físico-químicas oceânicas em contexto primitivo ......................................31

1.4 Condições físico-químicas dos campos hidrotermais de Lost City ….........................35

1.5 Condições físico-químicas e geoquímicas dos ambientes radioativos ....................... 38

1.6 Ecossistema de espécie única mantido por produto de radiólise em ambiente

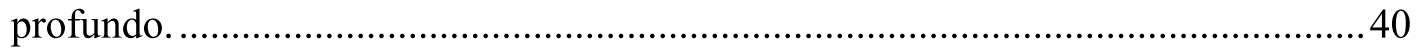

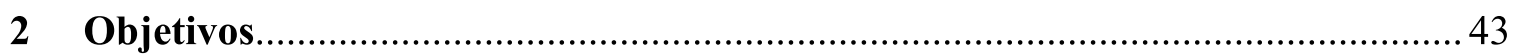

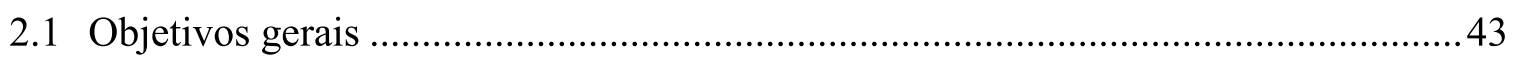

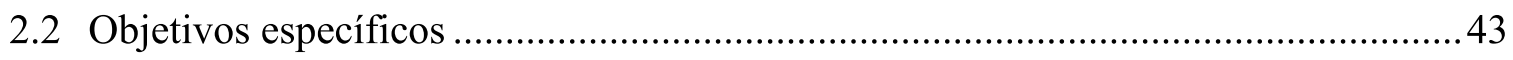

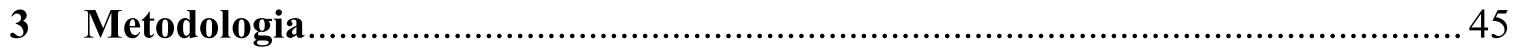

3.1 Condições físico-químicas dos ambientes e diversidade química pela radiólise

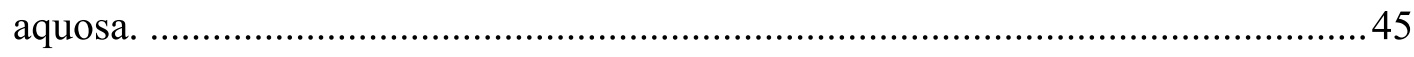

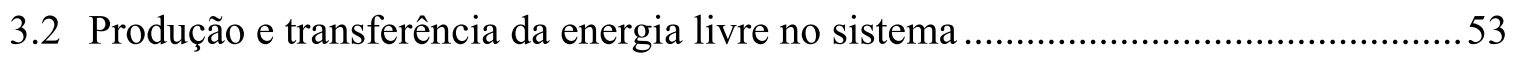

3.3 Mecanismos de transferência de energia entre sistema geológico e biológico...........54

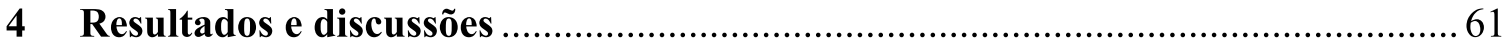

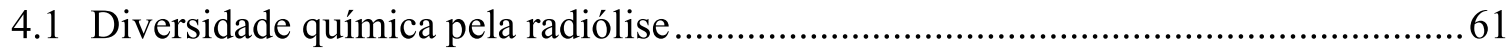

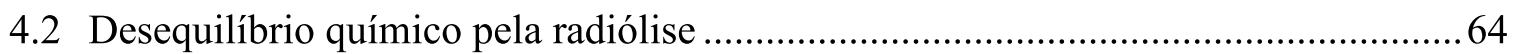

4.3 Condições para transdução da energia livre formada ...............................................68

4.4 Possibilidade de vida mantida a partir de decaimento radioativo em subsuperfície da

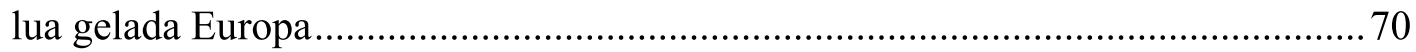

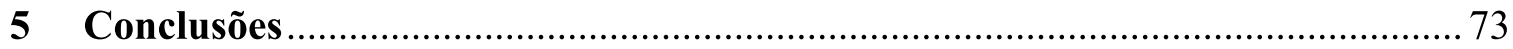

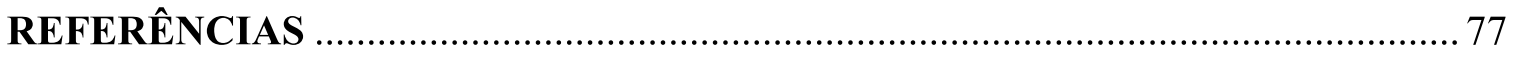

APÊNDICE A - Artigo publicado na Scientific Reports em 2018............................. 85

APÊNDICE B - Material Suplementar do artigo publicado na Scientific Reports... 93

APÊNDICE C - Resultados de modelo cinético de radiólise aquosa em diversos

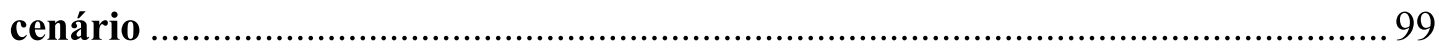

APÊNDICE D - Equações Diferenciais Ordinárias (EDOs) stiff e princípios de método Rosenbrock de integração numérica. 



\section{Introdução}

Já se é conhecido de que os ambientes de alta profundidade são onde habitam a maior parte da biomassa de procariotos, onde sua densidade celular é baixa e o metabolismo age extremamente lento. (1-2) Esses ambientes extremos, e sem contato com luz solar, apresentam grandes desafios para a existência de vida como estamos habituados - tal como alta pressão, altas ou baixas temperaturas, baixa disponibilidade de fontes de energia e nutrientes $(3,4)$, e ainda alta incidência de radiação ionizante -, nas chamadas condições mesofílicas. Alguns exemplos de ambientes radioativos com essas características já foram descritos na literatura, como é o caso de minas de ouro na região central e sul do continente africano $(3,5,6)$ ou regiões de exploração de urânio, no Canadá. (7) A partir destes casos de ambientes em profundidade com fontes de energia a partir de fenômenos nucleares naturais, que inclui ambientes habitáveis com organismos dependentes desses fenômenos para sua sobrevivência, como veremos adiante, cria perspectivas para fontes alternativas de energia para a emergência e manutenção da vida na Terra primitiva, que não seja provinda da radiação solar nem de fenômenos geotérmicos. Além disto, considerando que tais ambientes são enriquecido de material físsil remanescentes da supernova que precedeu a formação do Sistema Solar, conforme os modelos de acreção mais conhecidos (8), podemos traçar um paralelo de análogos existentes mesmo em ambientes extraterrestres, tais como as luas geladas do Sistema Solar. $(9,10)$

Consideraremos aqui os ambientes radioativos naturais definidos como arranjos geológicos que contenham, no interior de ambiente rochoso, material físsil naturalmente acumulado e presença de água. Tais ambientes, em geral, podem ter tido um papel relevante no processo de emergência de vida e evolução no contexto de ecossistemas no Pré-Cambriano (11) - época mais antiga em que se encontrou traços químicos associados a vida (12) -, por proverem energia continuamente na forma de radiação e os desequilíbrios químicos necessários. Neste trabalho, consideraremos os materiais de radionuclídeos de longa-vida que são fontes de radiação alfa, beta e gama, tal como ${ }^{238} \mathrm{U},{ }^{232} \mathrm{Th}$ e ${ }^{40} \mathrm{~K}$, devido ao conhecimento experimental e teórico já desenvolvido sobre seus efeitos nesse contexto geológico. $(10,13,14)$ A radiação emitida por estes nuclídeos é capaz de dissociar moléculas de água, formando espécies químicas radicalares e iônicas altamente reativas, além de espécies redutoras (7, 13-16), como se mostra ilustrado na equação.(1) Esse fenômeno gera uma condição físico-química capaz de acelerar a interação água-rocha, própria de ambientes de profundidade, além de transformar a energia livre liberada pelo decaimento em energia química, a partir de produtos que podem participar do metabolismo de algum sistema vivo. 


$$
\mathrm{H}_{2} \mathrm{O} \stackrel{\text { Radiação ionizante }}{\rightarrow} e_{a q}^{-}, \mathrm{H}^{\cdot}, \mathrm{HO}^{\prime}, \mathrm{HO}_{2}, \mathrm{H}_{2} \mathrm{O}_{2}, \mathrm{H}^{+}, \mathrm{OH}^{-}, \mathrm{H}_{2}
$$

Dada a diversidade química gerada pela radiólise, já se estimou no final do século passado a hipótese desta agir como fonte de energia e de espécies químicas para sustentar um sistema vivo em ambiente subterrâneo $(6,17,18)$, mas somente após recentes trabalhos (5) que foi considerada concreta tal hipótese. Veio então a conclusão de que, em ambientes radioativos naturais existe espécie microbiana litoautotrófica cuja sobrevivência é independente de fotossíntese a partir de luz solar; Mas dependente da energia as reações redox envolvendo espécies formadas direta ou indiretamente pela radiólise aquosa, como é o caso da reação do $\mathrm{H}_{2}$ com outras espécies aceptoras de elétrons (ex: $\mathrm{SO}_{4}{ }^{2-}, \mathrm{Fe}^{3+}$ ou $\left.\mathrm{CO}_{2}\right)$. $(5,16,18,19)$. Tal característica é associada à bactéria Candidatus Desulforudis audaxviator (Figura 1), encontrada predominando a uma profundidade de $2,8 \mathrm{~km}$ abaixo da superfície local, em acúmulo de água nas paredes da mina de ouro Mponeng, localizada na bacia de Witwatersrand, a 300 km de distância de Joanesburgo, Africa do Sul. (5) Os resultados da metagenômica de amostras dessas águas mostraram não apenas a presença de organismos vivos, mas, surpreendentemente, indicou a existência de um ecossistema proposto como de espécie única, em um ambiente com temperatura média de aproximadamente $60^{\circ} \mathrm{C}$ e o meio aquoso de $\mathrm{pH}$ igual a 9,3. (5) Esse seria o primeiro exemplo de ecossistema estável com apenas uma única espécie presente, e, além disso, dependente de espécies químicas provindas da atividade radioativa (Figura 1).

Apesar da notória importância das fontes de energia e do desequilíbrio para a vida, é evidente, todavia, que são necessários mecanismos que tornem esta energia livre em biologicamente aproveitável. Sistemas vivos atualmente fazem uso de inúmeros mecanismos, principalmente envolvendo complexos nano-motores movidos pelo gradiente quimiosmótico que trabalham conjuntamente à vias metabólicas. $(20,21)$ Para a emergência da vida, não podemos contar com este aparato complexo auxiliado por enzimas e outras macromoléculas que se encontram em seres vivos atuais. Desta maneira, é essencial uma melhor definição das reações protometabólica específicas para a sustentação de um sistema autopoiético (22) em um contexto prebiótico da Terra. 


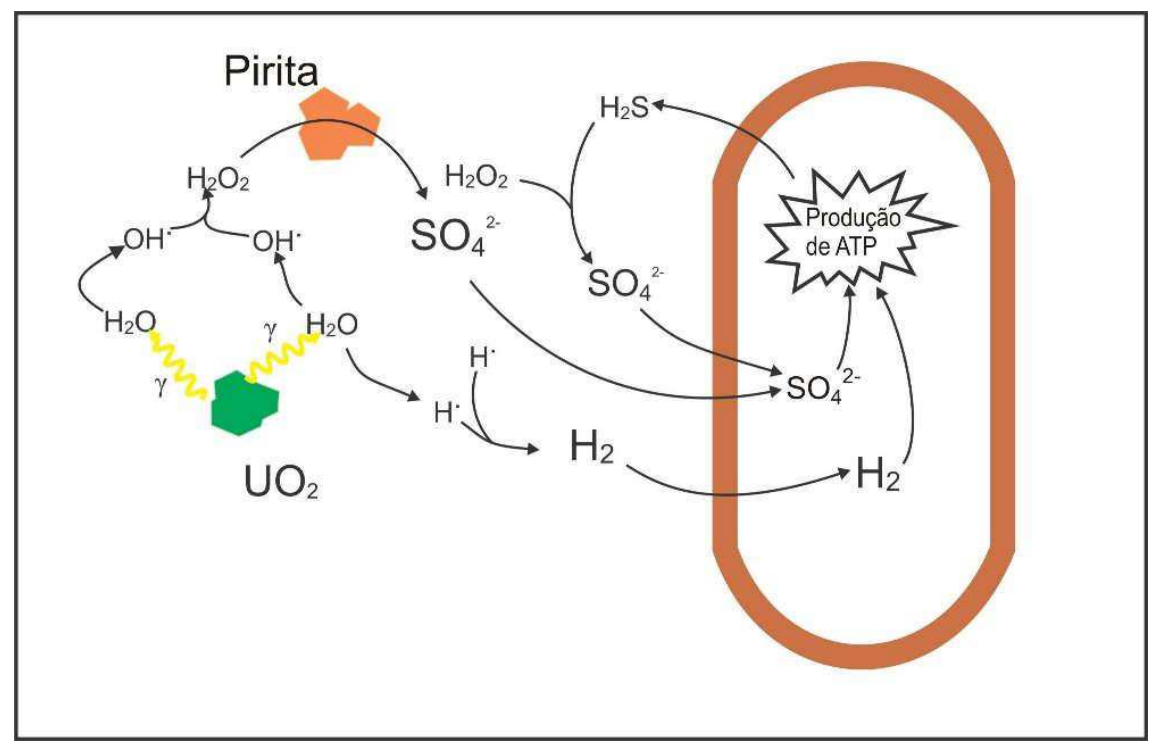

Figura 1 - Modelo da espécie proposta ser a única presente no ecossistema existente na subsuperfície profunda na formação de Witwatersrand em $2,8 \mathrm{~km}$ abaixo da superfície local. É representada uma das principais vias metabólicas do Ca. D. audaxviator, de redução de sulfato para a produção de ATP. São também representadas as fontes de energia e nutrientes a partir da radiólise aquosa.

Fonte: Adaptada de CHIVIAN et al. (5)

Este trabalho se foca em analisar a possível contribuição dos ambientes com fontes de energia radioativas para a origem e evolução da vida na Terra primitiva. Para contribuir a este fim, veremos a analogia entre estes ambientes radioativos e o ambiente de fontes hidrotermais alcalinas, como é o caso dos campos hidrotermais de Lost City (Figura 2) - que é proposto como um dos ambientes mais propícios para a origem da vida. (20,23-26) Tal analogia é feita devido à similaridade notada preliminarmente das condições químicas e térmica com ambientes radioativos onde se constatou a existência de organismos vivos (ver seção 1.5). Tais fontes possuem condições menos agressivas para a proposta de origem e manutenção de sistemas biológicos, comparadas aos demais tipos de fontes hidrotermais, principalmente por serem do tipo em que não há contato direto com câmara magmática. $(27,28) \mathrm{E}$, como consta em análise geoquímica destas fontes, se caracterizam pela conversão da energia provinda de uma reação química, a serpentinização, em gradientes quimiosmóticos capazes de gerar força eletromotriz. $(20,21,26,29,30) \mathrm{A}$ interface entre o meio alcalino, de alta temperatura (cerca de $70^{\circ} \mathrm{C} \mathrm{a} 90^{\circ} \mathrm{C}$ ) e o meio ácido de baixa temperatura dos oceanos primitivos (cerca de $1^{\circ} \mathrm{C}$ a $5^{\circ} \mathrm{C}$, mas discutiremos outros valores propostos a partir de diferentes estudos), mediado por interface mineral microporosa (tal como precipitados carbonáticos que formam as fontes alcalinas), torna possível um gradiente térmico, de pH e eletroquímico. $(20,21,26,29,30)$ Características 
similares de temperatura e $\mathrm{pH}$ e predomínio de espécies redutoras foram constatadas previamente onde se encontrou o organismo Ca. D. audaxviator. $(5,19)$ Isso nos chamou a atenção para a possibilidade de acontecerem gradientes similares, mediados por interface mineral com o oceano primitivo no eon Hadeano da Terra, há 4 bilhões de anos atrás. Dado que neste momento defende-se que a Terra primitiva estava passando pelo late heavy bombardment, no qual foi atingida por corpos e asteroides. (8) Sendo assim, ambientes subterrâneos profundos em meio rochoso poderiam estar protegidos dos estresses que ocorreram na superfície do planeta a essa época. Com isso, portanto, podemos avaliar a similaridade destes ambientes radioativos com as fontes hidrotermais alcalinas e até avaliar a possibilidade de associar modelos de conversão de energia para sistemas biológicos ou protobiológicos, como o fizeram para Lost City.
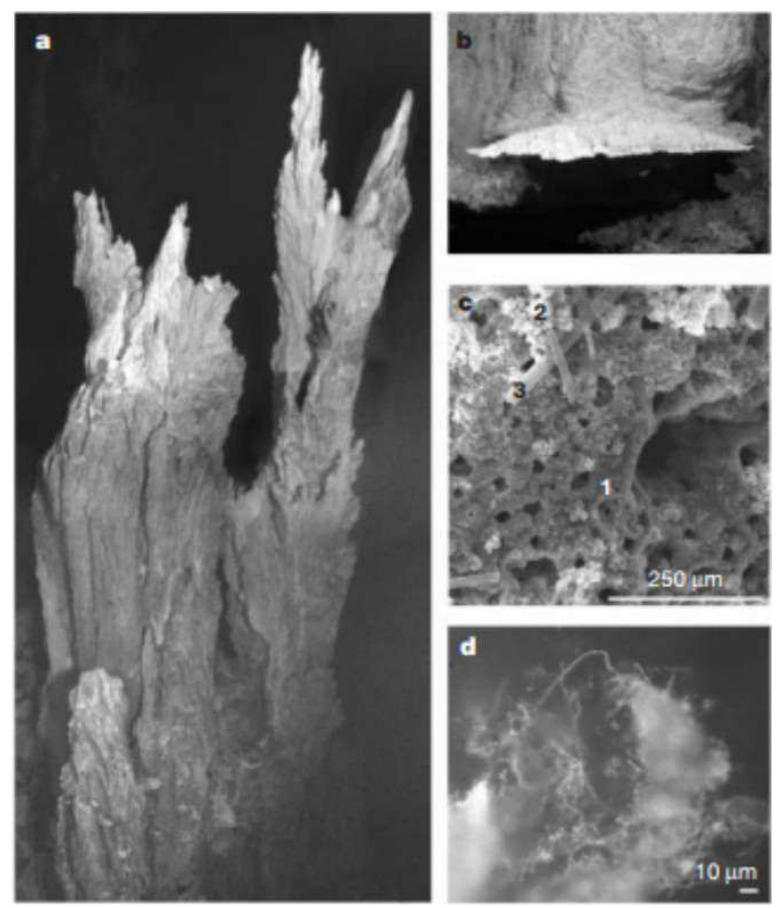

Figura 2 - Ambiente de fontes hidrotermais nos campos de Lost City.a: Imagem capturada pelo veículo submarino Argoll de um monte inativo de carbonato na parte oriental dos campos de Lost City, possuindo altura de $8 \mathrm{~m}$. b: flange da dimensão de $1 \mathrm{~m}$ com comunidades bacterianas de formação de carbonato e brucita crescendo horizontalmente a partir das laterais da chaminé. c: imagem de microscopia eletrônica de varrimento da flange apresentada em b coletada pelo veículo Alvin apresentando a matriz carbonática porosa. d: imagem de fluorescência de comunidades bacterianas da flange apresentada em $b$.

Fonte: KELLEY et al. (31) 
A partir de respostas encontradas para esse problema, mesmo que tendo como referência casos específicos a sistemas tais como o de ambientes radioativos naturais terrestres, procuramos analisar questões envolvendo a habitabilidade em um contexto mais geral. Sendo que esses ambientes na Terra podem possuir análogos em ambientes crípticos encontrados em outros corpos celestes, como as luas geladas de Júpiter - tais como Europa, Calisto e Ganimedes - principais alvos das próximas grandes missões de busca por vida no Sistema Solar. (32)

\subsection{Origens da vida: perspectiva termodinâmica e bioenergética da emergência a partir de sistemas geológicos.}

Fenômeno até então característico do planeta Terra, a vida ainda tem muitas lacunas a serem preenchidas quanto às questões sobre suas origens. Desde o século XX essa questão parte de uma abordagem de transição para a matéria viva a partir de matéria inanimada, que apresenta já considerável número de teorias e hipóteses. $(8,33-36)$ As lacunas e a ausência de respostas para a origem da vida na Terra podem ser consequência direta da improvável evidência em registro geológico desta transição. $(26,33,36,37)$ Ainda a teoria da chamada sopa primordial proposta por Charles Darwin e desenvolvida por J.B.S. Haldane há quase 90 anos, reforçada pela síntese de biomoléculas em atmosfera inorgânica por Miller (1953), se mostra fortemente associada à origem da vida. Atualmente a proposta do mundo RNA (38) se mostra bem ativa na comunidade científica que explora o problema, graças a contribuições recentes da genética molecular. E, apesar de serem construídas por importantes descobertas e hipóteses na área de química prebiótica e origem da replicação contemplando conceitos evolutivos, essas propostas não alcançam ainda um detalhamento com questões bioenergéticas e termodinâmicas $(20,39)$; mesmo sendo algo como um senso comum afirmar a importância da troca de energia para a vida. Atualmente defende-se que a proposta de origem da vida deva responder necessariamente a questão sobre a formação de moléculas orgânicas simples cuja dinâmica venha a formar o metabolismo (35); assim como deve estar relacionada com condições fora do equilíbrio termodinâmico, sendo esta uma condição própria de sistemas vivos, e de acoplamentos de reações exergônicas e endergônicas de forma que evite que o desequilíbrio leve apenas à dissipação da energia na forma de calor. (39-41)

Desde a proposta de que soluções hidrotermais de condição moderada podem ter condições interessantes para a origem da vida (42), e da descoberta dos campos hidrotermais de Lost City (ver seção 1.4), as fontes hidrotermais alcalinas se tornaram ambientes para diferentes modelos 
e abordagens de estudos da origem da vida. Nestes ambientes, há uma particular e contínua interação água-rocha dado o fenômeno geoquímico da serpentinização que é a principal fonte de energia e desequilíbrio químico. (ver seção 1.4) Tal proposta vem apresentando contrapartidas importantes no âmbito experimental para a chamada química prebiótica na síntese de importante biomoléculas e biopolímeros em condições primordiais (25); e, recentemente, grupos de pesquisas vêm apresentando hipóteses e modelos experimentais que envolvem princípios termodinâmicos e cinéticos. Isto é, propostas que busquem entender como o desequilíbrio de sistemas geológicos e químicos levam a um fenômeno emergente, tal como a auto-organização limitada espacialmente que levaria a um metabolismo. (40)

A partir da segunda lei da Termodinâmica, que define a entropia crescente internamente a um sistema (43-46), o desequilíbrio pode ser mantido por um processo contra as probabilidades em um estado estacionário (steady state) caso esteja acoplado a um processo de dissipação de um desequilíbrio de maior intensidade. Este processo é análogo ao processo mecânico de uma máquina de Atwood. (20) Por serem processos afastados do estado de equilíbrio, a taxa variação de entropia é o fator de principal importância. Como discutido por Prigogine (43) e por Dill (45), a taxa de produção de entropia $S$ de processos irreversíveis pode ser associada ao "fluxo" termodinâmico de matéria ou energia, $J_{i}$ e à "força" termodinâmica $X_{i}$ de associados a cada processo - ver equação (2) - sendo que fisicamente o segundo parâmetro resulta no primeiro. Os processos em um sistema limitado aberto podem ser inúmeros: reações químicas, difusão de espécies químicas, condução de calor, convecção, etc. Assim como os acoplamentos, que não são triviais, e resultantes de um estado bem especial de organização física, mediados por estruturas macroscopicamente ordenadas e estruturadas. $(20,21,39)$ A bioenergética trata justamente do estudo dos inúmeros acoplamentos de gradientes quimiosmóticos relacionado aos sistemas vivos e de seus mecanismos conversores de energia livre (no inglês, $F E C$ ), de maneira que as forças e os fluxos atuem como um único processo, na perspectiva termodinâmica. (20)

$$
\frac{d_{i} S}{d t}=\sum_{J} \frac{d_{i} S}{d t}=\sum_{J} J_{J} X_{J}
$$


Sistemas vivos atualmente fazem uso de inúmeros mecanismos, principalmente envolvendo complexos nano-motores movidos por gradientes quimiosmóticos que trabalham conjuntamente às vias metabólicas $(29,39,47)$, como o exemplo da maquinaria envolvendo a ATP sintase. (48) Nesses mecanismos, os gradientes quimiosmóticos são mantidos por membranas semipermeáveis que restringem a passagem de espécies químicas, permitindo a passagem através dos conversores complexos, levando à transdução da energia química armazenada pelos gradientes. (20) Para a emergência da vida nas fontes hidrotermais alcalinas, o problema da transferência da energia livre tem sido respondida com proposta análoga ao caso biológico atual, envolvendo gradientes quimiosmóticos. Seja pela presença natural de compostos orgânicos nesses ambientes e sendo os gradientes quimiosmóticos mediados por membranas inorgânicas milimétricas, resultantes de precipitação de material microporoso (24, 31); seja por uma questão de seletividade dos mecanismos de energia pelos sistemas vivos que impõe uma ligação entre metabolismo e geoquímica do ambiente. Além de que, uma descontinuidade desses mecanismos nos implicaria a uma busca à questão de quando e qual o sentido desta mudança de mecanismo nos processos de evolução dos sistemas vivos primordiais. Foi-se então, recentemente, elaboradas propostas de conversores catalíticos de energia livre movidos por gradientes de $\mathrm{pH}$, redox e térmicos, principalmente estudando minerais em ambientes de fontes hidrotermais. $(20,26)$

Nos ambientes de fontes alcalinas temos gradientes de $\mathrm{pH}$, eletroquímicos e térmicos devido à interface entre fluido hidrotermal e oceano primitivo, dado o contexto de emergência da vida que propomos analisar. O fluido hidrotermal aquecido, reduzido e alcalino, juntamente com a solução oceânica fria e moderadamente ácida (ver seção 1.3), percolam um labirinto de microporos no precipitado carbonático que formam os montes. (31) A precipitação de material poroso em fontes hidrotermais alcalinas (ver seção 1.4) leva a barreiras inorgânicas - compostas principalmente de aragonita, $\mathrm{CaCO}_{3}(31)$ - da espessura da ordem dos micrômetros $(21,49)$, enquanto membranas celulares são da ordem de nanômetros. (49) Com isto, em si, há certo problema em considerar que essas barreiras inorgânicas seriam análogos de membranas celulares. Porém o ponto mais importante do modelo consiste no mecanismo de catálise por minerais compostos de ferro, níquel e enxofre - $\mathrm{Fe}(\mathrm{Ni}) \mathrm{S}$ - ou os minerais de íons ferro e ânion hidroxila combinado a ânion sulfato, carbonato ou cloreto, os chamados green rusts. Minerais $\mathrm{Fe}(\mathrm{Ni}) \mathrm{S}$, como greigita $\left(\mathrm{Fe}_{3} \mathrm{~S}_{4}\right)$ ou mackinawita $\left(\mathrm{FeNiS}_{0,9}\right)$ são especulados de terem sido incorporados aos precipitados das fontes alcalinas nas condições da Terra primitiva, dada as condições do oceano e do fluido hidrotermal $(21,29,39,50)$, além de serem capazes de 
catalisarem reações de oxirredução. $(26,51)$ Clusters de $\mathrm{Fe}(\mathrm{Ni}) \mathrm{S}$, com estruturas como as dos minerais citados, são morfologicamente similares a importantes cofatores de enzimas necessárias para processos de transdução e fixação de carbono, como o caso da via de síntese de Acetil-CoA (via Wood-Ljunghdahl).(20, 21) A via de Acetil-CoA depende de um gradiente de prótons para a redução do $\mathrm{CO}_{2}$ pelo $\mathrm{H}_{2}$ usando proteínas de ferro-enxofre, como a ferredoxina, associada em membranas. $(21,52)$ Esta estrutura topológica de incorporação de $\mathrm{Fe}(\mathrm{Ni}) \mathrm{S}$, criando um sistema microporoso deste material, torna o sistema hidrotermal análogo ao da via de redução de $\mathrm{CO}_{2}$ na síntese de Acetil-CoA, como apresentado na Figura 3. A característica principal deste mecanismo é relacionada à necessidade da existência prévia de uma estrutura macroscópica. Sendo esta ausente de enzimas e membranas orgânicas, que envolve a interface entre o meio alcalino, em que haja moléculas de $\mathrm{H}_{2}$, dissolvidas e o meio ácido em presença de $\mathrm{CO}_{2}$ mediado pela uma membrana microporosa de material inorgânico, contendo clusters de minerais catalíticos $\mathrm{Fe}(\mathrm{Ni}) \mathrm{S}$. Com isto, o desequilíbrio químico leva a reações redox que iniciam o mecanismo em que fluxo de elétrons e de prótons estão acoplados reciprocamente.

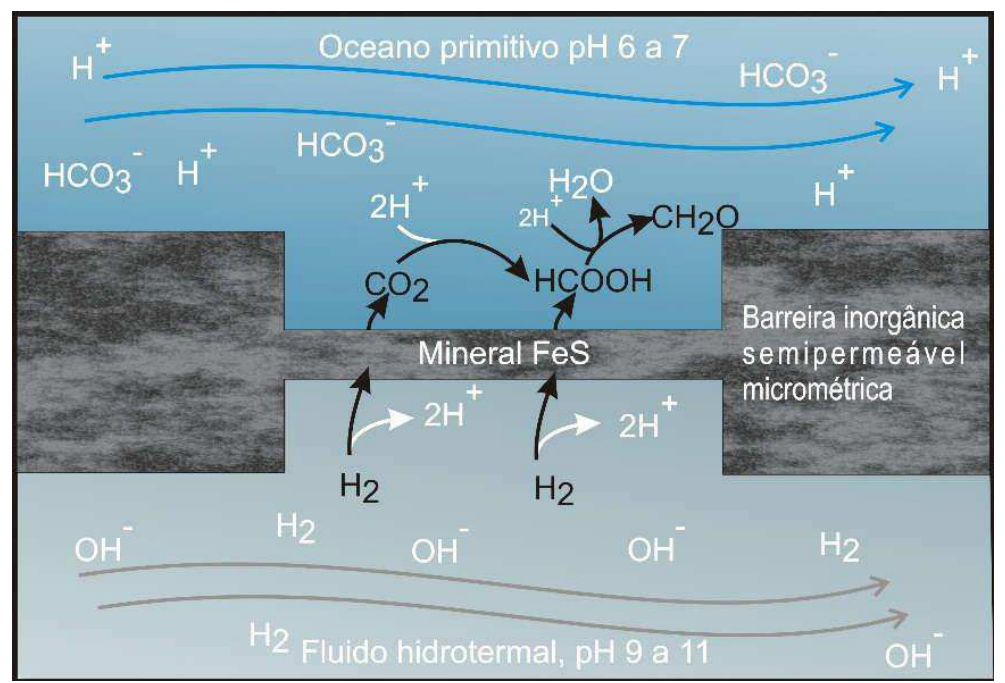

Figura 3 - Hipótese de mecanismo de redução de $\mathrm{CO}_{2}$ por $\mathrm{H}_{2}$ em poro de fontes hidrotermais. Nesta, as duas fases estão justapostas no poro do precipitado carbonáticos, onde a barreira de mineral do tipo $\mathrm{Fe}(\mathrm{Ni}) \mathrm{S}$ separa o fluido hidrotermal do oceano. $\mathrm{O}$ acúmulo de carga na barreira é evitada pelo fluxo e possível mistura dos fluidos em outra região.

Fonte: Adaptada de SOJO et al. 2016 (21) 
Tioésteres, como o Acetil-CoA, são de extrema importância em metabolismos primitivos em vias de transdução sem a participação de ATP ou qualquer outro trifosfato. (29) Não obstante, a via de Acetil-CoA é uma via comum em seres acetogênicos e metanogênicos, metabolismos de bactérias e archaea, respectivamente, duas formas primordiais de vida na Terra (53-55); o que leva a possibilidade de deduzir tal metabolismo como existente no Último Ancestral Comum Universal (em inglês, $L U C A)$. (29, 56) Mas esta dedução apresenta controversas intrínsecas ao problema da árvore filogenética universal. $(36,57)$

Apesar dos numerosos argumentos conceituais, ainda há muitas lacunas a serem preenchidas nesta proposta bioenergética da origem da vida. A maior parte da controvérsia envolve questões experimentais. $(37,49,58,59)$ A análise do mecanismo desses conversores minerais, além de resultados experimentais envolvendo a estabilidade das membranas inorgânicas em tal ambiente são alguns exemplos de questões ainda a serem abordadas experimentalmente nesta proposta.

\subsection{Fenômeno da radiólise e sua proposta prebiótica}

Há mais de um século, a radiólise da água vem sendo estudada, porém desde os anos 50 do século XX o número de publicações relacionada ao tema sofreu um aumento significativo. (17) O fenômeno é definido pela decomposição das moléculas de água do meio induzido por algum tipo de radiação, seja ela vinda do decaimento radioativo, do feixe de partículas carregadas aceleradas ou de fótons, quando estes possuem energia maior do que $50 \mathrm{eV}$. $(13,14,17,60$ 62) Uma das principais motivações do estudo do fenômeno está relacionada com organismos vivos, a princípio, com os efeitos da radiação em matéria viva, constituída prioritariamente de água. $(17,18,58)$ A partir da Segunda Guerra Mundial, mais especificamente a partir do Projeto Manhattan, houve especial ênfase nos estudos do mecanismo da radiólise aquosa, com forte motivação dado a necessidade de utilização de água em reatores nucleares. $(17,60)$

Os principais processos e etapas da radiólise aquosa atualmente são, de modo geral, bem compreendidos teórica e experimentalmente. $(17,63)$ A equação global da radiólise aquosa em água pura pode ser representada como se mostra na equação (3). Em que todas as espécies apresentadas na equação (3) configura o que recebe o título de produtos primários na radiólise da água. 


$$
\mathrm{H}_{2} \mathrm{O} \stackrel{\text { Radiação Ionizante }}{\rightarrow} \mathrm{e}_{\mathrm{aq}}^{-}, \mathrm{H}, \mathrm{HO}, \mathrm{HO}_{2}, \mathrm{H}_{2} \mathrm{O}_{2}, \mathrm{H}^{+}, \mathrm{OH}^{-}, \mathrm{H}_{2}
$$

De modo geral, divide-se a radiólise aquosa e a formação dos produtos primários em três etapas principais de diferentes períodos de tempo (63):

1) Etapa física, que ocorre em $1 \mathrm{fs}\left(10^{-15} \mathrm{~s}\right)$ após a interação radiação-matéria e consiste no processo de transferência de energia para o sistema de moléculas de água. Isto leva à formação de moléculas ionizadas $\left(\mathrm{H}_{2} \mathrm{O}^{+}\right)$, excitadas $\left(\mathrm{H}_{2} \mathrm{O}^{*}\right)$ e elétrons sub-excitados $\left(\mathrm{e}^{-}\right)$.

2) Etapa físico-química $\left(\sim 10^{-11} \mathrm{~s}\right)$ consiste no processo de equilíbrio térmico seguido de um rápido processo de relaxação. Aqui, elétrons equilibram termicamente $\left(\mathrm{e}_{\text {term }}^{-}\right)$e são $\operatorname{solvatados}\left(\mathrm{e}_{\mathrm{aq}}^{-}\right)$:

$$
\mathrm{e}^{-} \rightarrow \mathrm{e}_{\text {term }}^{-} \rightarrow \mathrm{e}_{\mathrm{aq}}^{-}
$$

Os íons $\mathrm{H}_{2} \mathrm{O}^{+}$trocam prótons com as moléculas de água adjacentes:

$$
\mathrm{H}_{2} \mathrm{O}+\mathrm{H}_{2} \mathrm{O}^{+} \rightarrow \mathrm{H}_{3} \mathrm{O}^{+}+\mathrm{OH}^{\cdot}
$$

Há a auto-ionização da molécula de água excitada:

$$
\mathrm{H}_{2} \mathrm{O}^{*} \rightarrow \mathrm{HO}^{\cdot}+\mathrm{H}^{\cdot}
$$

3) Etapa química $\left(10^{-12}-10^{-6} \mathrm{~s}\right)$, que consiste na etapa de difusão a partir do ponto de formação reação química das espécies formadas.

Um parâmetro cinético de principal importância para a radiólise vem a ser o rendimento de produção radiolítica, ou também citado como escape yield (13, 62-64), representado pela letra $G$ e, geralmente, na unidade de moléculas. $(100 \mathrm{eV})^{-1}$ ou em mol.J $\mathrm{J}^{-1}$ pelo S.I. O parâmetro $G(P)$ de um produto da radiólise depende de muitos fatores tais como o tempo, a transferência linear de energia (LET) da radiação e o pH do meio aquoso. $(62,63)$ E a relação entre $G(P)$ e cada um desses fatores varia conforme diferentes espécies formadas, principalmente em relação à LET. (63) 
Tabela 1 - Exemplos de reações e constantes de velocidades associadas que descrevem o processo de radiólise aquosa.

\begin{tabular}{ll}
\hline Reação & $\begin{array}{l}\text { Constante de } \\
\text { velocidade da reação } \\
\left(\mathbf{m o l}-\mathbf{1 . s ^ { - 1 }}\right)\end{array}$ \\
\hline$H^{\cdot}+\mathrm{HO}^{\cdot} \rightarrow \mathrm{H}_{2} \mathrm{O}$ & $2,0 \times 10^{10}$ \\
$\mathrm{HO}+\mathrm{HO}^{\cdot} \rightarrow \mathrm{H}_{2} \mathrm{O}_{2}$ & $3,6 \times 10^{9}$ \\
$\mathrm{H}^{\cdot}+\mathrm{H}^{\cdot} \rightarrow \mathrm{H}_{2}$ & $7,8 \times 10^{9}$ \\
$e^{-}+\mathrm{H}_{3} \mathrm{O}_{a q}^{+} \rightarrow H^{\cdot}+\mathrm{H}_{2} \mathrm{O}$ & $2,3 \times 10^{10}$ \\
\hline
\end{tabular}

Fonte:LE CAËR $\overline{(58)}$

Além das espécies efêmeras formadas primariamente através da trilha de radiação, com o crescimento do número de publicações sobre radiólise aquosa, foi-se apontando tratamentos teóricos de processos posteriores que alterariam essa característica primária da radiólise formando novas espécies radicalares, carregadas, além de produtos moleculares. Atualmente é possível encontrar propostas de conjunto de reações que possam ocorrer posteriormente, como está apresentado na Tabela 1. Com estas reações, podemos descrever a radiólise aquosa em uma escala de tempo maior.

A radiólise na natureza é algo que recebeu atenção recente, tanto que até se propõe importância deste fenômeno na origem da vida na Terra. $(6,11,60)$ Uma vez que a radiólise, principalmente por decaimento radioativo, é estimada estar presente em ambientes espalhados pelo planeta desde o Pré-Cambriano. $(6,11)$ Além disto, foi-se apresentado projetos de exploração espacial de modo a estudar os efeitos químicos da radiação em contexto extraterrestre e até tem-se simulado efeito de material físsil natural em contexto da Terra primitiva. (11) Por conta da produção de diversas espécies que participam de metabolismos já conhecidos pela radiólise, encontramos propostas e modelos de produção de espécies primárias para a manutenção de ecossistemas em alta profundidade. $(9,16)$

\subsection{Condições físico-químicas oceânicas em contexto primitivo}

Durante eventos que ocorreram em escala global no éon Proterozóico da Terra, houve significativa alteração dos oceanos e atmosfera (12), que é ainda desconhecida e tema de 
controvérsia. $(55,65,60)$ Essa informação é crucial para uma modelagem envolvendo a Terra primitiva e, claro, implicações prebióticas de seu ambiente aquoso. Nesta seção, fazemos uma breve revisão, prioritariamente por certos autores da área da geologia que são citados por pesquisadores em trabalhos sobre origem da vida em fontes hidrotermais alcalinas $(21,24,29$, $42,67)$ ou autores que realizaram revisões envolvendo modelos de oceanos do período primitivo da Terra. $(66,68-72) \mathrm{E}$, dado nosso propósito, atribuímos ênfase a parâmetros que podem afetar o desenvolvimento da vida e da habitabilidade em ambientes imersos ao meio aquoso do oceano $(22,73,74)$, tais como $\mathrm{pH}$, temperatura, composição química e potencial de redução. Muitos dos trabalhos apresentam resultados que descrevem uma modelagem de oceano primitivo com condições físico-químicas mais conservadoras, quanto com condições mais diferenciadas, se comparadas às condições constatadas para os oceanos atualmente. Propomo-nos a nos ater às convergências e consensos, mas procuramos não restringir nossa análise no decorrer deste trabalho a estes pontos que se apresentam, em demasia, específicos.

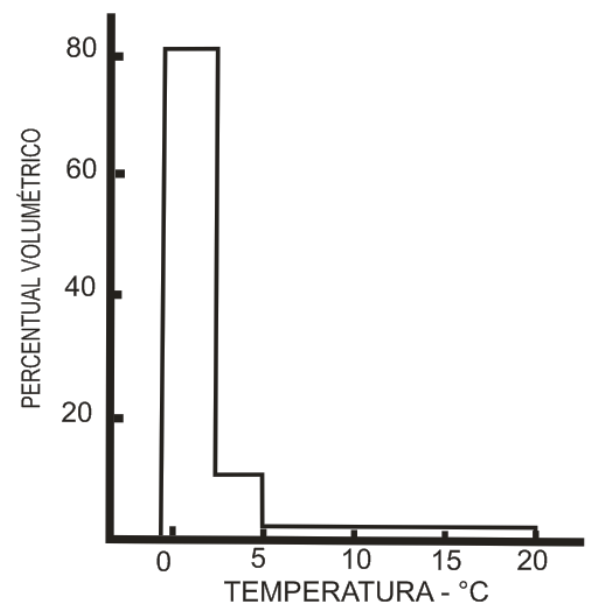

Figura 4 - Distribuição térmica nos oceanos modernos.

Fonte: Adaptada de SVERDRUP.; JOHNSON.; FLEMING. (75)

As modelagens e conclusões baseiam-se predominantemente tanto em registros geológicos, como é o caso de inclusões fluidas $(55,72,76)$ ou registros de sedimentação $(71)$, quanto a partir de estudos termodinâmicos e de equilíbrios químicos estimados. $(71,72,77,78)$ Nas referências envolvendo fontes hidrotermais e as implicações prebióticas destas, em contexto primitivo, apresentaram modelagens partindo de um oceano primitivo que, se comparadas às revisões e aos trabalhos que estes referenciavam, apresentavam tantos pontos de divergência sobre a composição, temperatura e pH estimados por demais trabalhos da área de geologia e das ciências oceânicas. Russell et al. (42) e Herschy et al. (26) pressupõem que os oceanos primitivos, de modo geral, apresentavam temperatura homogênea a partir de $16^{\circ} \mathrm{C}$. 
Essas suposições foram utilizadas por Grotzinger e Kasting (71) e Walker (77), que pressupuseram temperatura homogênea de $25^{\circ} \mathrm{C}$, deduzida a partir da modelagem atmosférica com efeito estufa causado pela alta concentração de $\mathrm{CO}_{2}$, se comparada a valores atuais. Ambas as temperaturas são superiores à predominante dos oceanos atuais de $0^{\circ} \mathrm{C} \mathrm{a} 6^{\circ} \mathrm{C}$ (Figura 4), que abrange praticamente a totalidade do seu volume, tendo valores maiores e variados na superfície. $(75,79)$ Como registros paleotermométricos se mostraram fontes controversas, por exigirem alta confiabilidade relacionada às suas origens (66), chamamos a atenção para a convergência que praticamente todos os autores aqui citados apresentaram trabalhos que concordam que a radiação solar e a atmosfera influenciam mais a temperatura oceânica do que o calor provindo da dinâmica interna da Terra. Há, como citado, algumas restrições relacionadas à possíveis valores de temperatura oceânica no Pré-Cambriano, mas ainda não vemos parâmetros suficientes para julgar que um resultado seja mais promissor que outro. Conclui-se, portanto, que o oceano não se apresentava congelado, devido à ausência de evidências de glaciação neste período, assim como concluímos que a temperatura não seria tão alta, devido ao grande volume e capacidade térmica dos oceanos e da escassez de fontes de calor suficientes para elevar homogeneamente todo o volume do oceano, e principalmente em profundidade, a condições de temperatura superiores às padrão. Assim, como conclui-se que a temperatura baixa, mas ainda superior ao caso atual apresentado na Figura 4, adotada em modelos de fontes hidrotermais estão bem de acordo com os argumentos com base em efeitos atmosféricos e solares que consideram o oceano primitivo mais aquecido do que o é atualmente. Tal parâmetro influi consideravelmente na difusão das espécies químicas envolvidas em um sistema, consequentemente, na energia livre associada à difusão e até mesmo à convecção do meio aquoso.

Relacionado ao $\mathrm{pH}$ no período Arqueano, autores apresentam consenso relativo a condições neutras ou tendendo a certa acidez, mas é rara a conclusão da possibilidade de um oceano alcalino. Isto vem a ser justificado pela maior pressão de $\mathrm{CO}_{2}$ na atmosfera, comparado ao atual. $(66,78)$ Muitos autores, ao tratar das fontes hidrotermais, apresentaram suposições de um oceano fortemente ácido, chegando até no caso de se especificar dentro da faixa de $\mathrm{pH}$ entre 2 a $6(21,24,26,28,42)$; Outros trabalhos, a partir de análise de parâmetros termodinâmicos e de modelagens partindo de registros geológicos com datação das eras do Neo-Arqueano e Paleoproterozóico - como é o caso, por exemplo, de carbonatos, evaporitos e formações bandeadas de ferro (banded iron formations, BIFs) (e.g. Grotzinger and Kasting; Pinti) reafirmaram a hipótese do oceano ácido, apesar de que apresentaram valores de $\mathrm{pH}$ próprios de 
meios ácidos mais brandos. Registros geológicos de deposição e a abundância de minerais são usados para estabelecer limites relativos a condições de acidez, condições redox dos oceanos primitivos e de sua composição. Estes limites envolvem as concentrações de componentes oceânicos estimados a partir das reações de precipitações dos minerais, e das fontes dos componentes - sejam fontes atmosféricas, seja o intemperismo da crosta, sejam fontes por atividades hidrotermais e vulcânicas - para isto, parte-se do pressuposto de que o oceano possui variações ínfimas de concentrações em diferentes regiões, e encontra-se em estado estacionário ou quasi estacionário. Esses trabalhos apresentaram restrições para os valores de $\mathrm{pH}$ entre 5,7 a 8,6 $(71,72)$ e valores 0 a 6. (68) De Ronde (76), a partir de rochas ricas em ferro da região de Barberton, pertencente à de Witwatersrand, estimou uma composição para águas oceânicas (Tabela 2), apresentando $\mathrm{pH}$ de 6,5 (66) que se mostra completa o suficiente para ser utilizada para modelagem de oceano Arqueano em experimentos de caráter prebiótico propostos por Zaia (65). E cabe, para fim de comparação, considerar o valor constatado predominante nos oceanos atuais que é próximo a faixa entre 7 e $8 .(72,78)$

Relacionado à composição, esta se apresenta comum à atual desde o oceano primitivo até o oceano atual, apenas tendo alteração em seu estado de oxidação devido aos eventos de acúmulo de $\mathrm{O}_{2}$ na era Paleoproterozoica $(80,81)$. Estima-se que o carbono oceânico no período possa ser encontrado predominantemente na forma de bicarbonato $\left(\mathrm{HCO}_{3}{ }^{-}\right)(21,71,82)$, o que se mostra plausível a partir de cálculos simples, sendo que este se converte a carbonato dentro da faixa de $\mathrm{pH}$ entre os valores 10 e 11 para o caso das temperaturas estimadas para o oceano

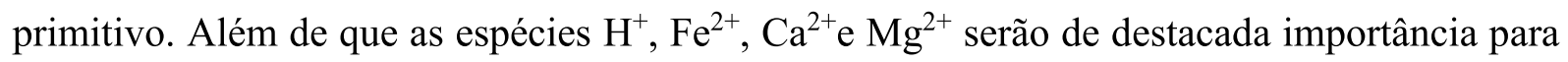
estudarmos a possibilidade de precipitação de interfaces de membranas minerais nos ambientes radioativos, formadas por carbonatos ou pirita. Tais íons se apresentam dominantes no oceano primitivo $(68,72,76,77)$, e suas concentrações se encontram na ordem dos milimolar, cujas estimativas de concentração encontramos alguns exemplos (Tabela 2). 
Tabela 2 - Diferentes concentrações de produtos abundantes conforme diferentes propostas para o oceano primitivo

\section{Modelos de oceano no Arqueano}

\begin{tabular}{ccc}
\hline Espécie & Concentração (mM) & Referência \\
$\mathrm{Fe}^{2+}$ & 200 & Sojo et al. (21) \\
$\mathrm{Mg}^{2+}$ & 0,67 & Kramer et al. (69) \\
& 50,9 & de Ronde et al. (68) \\
$\mathrm{Ca}^{2+}$ & 6,1 & Kramer et al. (69) \\
& 232 & de Ronde et al.(68) \\
\hline
\end{tabular}

\section{Oceano no período moderno}

\begin{tabular}{ccc}
$\mathrm{Fe}^{2+}$ & $3,5.10-5$ & Chester (74) \\
$\mathrm{Mg}^{2+}$ & 0,53 & Chester (74) \\
& 0,54 & Kramer et al. (69) \\
& 54,2 & Ronde et al. (68) \\
& & \\
\hline $\mathrm{Ca}^{2+}$ & 0,10 & Chester (74) \\
& 0,1 & Kramer et al. (69) \\
& 10,2 & de Ronde et al. (68) \\
\hline
\end{tabular}

Fontes: CHESTER (74) ; DE RONDE et al. (68); KRAMER (69); SOJO et al. (21)

\subsection{Condições físico-químicas dos campos hidrotermais de Lost City}

Desde a descoberta, nos anos 70 do século $\mathrm{XX}$, sistemas hidrotermais receberam considerável atenção como possíveis ambientes onde a vida pode ter se originado na Terra. (53, 54) As fontes hidrotermais descobertas, hoje chamadas fumarolas negras (black smoker vents) 
se caracterizam pelo contato da água oceânica com material magmático que se resfria a temperaturas $\sim 1200^{\circ} \mathrm{C}$, criando um fluido hidrotermal com alta temperatura $\left(\sim 350^{\circ} \mathrm{C}\right)$ e $\mathrm{pH}$ de meio ácido, mas ainda apresenta biota extremófila, que inclui espécies de moluscos e artrópodes. (31) Tendo registro de sua descoberta no ano 2000 a partir de explorações com veículos submersíveis (23), os campos hidrotermais de Lost City foram encontrados situados no chamado Maciço de Atlantis com idade de 1,5 Ma, à aproximadamente $15 \mathrm{~km}$ à oeste do vale das cadeias meso-oceânicas do Atlântico, $30^{\circ}$ ao Norte no equador e a uma profundidade de 750 a 900 m abaixo da superfície. $(23,31)$ Os campos consistem de "montes hidrotermais" que atingem a altura de até $60 \mathrm{~m}$, como é o caso de Posseidon, o monolito de fontes ativas central no campo de Lost City. No ambiente se encontram alta densidade de comunidades microbianas, incluindo espécies termófilas anaeróbicas, eubactérias e até macrofauna de espécies de caranguejos, ouriços-do-mar e corais. (23) Estes apresentam condições similares às das propostas para as teorias de origem da vida desenvolvidas no final dos anos 80 , como às de Russell (42). São condições muito menos extremas às dos fluidos hidrotermais dos ambientes dos black smokers que são encontrados em regiões próximas à cadeia meso-oceânica - distância inferior a $5 \mathrm{~km}$ - cujas condições levam à degradação de compostos orgânicos mais do que sua formação. (55)

As fontes de Lost City apresentam, além de característica superficial porosa, um ambiente aberto e em fluxo, condições de temperatura bem mais baixas que o caso de fontes tais como as fumarolas e composição característica devido às reações de hidrólise de material ultramáfico soerguido na base oceânica, processo exotérmico conhecido como serpentinização. $(21,23,27,83,84)$ Este processo resulta na precipitação de material carbonático $\left(\mathrm{CaCO}_{3}\right)$ predominantemente aragonita $(23,31,84)$ - que apresenta característica porosa, quando o fluido hidrotermal se encontra com o meio oceânico. $(30,52,85)$ Tais fenômenos não são únicos em Lost City, mas ocorrem em outras fontes hidrotermais na região pouco distante da cadeia mesooceânica do Atlântico, como é o caso dos campos hidrotermais Saldanha. $(27,86)$

No processo de serpentinização, em que ocorre o metamorfismo da olivina em serpentina $(24,27,31,39)$, os principais reagentes da reação presentes no meio oceânico são $\mathrm{H}_{2} \mathrm{O}$ e o $\mathrm{CO}_{2}$, que se encontra na forma de $\mathrm{HCO}_{3}{ }^{-}$. Nas condições da reação, que acontece há $500 \mathrm{~m}$ abaixo do solo oceano, quando há percolações aquosas o Fe da olivina $\left(\sim \mathrm{Mg}_{1.6} \mathrm{Fe}_{0.4} \mathrm{SiO}_{4}\right)$, como é o caso em Lost City, é oxidado e reduz a água produzindo hidrogênio e certos hidrocarbonetos, tal como $\mathrm{CH}_{4}$; e se produz magnetita $\left(\mathrm{Fe}_{2} \mathrm{O}_{3}\right)$, brucita $\left(\mathrm{MgOH}_{2}\right)$ e serpentina. Ainda estão sob estudos todos os processos envolvidos na serpentinização, trabalhos como o de 
Martin et al. (24) o resume quimicamente conforme equação (7). Devido este processo, o interior dos montes precipitados em Lost City apresentam não somente temperaturas razoavelmente altas, mas meio fortemente alcalino - no caso de Lost City a temperaturas variam entre 40 a $75^{\circ} \mathrm{C}$ e apresenta $\mathrm{pH}$ na faixa de 9,0 a 11 . $(27,83)$ Nota-se também a produção de $\mathrm{H}_{2}$, que contribui, juntamente com os compostos orgânicos a criar um ambiente com fluido hidrotermal redutor. Atualmente, trabalhos apresentam valores atribuídos à concentração de $\mathrm{H}_{2}$ no atual ambiente de Lost City de 0,25 a $0,43 \mathrm{mmol} / \mathrm{kg}(27,84)$, assim como é calculada a produção de $\mathrm{H}_{2}$ pelo processo de serpentinização em $0,5 \mathrm{~mol} / \mathrm{L}_{\text {olivina. }}$ (83)

$(\mathrm{Mg}, \mathrm{Fe})_{2} \mathrm{SiO}_{4}+\mathrm{H}_{2} \mathrm{O}+\mathrm{C} \rightarrow \mathrm{Mg}_{3} \mathrm{SiO}_{5}(\mathrm{OH})_{4}+\mathrm{Mg}(\mathrm{OH})_{2}+\mathrm{Fe}_{3} \mathrm{O}_{4}+\mathrm{H}_{2}+\mathrm{CH}_{4}+\mathrm{C}_{2} \quad \mathrm{C}_{5}$

As fontes de Lost City apresentam condições similares às propostas por Russell em 1989 em sua proposta de emergência da vida em ambiente submarino primitivo (42). Com o encontro entre a solução de menor $\mathrm{pH}$, caso das águas oceânicas com o fluído hidrotermal, há precipitação mineral formando estruturas de característica porosa, contendo brucita e Fe-brucita $\left([\mathrm{Fe}, \mathrm{Mg}](\mathrm{OH})_{2}\right)$ em torno de minerais carbonáticos tais como calcita e aragonita $\left(\mathrm{CaCO}_{3}\right)$. (31) A partir da datação de ${ }^{14} \mathrm{C}$, estima-se que a atividade hidrotermal de Lost City já dura cerca de 30000 anos, e estruturas de aparência similar a "veias" de carbonatos nas rochas nos arredores são indícios de fontes hidrotermais que foram ativas, mas que hoje se encontram extintas. (31)

Com a proposta de emergência da vida, surgiram modelos teóricos e experimentais de química prebiótica a partir dos ambientes de Lost City. Modelos que envolvem o potencial eletroquímico gerado pelo gradiente e a polimerização de nucleotídeos. (25) A proposta de modelo que pretendemos abordar aqui envolve a estimativa de que podem ter acontecido precipitações de outros minerais, em condições da Terra primitiva, tais como siderita $\left(\mathrm{FeCO}_{3}\right)$ que, pelas condições encontradas, podem ter sido substituída por greigita; ou diretamente como makinawita (ver seção 1.1). Estes últimos, como citado, podem ter importância para a catálise de reações protometabólicas, como é o caso das precursoras e análogas da via WoodLjunghdahl $(21,39)$, como descrito em maiores detalhes na seção 1.1 . 


\subsection{Condições físico-químicas e geoquímicas dos ambientes radioativos}

Alguns ambientes radioativos têm sido reportados recentemente em localizações diversas levando em conta seus aspectos geológicos. Dentre os ambientes radioativos encontrados, temos o caso do reator natural de Oklo, na bacia de Franceville, Gabão $(6,7)$; os reatores em depósitos das regiões de lagos Cluff e Rabbit na área da província de Saskatchewan, Canadá (7); e, por fìm, o já citado ambiente radiolítico onde há depósito de material físsil encontrado na região da bacia de Witwatersrand, África do Sul $(16,87,88)$, onde foi reportado a presença do Candidatus Desulforudis audaxviator (ver seção 1.6).

Análises das inclusões fluídas, tais como amostras de águas presentes em fraturas rochosas, assim como a análise geológica destes ambientes radiolítico nos revelou, preliminarmente, certa proximidade de condições entre alguns ambientes radioativos em Witwatersrand e as fontes hidrotermais alcalinas de Lost City (ver seção 1.4). Amostras de águas encontradas em fraturas rochosas em Witwatersrand em nível subterrâneo, apresentaram características alcalinas com $\mathrm{pH}$ que variam de 7,2 a 9,3 e temperaturas que variam de 40 a até acima dos $60^{\circ} \mathrm{C}$ (Tabela 3). Chama a atenção, principalmente, uma amostra de ambiente a 2,8 $\mathrm{km}$ abaixo da superfície na região de Witwatersrand na formação geológica de Ventersdorp, a qual se encontrava em temperatura próxima a $60^{\circ} \mathrm{C}$ e $\mathrm{pH} 9,3$.

Tabela 3 - Características de amostras de águas subterrâneas de diferentes regiões e formações geológicas na bacia de Witwatersrand, África do Sul.

\begin{tabular}{llllll}
\hline Profundidade & $\begin{array}{l}\text { Formação } \\
\text { geológica }\end{array}$ & $\begin{array}{l}\text { Temperatura } \\
(\mathbf{k m})\end{array}$ & $\mathbf{p H}$ & $\begin{array}{l}\text { Concentração } \\
\left.{ }^{\circ} \mathbf{C}\right)\end{array}$ & $\mathbf{1 6 S ~ r D N A}^{\mathbf{b}}$ \\
\hline 0,718 & Witwatersrand & 34 & 8,4 & $\mathrm{NA}$ & \\
2,825 & Ventersdorp & $>60$ & 9,3 & 54000 & MB \\
0,850 & Karoo & 26 & 10,2 & NA & MSae
\end{tabular}

${ }^{a}$ Valores da concentração a partir do valor medido nas amostras, corrigidos para o consumo de $\mathrm{H}_{2}$ para formação abiogenética de $\mathrm{CH}_{4}$ e para a perda por difusão. NA, não disponível

${ }^{\mathrm{b}} \mathrm{MB}$, Methanobacterium; MSae, Methanosaeta; ND, não detectou archaea.

Fonte: Adaptada de LIN et al. (16) 
A partir de estudos da formação geológica da região da bacia de Witwatersrand e a partir de análise das condições encontradas para este ambiente, podemos avaliar a presença de material similar aos encontrados em Lost City, tais como materiais porosos provindo de precipitação de brucitas $\left([\mathrm{Fe}, \mathrm{Mg}](\mathrm{OH})_{2}\right)$ e minerais carbonáticos, predominantemente calcita $\left(\mathrm{CaCO}_{3}\right)$, que pode transitar de fase com aragonita conforme condições de temperatura e pressão, e dolomita $\left([\mathrm{Ca}, \mathrm{Mg}]\left(\mathrm{CO}_{3}\right)_{2}\right)$. A presença de dolomita e calcita é constatada em estudos geológicos da região $(3,19)$; assim como a presença de pirita $\left(\mathrm{FeS}_{2}\right)$ é constatada em regiões ricas em minerais radioativos de mais de 2700 Ma. $(5,18,87,88)$ Nos demais depósitos de material físsil, em especial urânio, que estudamos foi constatado a presença de abundante material carbonático nestes depósitos. (7)

Dentre os ambientes radiolíticos, em todos foi constatada em amostras de águas subterrâneas, presença significativa de $\mathrm{H}_{2} .(5,7,14,16)$ Dubessy, que enfatizou sua análise em ambientes como o de Oklo e o dos depósitos dos lagos Cluff e Rabbit, defende que a presença tanto de hidrogênio quanto a de oxigênio molecular - encontrado em alguns pouco ambientes nas duas regiões no Canadá - indica fortemente que se tratou predominantemente de casos de radiólise da água presente. Foram apresentados dados relativos à concentração atual de hidrogênio para Witwatersrand (ver Tabela 3). Para a amostra que destacamos, a 2,8 km abaixo da superfície, a concentração de hidrogênio foi consideravelmente inferior à medida em fluído hidrotermal em Lost City, que se encontra na ordem de mM, como apresentado na seção 1.4. Como há inúmeros fatores que possam interferir nesse resultado final de concentração (fatores bióticos e abióticos na produção e consumo de hidrogênio). O modelo proposto inicialmente por Hoffmann (89) e utilizado por Lin et al. (16) e Savary e Pagel (14) aplicando para o caso de ambientes radiolíticos chegou ao resultado da produção de hidrogênio da ordem de 0,1 a 1 $\mathrm{nM} /$ ano em ambientes radioativos naturais em Witwatersrand. Deste modo, pela modelagem de Lin, demoraria alguns milhões de anos até inclusões fluidas em Witwatersrand atingir concentração comparável ao ambiente de Lost City, desprezando reações paralelas (de consumo ou produção) e processos de difusão do hidrogênio. De todo modo, tendo o organismo $C a$. $D$. audaxviator sua sobrevivência à base de produtos da radiólise, incluindo o $\mathrm{H}_{2}$ (ver seção 1.6), se pode concluir que a taxa de produção do hidrogênio seria, mesmo baixa, suficiente para uma habitabilidade local do ambiente radioativo. 


\subsection{Ecossistema de espécie única mantido por produto de radiólise em ambiente profundo.}

Um trabalho publicado recentemente por Chivian et al. (5), que complementa os trabalhos de Lin et al. (19) e de Omar et al. (18) apresenta um resultado promissor à proposta de energia de decaimento radioativo como útil a sistema vivo e também útil para o contexto da origem da vida, algo já proposto por alguns autores. A partir do processo de genômica ambiental ou metagenômica - técnica de análise genômica que independe de cultura para análise de comunidades microbianas inteiras e se torna útil quando há espécie cujo isolamento é inviável $(90,91)$ - o trabalho de Chivian et al. concluiu a presença da espécie então chamada Candidatus Desulforudis audaxviator em inclusões fluídas na região da bacia de Witwatersrand, na África do Sul. Além de habitar região termofílica, alcalina, rica em sulfato e moderadamente salina de fluídos incrustados e água acumulada de numerosas minas de ouro na região. (19) Pelos resultados, conclui-se total ausência de sistema para resistência a $\mathrm{O}_{2}$, esta sensibilidade que o dificulta de isolar amostras com a espécie e o que leva os pesquisadores a manter a intitulação Candidatus. (5) O resultado veio em decorrência de estudos relativos à diversidade microbiana que se desenvolvia com amostras coletadas na região. Esta espécie foi constatada proeminentemente em amostras coletadas de abaixo de 1,5 km abaixo do nível da superfície em análise de RNA ribossômico 16S, e mostrou ser dominante em amostra coletada 2,8 km abaixo da superfície, em proporção de $>99,9 \%$ na biblioteca de clones resultante da metagenômica (5), até então a menor diversidade constatada naturalmente de comunidade bacteriana. Não obstante este resultado, o genoma apresentou inúmeras características para esta forma de vida praticamente independente em seu habitat.

A espécie compõe o filo Firmicutes, que compunha o filotipo dominante do bioma microbiano de termófilos e sulfo-redutores do subterrâneo de Witwatersrand. (13) Seu genoma, segundo o trabalho de Chivian et al. vai de acordo com o resultado de análise termoquímica prévio no ambiente que apresenta temperatura $\sim 60^{\circ} \mathrm{C}$ e $\mathrm{pH}=9,3 .(5,16,19)$ Do mesmo modo que apresenta total ausência de sistema para resistência ao $\mathrm{O}_{2}$ e habilidades para formar endósporos o que torna viável o ambiente de altas temperaturas e profundidades. Essas constatações confirmam com todas as condições ambientais do habitat em profundidade do organismo, que se diferenciam fundamentalmente das da superfície ou das condições oceânicas.

Para fixação de carbono, o organismo $C a$. $D$. audaxviator apresenta maquinaria para síntese de acetil-CoA que usa monóxido de carbono desidrogenase (CODH), para assimilação 
de carbono orgânico a partir de bicarbonato, formato ou do próprio monóxido de carbono. Apesar deste sistema, o genoma apresenta genes para transportadores de aminoácidos e açucares, um sistema próprio para assimilação de carbono heterotrófica própria para ambientes caso haja grande densidade biológica. Além destes, o Ca. D. audaxviator apresenta um sistema para obter nitrogênio a partir de amônia, que se encontra presente nas inclusões fluidas da região. Não obstante, o genoma apresenta capacidade para redução de sulfato e é por esta via que também ocorre transferência de energia livre para formação de ATP (Figura 1). Nesta via, a energia para a manutenção do sistema vivo e até para resistir aos danos causados pela própria radiação é obtida por meio de dois produtos da radiólise aquosa, o sulfato e o hidrogênio. Além disto, pelo genoma constou-se habilidades quimiotáticas e flagelos motores no organismo.

Usando modelos que envolvem a reação do metabolismo de redução de sulfato, como apresentado na equação (8) e a reprodução da assinatura isotópica em sulfato e sulfito por organismos sulforredutores foi possível estimar a demanda de sulfato do ecossistema encontrado em Witwatersrand. Em Lin et al., foi reproduzido um fracionamento de Rayleigh em dois estágios por redução microbiana de sulfato em sistema fechado. Neste, sulfato produzido por dissolução de barita e oxidação de pirita por radiólise foi utilizado por redutores de sulfato. Com isso e as composições isotópicas já mensuradas no estudo, foi possível criar uma faixa de restrição de sulfeto produzido bioticamente, que foi associado à densidade celular e ao sulfeto medido in situ. Considerando que todas as células consumiram sulfato, a taxa de consumo de sulfato estimada baseada no possível sulfeto produzido bioticamente está na faixa de $5,5 \cdot 10^{-18}$ a $3,6 \cdot 10^{-17} \mathrm{~mol}$ por célula por ano (19). O predomínio do Ca. D. audaxviator na região para onde foi feita esta estimativa nos dá uma referência de consumo de sulfato pelo organismo, o que nos será útil para os modelos que desenvolveremos neste trabalho.

$$
4 \mathrm{H}_{2}+\mathrm{H}^{+}+\mathrm{SO}_{4}^{2-} \rightarrow \mathrm{HS}^{-}+4 \mathrm{H}_{2} \mathrm{O}
$$

Desde a descoberta feita pelo grupo de Chivian, houve diversos resultados envolvendo o genoma do Ca. D. audaxviator por diferentes grupos. Sequencias de RNA ribossomal virtualmente idênticos ao de genes do organismo foram detectados em diversos ambientes de subsuperfície, tal como os do escudo Báltico, na Finlândia (92); de aquíferos na Alemanha (93); ou os de fluídos basálticos de Juan de Fuca. (94) Há, recentemente, trabalho complementar à metagenômica, apresentando estudos de sequenciamento de célula única (single cell genomics), 
de onde se conclui que o organismo transfere lateralmente seus genes como estratégia para adaptação às mudanças das condições ambientais. (1) 


\section{Objetivos}

\subsection{Objetivos gerais}

A proposta, neste trabalho, foi de analisar, de forma analítica e numérica, o desequilíbrio químico em ambientes radioativos naturais assim como analisar possível modelo de transdução para estes sistemas considerando o contexto geológico da Terra primitiva e de um corpo celeste potencialmente habitável segundo a pesquisa astrobiológica atual, a lua gelada Europa. Os possíveis mecanismos de transferência de energia para sistemas biológicos têm com base mecanismos de transferência já avaliados plausíveis para as fontes hidrotermais alcalinas ou com base o metabolismo de organismos já constatados capazes de sobreviverem a partir dos produtos da radiólise aquosa, como é o caso do $C a$. D. audaxviator. A partir dos resultados deste trabalho, analisamos as implicações prebióticas destes ambientes, isto é, a possível relação dos fenômenos que ocorrem neste ambiente e suas consequências para uma hipótese da emergência da vida na Terra. De modo análogo, procuramos analisar as implicações do desequilíbrio destes ambientes para a manutenção da vida e a habitabilidade na subsuperfície da lua gelada Europa.

\subsection{Objetivos específicos}

- Levantar características físico-químicas propostas para o oceano existente no período primitivo da Terra, de modo a nos dar base para modelar um oceano primitivo cuja solução aquosa estaria sujeita à radiólise própria dos ambientes radioativos na Terra primitiva;

- Levantar dados relativos à geologia de ambientes radioativos, prioritariamente aos que se encontram habitados por microrganismos dependentes de produtos formados por radiólise aquosa, como é o caso dos existentes na formação em Witwatersrand. Estes dados remetem tanto à distribuição de radionuclídeos atuais ou modelos de concentração na Terra primitiva, como à presença de minerais importantes para os modelos de transdução que propomos desenvolver- tal como pirita ou minerais carbonáticos;

- Desenvolver modelagem analítica e numérica para apresentar a diversidade química e o desequilíbrio consequente da radiólise aquosa nos ambientes radioativos. Assim como modelos conceituais e analíticos para análise da habitabilidade em ambientes radioativos, e em ambientes análogos aos da Terra, situado na subsuperfície da lua gelada de Júpiter Europa; 
- Avaliar a adequação de mecanismos de transferência de energia livre para sistemas biológicos ou protobiológicos propostos para fontes hidrotermais alcalinas em sistemas em ambientes radioativos. 


\section{Metodologia}

\subsection{Condições físico-químicas dos ambientes e diversidade química pela radiólise aquosa.}

Os resultados de análise geoquímica de ambientes radiolíticos já descobertos e analisados, onde se encontraram espécies microbianas habitando, serão usados como nossa principal referência aos modelos desenvolvidos neste trabalho. Complementarmente, foram revisadas informações relativas aos oceanos primitivos em artigos de revisão e em livros até então publicados que remetem ao tema, de modo a permitir fidelidade aos modelos conceituais, analíticos e numéricos propostos (ver seção 1.3). Para estes, temos dados relativos ao material físsil presente, além da temperatura e $\mathrm{pH}$ do meio aquoso. Realizamos então uma modelagem de sistema em ambiente radioativo natural, contemplando fontes radiolíticas minerais de radionuclídeos de longa vida, que estavam em decaimento na Terra primitiva, isto é, ${ }^{238} \mathrm{U},{ }^{232} \mathrm{Th}$

$\mathrm{e}^{40} \mathrm{~K}$. Além de contemplar as condições físico-químicas do meio aquoso com base em modelos para o oceano primitivo conforme revisão citada. Para os resultados a longo prazo dos efeitos da radiólise para a diversidade química ainda desconsiderando sorvedouros químicos ou de difusão das espécies e considerando que, por se tratar de água provinda de oceano, há reposição desta. Para os valores das concentrações dos radionuclídeos citados, utilizamos os apresentados em resultados na literatura característico da região de estrato geológico mineralizado e nãomineralizado em Witwatersrand, considerando que esta é uma formação geológica com ambientes radioativos naturais do Arqueano (87), com exceção do valor da concentração de ${ }^{40} \mathrm{~K}$ dissolvido no oceano primitivo, para o qual utilizamos o valor oceânico moderno. Como referência aos resultados, realizamos os cálculos de diversidade química a partir da concentração de radionuclídeos constatada em condritos carbonáticos, corpos mais primitivos do sistema Solar, considerando diferentes modelos de oceano primitivo. Estes apresentam concentração consideravelmente menor do que qualquer ambiente radioativo em Witwatersrand. As concentrações associadas foram constatadas em análise geológica atual, mas, como detalharemos adiante, faremos a correção da energia nos decaimentos para a adequar a um valor próprio para $4 \mathrm{Ga}$, período anterior a qualquer fóssil constatado até então, mas posterior à idade da formação mineral mais antiga preservada e constatada, o zircões encontrados na região de Jack Hills, Austrália. (12) A Tabela 4 resume os valores associados aos radionuclídeos que estamos considerando para o modelo proposto nos diferentes cenários. A partir destes dados, calculamos a concentração das diferentes espécies químicas produto da 
radiólise aquosa em função do tempo de radiação local do oceano primitivo, considerando não somente a produção direta, mas também o consumo destas por sorvedouros químicos e processos de difusão, seja a partir de modelagens analíticas ou, numericamente, a partir de modelagem em implementos computacionais.

Tabela 4- Valores associados ao radionuclídeos utilizados para o modelo de produção de espécies químicas por radiólise aquosa

\begin{tabular}{|c|c|c|c|c|c|}
\hline Radionuclídeo & $\begin{array}{l}\text { Proporção } \\
\text { percentual } \\
\text { isotópica } \\
\text { atual }(\%)^{\mathrm{a}}\end{array}$ & $\begin{array}{l}\text { Concentra } \\
\text { ção em } \\
\text { condritos } \\
(\mathrm{ppb})^{\mathrm{b}}\end{array}$ & $\begin{array}{l}\text { Concentração } \\
\text { em estrato não } \\
\text { mineralizado } \\
\text { em } \\
\text { Witwatersrand } \\
(\mathrm{ppm})^{\mathrm{c}}\end{array}$ & $\begin{array}{l}\text { Meia-Vida } \\
\quad(\operatorname{anos})^{\mathrm{a}}\end{array}$ & $\begin{array}{c}\text { Energia por } \\
\text { decaimento } \gamma \\
(\mathrm{MeV} / \text { decaimento })^{\mathrm{d}}\end{array}$ \\
\hline${ }^{40} \mathrm{~K}$ & $0,0117(1)$ & 105 & $380^{*}$ & $1,25.10^{9}$ & 0,1566 \\
\hline${ }^{232} \mathrm{Th}$ & 100 & 40 & 15 & $1,4.10^{10}$ & 2,2447 \\
\hline${ }^{238} \mathrm{U}$ & $99,2742(10)$ & 12 & 271 & $4,46.10^{9}$ & 1,7034 \\
\hline
\end{tabular}

Notas

${ }^{a}$ LIDE. (95)

${ }^{b}$ WAITE et al.(96)

${ }^{\mathrm{c}}$ LEFTICARIU et al.(13)

${ }^{\mathrm{d} B L A I R}$ et al.(9)

*Concentração oceânica atual de $\mathrm{K}$

Fonte: Elaborada pelo autor

Durante o processo da radiólise aquosa (ver seção 1.2), a interação da radiação com a água por si forma inúmeras espécies que, por outro lado, reagem entre si alterando a quantidade de produtos primários ou formando novas espécies químicas. O escape yield, $\mathrm{G}$, tem valor encontrado para inúmeras espécies, como apresentamos na tabela 5 para a radiólise por raios gama $(\gamma)$, sendo que para este tipo de radiação, é possível facilmente encontrar valores de $\mathrm{G}$ 
para grande número de espécies (Tabela 5). Para os modelos aqui apresentados, consideramos o valor de $\mathrm{G}$ como constante.

Tabela 5 - Taxa de produção de diversas espécies químicas para raios gama.

\begin{tabular}{ll}
\hline Espécie química & Gp (moléculas/100eV) \\
\hline $\mathrm{e}_{\mathrm{aq}}^{-}$ & 2,6 \\
$\mathrm{H}$ & 0,66 \\
$\mathrm{H}_{2}$ & 0,45 \\
$\mathrm{OH}$ & 2,70 \\
$\mathrm{H}_{2} \mathrm{O}_{2}$ & 0,70 \\
$\mathrm{HO}_{2}$ & 0,02 \\
$\mathrm{H}^{+}$ & 3,10 \\
$\mathrm{OH}^{-}$ & 0,5 \\
\hline
\end{tabular}

Fonte: Adaptada de PASTINA ; LAVERNE (64)

A partir dos valores de $\mathrm{G}$ apresentados na Tabela 5, calculamos a produção das diversas espécies produto da radiólise aquosa por raios $\gamma$ usando as equações (9) e (10) baseada em trabalhos como o de Hoffmann (89), Spinks e Woods (62), Blair et al. (9) e Lin et al. (16).

$$
\begin{gathered}
D_{e f f}=\frac{\rho \cdot \sum_{n} D_{n}}{\frac{1}{1 \varphi}+\frac{1}{S . \varphi}} \\
Y_{P}=\sum_{P} D_{e f f} \cdot G_{p}
\end{gathered}
$$


Onde os índices n e p representam, respectivamente, um dos radionuclídeos $\left({ }^{238} \mathrm{U},{ }^{232} \mathrm{Th}\right.$ ou ${ }^{40} \mathrm{~K}$ ) e dado produto da radiólise; YP nos dá o valor da produção de formação da espécie pela radiólise em mol.(1.s) $)^{-1} ; \rho$ representa a densidade da matriz rochosa local em g. $(\mathrm{cm})^{-3} ; D_{n}$, a dose de radiação emitida pelo radionuclídeo $n$ em MeV.(kg.s $)^{-1}$, que calculamos conforme a equação $(11) ; \phi$ representa a porosidade rochosa, que aqui consideraremos igual a 0,1 (a porosidade atual constatada em Witwatersrand (16) e valor máximo constatado em profundidade a partir de $1000 \mathrm{~m}$ na crosta terrestre (97); e representamos por S o stopping power da matriz rochosa (assim como em Lin (16) e em Blair et al. (9), usaremos o valor $S=1,14$ para a radiação gama); por fim, o valor de G se apresenta em mol.(Mev) ${ }^{-1}$.

$$
D_{n}=\frac{E \cdot \lambda \cdot c \cdot N_{A}}{A_{n}}
$$

A dose a qual o meio aquoso é submetida, $D_{n}$, é calculada considerando $E$ (J/decaimento) como a energia por decaimento corrigida pela perda de neutrino via decaimento beta e que corrigimos para representar a atividade de decaimento dos radionuclídeos há $4 \mathrm{Ga} ; \lambda$ $=1 / T_{1 / 2}$ (decaimento por ano) é a constante de decaimento, $c$ (ppm) é a concentração do radionuclídeo, $N_{A}$ é a constante de Avogadro e $A_{n}(\mathrm{~g} / \mathrm{mol})$ é a massa atômica do radionuclídeo.

Como estamos considerando os efeitos da radiólise em longo-prazo, devemos considerar também as diversas reações químicas que acontecem entre as espécies formadas pela radiólise aquosa. Baseado no modelo cinético apresentado no trabalho de Pastina e La Verne (12), utilizamos os parâmetros apresentados na Tabela 6 .

Como as constantes de reação são consideravelmente distintas em ordem de grandeza, obtivemos um conjunto de equações diferenciais ordinárias (EDOs) denominadas stiff, cuja integração requer o uso de métodos adequados de modo a obtermos soluções estáveis. O algoritmo computacional desenvolvido com base em métodos de Rosenbrock foi o que utilizamos para resolver este tipo de sistema. O método é considerado um método de esforço computacional aceitável por apresentar resultados estáveis e convergentes ao caso de sistemas stiff (ver Apêndice D). (98) Este é recomendado para problemas de química atmosférica, e é empregado em modelos como o de previsão do tempo local do CCATT-BRAMS (Coupled Aerosol and Tracer Transport model to the Brazilian developments on the Regional Atmospheric Modelling System) do Centro de Previsão de Tempo e Estudos Climáticos (CPTEC/INPE). (99) 
Tabela 6 - Reações envolvendo produtos da radiólise e suas respectivas constantes de reação

\begin{tabular}{ccccc}
\hline \multicolumn{5}{c}{ Reação química } \\
\hline \multicolumn{5}{c}{ Reações } \\
reversíveis \\
\hline 1 & $\mathrm{H}_{2} \mathrm{r}$ & $\leftrightarrow$ & $H^{+}+\mathrm{OH}^{-}$ & 13,999 \\
2 & $\mathrm{H}_{2} \mathrm{O}_{2}$ & $\leftrightarrow$ & $H^{+}+\mathrm{HO}_{2}^{-}$ & 11,65 \\
3 & $\mathrm{OH}$ & $\leftrightarrow$ & $O^{-}+H^{+}$ & 11,9 \\
4 & $\mathrm{HO}_{2}$ & $\leftrightarrow$ & $O_{2}^{-}+H^{+}$ & 4,57 \\
& & & & 9,77
\end{tabular}

Constante

de

velocidade

da reação

(M/s)

\begin{tabular}{|c|c|c|c|c|}
\hline 7 & $H^{+}+O H^{-}$ & $\rightarrow$ & $\mathrm{H}_{2} \mathrm{O}$ & $1,4 \times 10^{11}$ \\
\hline 8 & $\mathrm{H}_{2} \mathrm{O}$ & $\rightarrow$ & $\mathrm{H}^{+}+\mathrm{OH}^{-}$ & $\begin{array}{c}\mathrm{K}_{7} \mathrm{X} \\
\mathrm{K}_{2} /\left[\mathrm{H}_{2} \mathrm{O}\right]\end{array}$ \\
\hline 9 & $\mathrm{H}_{2} \mathrm{O}_{2}$ & $\rightarrow$ & $H^{+}+H O_{2}^{-}$ & $\mathrm{k}_{10} \times \mathrm{K}_{3}$ \\
\hline 10 & $\mathrm{H}^{+}+\mathrm{HO}_{2}^{-}$ & $\rightarrow$ & $\mathrm{H}_{2} \mathrm{O}_{2}$ & $5,0 \times 10^{10}$ \\
\hline 11 & $\mathrm{H}_{2} \mathrm{O}_{2}+\mathrm{OH}^{-}$ & $\rightarrow$ & $\mathrm{H}_{2} \mathrm{O}+\mathrm{HO}_{2}^{-}$ & $1,3 \times 10^{10}$ \\
\hline 12 & $\mathrm{HO}_{2}^{-}+\mathrm{H}_{2} \mathrm{O}$ & $\rightarrow$ & $\mathrm{H}_{2} \mathrm{O}_{2}+\mathrm{OH}^{-}$ & $\begin{array}{c}\mathrm{k}_{11} \times \mathrm{K}_{2} / \mathrm{K}_{3} \\
\times\left[\mathrm{H}_{2} \mathrm{O}\right]\end{array}$ \\
\hline 13 & $e_{a q}^{-}+H_{2} 0$ & $\rightarrow$ & $H+O H^{-}$ & $1,9 \times 10^{1}$ \\
\hline 14 & $H+O H^{-}$ & $\rightarrow$ & $e_{a q}^{-}+H_{2} 0$ & $2,2 \times 10^{7}$ \\
\hline 15 & $H$ & $\rightarrow$ & $e_{a q}^{-}+H^{+}$ & $\begin{array}{c}\mathrm{k}_{16} \times \mathrm{K}_{6} \\
\text { (Continua) }\end{array}$ \\
\hline
\end{tabular}


(Continuação)

16

17

18

19

20

21

22

23

24

25

26

27

28

29

30

31

32

33

34

35

36

$$
e_{a q}^{-}+H^{+}
$$$$
\rightarrow
$$

H

$2,3 \times 10^{10}$

$$
\mathrm{OH}+\mathrm{OH}^{-}
$$

$\rightarrow$

$\mathrm{O}^{-}+\mathrm{H}_{2} \mathrm{O}$

$1,3 \times 10^{10}$

$$
\mathrm{O}^{-}+\mathrm{H}_{2} \mathrm{O}
$$

$\rightarrow$

$O H+O H^{-}$

$\mathrm{k}_{17} \times \mathrm{K}_{2} / \mathrm{K}_{4}$

$x\left[\mathrm{H}_{2} \mathrm{O}\right]$

9

$$
O H
$$

$\rightarrow$

$$
O^{-}+H^{+}
$$

$\mathrm{K}_{20} \times \mathrm{K}_{4}$

$$
\mathrm{O}^{-}+H^{+}
$$

$\mathrm{OH}$

$1,0 \times 10^{11}$

1

$$
\mathrm{HO}_{2}
$$

$\rightarrow$

$\mathrm{O}_{2}^{-}+\mathrm{H}^{+}$

$\mathrm{K}_{22} \times \mathrm{K}_{5}$

$$
\mathrm{O}_{2}^{-}+\mathrm{H}^{+}
$$$$
\rightarrow
$$

$\mathrm{HO}_{2}$

$5,0 \times 10^{10}$

$$
\mathrm{HO}_{2}+\mathrm{OH}^{-}
$$

$\rightarrow$

$\mathrm{O}_{2}{ }^{-}+\mathrm{H}_{2} \mathrm{O}$

$5,0 \times 10^{10}$

$\mathrm{O}_{2}{ }^{-}+\mathrm{H}_{2} \mathrm{O}$

$\rightarrow$

$\mathrm{HO}_{2}+\mathrm{OH}^{-}$

$\mathrm{k}_{23} \times \mathrm{K}_{2} / \mathrm{K}_{5}$

$x\left[\mathrm{H}_{2} \mathrm{O}\right]$

5

$$
e_{a q}^{-}+O H
$$$$
\rightarrow
$$

$\mathrm{OH}^{-}$

$3,0 \times 10^{10}$

$e_{a q}^{-}+H_{2} 0_{2}$

$\rightarrow$

$\mathrm{OH}+\mathrm{OH}^{-}$

$1,1 \times 10^{10}$

$e_{a q}^{-}+O_{2}^{-}+H_{2} 0 \quad \rightarrow$

$\mathrm{HO}_{2}^{-}+\mathrm{OH}^{-}$

$$
1,3 x
$$

$10^{10} /\left[\mathrm{H}_{2} \mathrm{O}\right]$

8

$$
e_{a q}^{-}+\mathrm{HO}_{2}
$$

$\rightarrow$

$\mathrm{HO}_{2}^{-}$

$2,0 \times 10^{10}$

$5,5 x$

$2 e_{a q}^{-}+2 \mathrm{H}_{2} \mathrm{O}$

$\rightarrow$

$\mathrm{H}_{2}+2 \mathrm{OH}^{-}$

$10^{9} /\left[\mathrm{H}_{2} \mathrm{O}\right]$

0

$$
e_{a q}^{-}+H+H_{2} \mathrm{O}
$$

$\rightarrow$

$\mathrm{H}_{2}+\mathrm{OH}^{-}$

$2,5 \mathrm{x}$

$10^{10} /\left[\mathrm{H}_{2} \mathrm{O}\right]$

1

$$
e_{a q}^{-}+\mathrm{HO}_{2}^{-}
$$

$\rightarrow$

$\mathrm{HO}_{2}^{-}+\mathrm{OH}^{-}$

$3,5 \times 10^{9}$

$2,2 \times$

$10^{10} /\left[\mathrm{H}_{2} \mathrm{O}\right]$

3

$e_{a q}^{-}+O^{-}+H_{2} O$

$\rightarrow$

$O H^{-}+O H^{-}$

$1,1 \times 10^{1}$

$$
\mathrm{H}+\mathrm{H}_{2} \mathrm{O}
$$

$\rightarrow$

$\mathrm{H}_{2}+\mathrm{OH}$

$1,0 \times 10^{10}$

5

$$
\mathrm{H}+\mathrm{O}^{-}
$$

$\rightarrow$

$\mathrm{OH}^{-}$

$9,0 \times 10^{7}$

$H_{2}$

$7,8 \times 10^{9}$

(Continua) 
(Continuação)

\begin{tabular}{|c|c|c|c|c|}
\hline 37 & $H+O H$ & $\rightarrow$ & $\mathrm{H}_{2} \mathrm{O}$ & $7,0 \times 10^{9}$ \\
\hline 38 & $\mathrm{H}+\mathrm{H}_{2} \mathrm{O}_{2}$ & $\rightarrow$ & $\mathrm{OH}+\mathrm{H}_{2} \mathrm{O}$ & $9,0 \times 10^{7}$ \\
\hline 39 & $\mathrm{H}+\mathrm{HO}_{2}$ & $\rightarrow$ & $\mathrm{H}_{2} \mathrm{O}_{2}$ & $1,8 \times 10^{10}$ \\
\hline 40 & $\mathrm{H}+\mathrm{O}_{2}^{-}$ & $\rightarrow$ & $\mathrm{HO}_{2}^{-}$ & $1,8 \times 10^{10}$ \\
\hline 41 & $O H+O H$ & $\rightarrow$ & $\mathrm{H}_{2} \mathrm{O}_{2}$ & $3,6 \times 10^{9}$ \\
\hline 42 & $\mathrm{OH}+\mathrm{HO}_{2}$ & $\rightarrow$ & $\mathrm{H}_{2} \mathrm{O}+\mathrm{O}_{2}$ & $6,0 \times 10^{9}$ \\
\hline 43 & $\mathrm{OH}+\mathrm{O}_{2}^{-}$ & $\rightarrow$ & $\mathrm{OH}^{-}+\mathrm{O}_{2}$ & $8,2 \times 10^{9}$ \\
\hline 44 & $\mathrm{OH}+\mathrm{H}_{2}$ & $\rightarrow$ & $H+H_{2} 0$ & $4,3 \times 10^{7}$ \\
\hline 45 & $\mathrm{OH}+\mathrm{H}_{2} \mathrm{O}_{2}$ & $\rightarrow$ & $\mathrm{HO}_{2}+\mathrm{H}_{2} \mathrm{O}$ & $2,7 \times 10^{7}$ \\
\hline 46 & $\mathrm{OH}+\mathrm{O}^{-}$ & $\rightarrow$ & $\mathrm{HO}_{2}^{-}$ & $2,5 \times 10^{10}$ \\
\hline 47 & $\mathrm{OH}+\mathrm{HO}_{2}^{-}$ & $\rightarrow$ & $\mathrm{HO}_{2}+\mathrm{OH}^{-}$ & $7,5 \times 10^{9}$ \\
\hline 48 & $\mathrm{HO}_{2}+\mathrm{O}_{2}^{-}$ & $\rightarrow$ & $\mathrm{HO}_{2}^{-}+\mathrm{O}_{2}$ & $8,0 \times 10^{7}$ \\
\hline 49 & $\mathrm{HO}_{2}+\mathrm{HO}_{2}$ & $\rightarrow$ & $\mathrm{H}_{2} \mathrm{O}_{2}+\mathrm{O}_{2}$ & $7,0 \times 10^{5}$ \\
\hline 50 & $\mathrm{HO}_{2}+\mathrm{O}^{-}$ & $\rightarrow$ & $\mathrm{O}_{2}+\mathrm{OH}^{-}$ & $6,0 \times 10^{9}$ \\
\hline 51 & $\mathrm{HO}_{2}+\mathrm{H}_{2} \mathrm{O}_{2}$ & $\rightarrow$ & $\mathrm{OH}+\mathrm{O}_{2}+\mathrm{H}_{2} \mathrm{O}$ & $5,0 \times 10^{-1}$ \\
\hline 52 & $\mathrm{HO}_{2}+\mathrm{HO}_{2}^{-}$ & $\rightarrow$ & $\mathrm{OH}+\mathrm{O}_{2}+\mathrm{OH}^{-}$ & $5,0 \times 10^{-1}$ \\
\hline 53 & $2 \mathrm{O}_{2}^{-}+2 \mathrm{H}_{2} \mathrm{O}$ & $\rightarrow$ & $\mathrm{H}_{2} \mathrm{O}_{2}+\mathrm{O}_{2}$ & $1,0 x$ \\
\hline & $2 U_{2}+2 \Pi_{2} U$ & $\rightarrow$ & $+2 O H^{-}$ & $10^{2} / 2\left[\mathrm{H}_{2} \mathrm{O}\right]$ \\
\hline 54 & $\mathrm{O}_{2}^{-}+\mathrm{O}^{-}+\mathrm{H}_{2} \mathrm{O}$ & $\rightarrow$ & $\mathrm{O}_{2}+2 \mathrm{OH}^{-}$ & $\begin{array}{c}6,0 x \\
10^{8} /\left[\mathrm{H}_{2} \mathrm{O}\right]\end{array}$ \\
\hline 55 & $\mathrm{O}_{2}^{-}+\mathrm{H}_{2} \mathrm{O}$ & $\rightarrow$ & $\mathrm{OH}+\mathrm{O}_{2}+\mathrm{OH}^{-}$ & $1,3 \times 10^{-1}$ \\
\hline 56 & $\mathrm{O}_{2}^{-}+\mathrm{HO}_{2}^{-}$ & $\rightarrow$ & $\mathrm{O}^{-}+\mathrm{O}_{2}+\mathrm{OH}^{-}$ & $1,3 \times 10^{-1}$ \\
\hline 57 & $20^{-}+H_{2} 0$ & $\rightarrow$ & $\mathrm{HO}_{2}^{-}+\mathrm{OH}^{-}$ & $\begin{array}{c}1,0 x \\
10^{9} /\left[\mathrm{H}_{2} \mathrm{O}\right]\end{array}$ \\
\hline 58 & $\mathrm{O}^{-}+\mathrm{H}_{2}$ & $\rightarrow$ & $\mathrm{H}+\mathrm{OH}^{-}$ & $\begin{array}{l}8,0 \times 10^{7} \\
\text { (Continua) }\end{array}$ \\
\hline
\end{tabular}


(Continuação)

59

$$
\begin{array}{cccc}
\mathrm{O}^{-}+\mathrm{H}_{2} \mathrm{O}_{2} & \rightarrow & \mathrm{H}_{2} \mathrm{O} & 5,0 \times 10^{8} \\
\mathrm{O}^{-}+\mathrm{HO}_{2}^{-} & \rightarrow & \mathrm{O}_{2}{ }^{-}+\mathrm{OH}^{-} & 4,0 \times 10^{8}
\end{array}
$$

60

Fonte: Adaptada de PASTINA; LAVERNE (12)

Considerando a importância da interface entre o fluido hidrotermal e o oceano primitivo nas propostas de emergência da vida em Lost City, propomos o modelo análogo desta interface, considerando uma continuidade na interface entre o fluido resultante da radiólise aquosa em ambiente radioativo natural - chamado aqui fluido radiolítico-, e o oceano primitivo. Sendo assim, consideramos que, com a alteração química local, as espécies difundam para as águas oceânicas, mesmo que percolando fissuras rochosas. Se inicialmente considerarmos que nesta interface, a difusão ocorra em condição isotérmica e considerando a baixa concentração local das espécies podemos analisar este fenômeno à perspectiva da lei de Fick - equação (12)- que relaciona o fluxo termodinâmico da espécie química $K, J_{N, P}$, com a variação de densidade molar do componente no espaço, $\frac{\partial C_{P}}{\partial x}$, a partir de um coeficiente de difusão $(43,100)$ ou difusividade , $D_{P}$. A partir desta correlação, podemos analisar o fluxo de dada espécie química considerando a secção da interface fluido radiolítico-oceano primitivo.

$$
J_{N, P}=D_{P} \frac{\partial C_{P}}{\partial x}
$$

A partir do fluxo termodinâmico, $J_{N, P}$, expresso em mols da espécie $P$ difundindo por unidade da seção da interface, pode-se calcular a entropia gerada por este gradiente de densidade molar, sabendo que a força termodinâmica que move o fenômeno está relacionada com a diferença de potencial químico, como representado na equação (13).

$$
\frac{d_{i} S}{d t}=\quad \sum_{P} \frac{1}{T}\left(\frac{d \mu}{d x}\right) J_{N, P}
$$


Com os valores obtidos das concentrações locais das diversas espécies formadas a longo prazo, propomos complementarmente um modelo numérico para analisarmos os efeitos desta radiólise no espaço. Para isto, realizamos um modelo simples de difusão em uma dimensão das espécies químicas resultantes no modelo cinético utilizando a segunda lei de Fick (eq. 14).

$$
\frac{\partial C}{\partial t}=D_{P} \cdot \frac{\partial^{2} C}{\partial x^{2}}
$$

Nesta equação, relaciona à variação de $C$, a concentração da espécie química $\mathrm{P}$ em mol.1 $1^{-1}$, em relação ao espaço $x$ e ao tempo t; sendo $D_{P}$ o coeficiente de difusão do produto $\mathrm{P}$ em $\mathrm{cm}^{2} . \mathrm{s}^{-1}$, que consideraremos para o meio oceânico em temperatura de $5^{\circ} \mathrm{C}$, valor dentro da faixa de temperatura que predomina nos oceanos primitivos, conforme modelos revisados e apresentados na seção 1.3. Para encontrar a solução desta equação diferencial parcial de segunda ordem, utilizamos do pacote NSolve do Wolfram Mathematica supondo que na secção $x=0$ a concentração da espécie é constante e igual ao valor calculado no modelo cinético após período de estabilização das concentrações; e inicialmente o valor do $\mathrm{pH}$ oceânico é 5,0 - para termos um comparativo aos modelos de fontes hidrotermais, que pautam em modelos de oceano primitivo moderadamente ácido. Assumimos o cálculo em espaço relativamente curto na interface fluido radiolítico-oceano primitivo. Além de que a precipitação de minerais, que avaliaremos adiante, frustraria esta difusão independente da dimensão da interface. E consideramos constante o valor da constante de difusão, algo que pode ser assumido dada a alta diluição em que se encontram as espécies no meio oceânico primitivo. (101)

\subsection{Produção e transferência da energia livre no sistema}

Quanto à energia livre produzida pelos desequilíbrios locais, priorizamos a possível energia livre produzida a partir do gradiente de $\mathrm{pH}$ e do gradiente eletroquímico de espécies químicas formadas. Ambos os desequilíbrios geram potenciais eletroquímicos (ou força eletromotriz, F.E.M.), que são associados à um potencial químico $(\mu P)$. Sendo assim, podemos calcular o potencial relativo ao oceano utilizando a equação de Nernst (equação 15), o exemplo demonstrado abaixo para o gradiente de $\mathrm{pH}$, em que ocorre com diferentes atividades de $\mathrm{H}^{+}$na interface entre o ambiente radioativo e o oceano primitivo.

$$
\phi_{\text {ion }, H^{+}}=\frac{R T}{z F} \ln \frac{C_{H^{+}, \text {oceano }}}{C_{H^{+}, \text {ambiente }}}
$$


Seja $\mathrm{R}$ a constante universal dos gases igual a $8,314 \mathrm{~J}$. $(\text { mol.K })^{-1}$; T a temperatura da solução em K; z o valor numérico da carga elétrica do íon; e sendo F a constante de Faraday, equivalente a $96.485 \mathrm{C} \cdot \mathrm{mol}^{-1}$.

A partir da equação, podemos estimar quantitativamente a expectativa de que a diferenciação de valores de $\mathrm{pH}$ entre o sistema e o oceano intensifica a voltagem entre estes sistemas. Com isto, há uma intensificação do potencial químico, que podemos relacionar com a F.E.M., como relacionado por Guggemhein.

$$
\Delta \mu_{i o n}=F z \phi_{i o n}
$$

Em resumo, com a produção das espécies e sua distribuição no tempo e no espaço, temos o valor da concentração das diversas espécies químicas envolvidas. A partir destes valores, temos o potencial eletroquímico a partir da equação (16) e, consequentemente, temos um parâmetro de desequilíbrio químico gerado pela radiólise.

Com os resultados do estudo físico-químico envolvendo principalmente a concentração das espécies no tempo, é possível estimar a produção de energia livre potencialmente disponível, no tempo e no espaço. Desta maneira, esperamos obter considerável noção da oferta de energia que seria o máximo de energia biologicamente aproveitável disponível no gradiente formado. A partir desta disponibilidade, das condições ambientais e a partir de mecanismos de transferência da energia livre para o aproveitamento biológico - que discutiremos no próximo tópico desta seção - há a possibilidade de se estimar a suficiência desta oferta para a manutenção de um sistema biológico.

\subsection{Mecanismos de transferência de energia entre sistema geológico e biológico}

Para as implicações prebióticas e astrobiológicas que tomamos como objetivos deste trabalho, foi analisado e discutidos os plausíveis mecanismos de transferência de energia a partir do desequilíbrio termodinâmico gerado pela radiólise aquosa nos ambientes radioativos. Propomos, em resumo, discutir a condição para transdução com base em modelos de ambiente radioativo na Terra primitiva e na subsuperfície rochosa da lua gelada Europa. Os modelos envolvem cenários de subsuperfície, candidatos a análogos geológicos à subsuperfície de Europa ou aos ambientes radioativos pretensamente existentes na Terra primitiva. Em resumo, 
para a Terra primitiva tomamos como base de modelo de transdução o protometabolismo análogo primitivo da via de acetil-CoA, mesmo utilizado para a hipótese de origem da vida em ambientes de fontes hidrotermais alcalinas. Enquanto que, para a transdução nos cenários associados a Europa, utilizaremos modelo de ecossistema baseado em metabolismo para obtenção de energia deduzido a partir do genoma do organismo Ca. D. audaxviator.

\subsubsection{Possível mecanismo de transdução em ambiente radioativo na Terra primitiva}

Há considerável enfoque no mecanismo de transdução pela via proto-metabólica precursora à do acetil-CoA que envolve a proteína ferredoxina, prioritariamente por ser uma via importante não somente por seu poder de conversão de energia livre sem o uso de uma ATP sintase; mas também para processo de fixação de carbono, essencial para o desenvolvimento em células autotróficas (ver seção 1.1); por ser relativamente simples, de poucas etapas, que converte $\mathrm{H}_{2}$ e $\mathrm{CO}_{2}$ - que no caso análogo, está presente em alta concentração no oceano primitivo - em acetil-CoA; e por ser uma via comum aos dois principais domínios da vida, bactéria e archaea (21) e proposta como uma via importante do Último Ancestral Comum Universal (LUCA). (28)

A característica principal deste mecanismo é relacionada à necessidade da existência prévia de uma estrutura macroscópica, ausente de enzimas e membranas orgânicas, que envolve a interface entre o meio alcalino em que haja moléculas de $\mathrm{H}_{2}$ dissolvidas e o meio ácido em presença de $\mathrm{CO}_{2}$, mediado por uma membrana microporosa de material inorgânico, contendo clusters de minerais de propriedade catalítica, como greigita - algo que se espera estar presente no caso de fontes hidrotermais (20) e que pretendemos avaliar se é possível para o caso de fontes radiolíticas.

Para a modelagem, a proposta de mecanismo de transferência de energia livre foi uma via protometabólica análoga à via de síntese Acetil-CoA que, conforme apresentada (ver seção 1.1), cuja catálise enzimática utiliza de cofator de estrutura análoga a de minerais tal como greigita. (ver seção 1.1) Nesta via, $\mathrm{H}_{2}$ e $\mathrm{CO}_{2}$, ambos componentes presentes em nosso sistema e em quantidade considerável no oceano primitivo, respectivamente. Na interface sistemaoceano, o $\mathrm{CO}_{2}$ sofre diretamente redução por parte do $\mathrm{H}_{2}$, e o gradiente eletroquímico gerado nesta interface seria a força termodinâmica desta redução. Utilizamos portanto, como no 
trabalho de Sojo et al. (21), a redução do $\mathrm{CO}_{2}$ a formaldeído, a etapa inicial mais difícil da via, que exige a transferência de quatro elétrons por dióxido de carbono.

$$
\begin{gathered}
\mathrm{H}_{2} \rightarrow 2 \mathrm{H}^{+}+2 e^{-} \\
\mathrm{CO}_{2}+4 \mathrm{H}^{+}+4 e^{-} \rightarrow \mathrm{CH}_{2} \mathrm{O}+\mathrm{H}_{2} \mathrm{O}
\end{gathered}
$$

Para tal formação, que envolve a proteína ferredoxina, avaliamos a plausibilidade da formação de estrutura microporosa em que predomine carbonato de cálcio $\left(\mathrm{CaCO}_{3}\right)$ com cluster de minerais catalisadores, analogamente ao caso de fontes hidrotermais que seriam requisito para a emergência do arranjo de transdução por sistema precursor à via metabólica de acetilCoA (ver 1.1). Essa análise visou ser feita com base em parâmetros de estabilidade dos minerais envolvidos, seja através dos respectivos potenciais de precipitação considerando condições de temperatura e pressão constatadas em ambientes radioativos estudados; seja através de diagramas de estabilidade, como os diagramas Eh-pH (conhecido também como diagramas de Pourbaix).

\subsubsection{Possibilidade de vida em ambiente radioativo em Europa}

Para os objetivos relativos à habitabilidade de possível ambiente radioativo em Europa a partir do fenômeno da radiólise aquosa em ambientes de subsuperfície profunda, desenvolvemos um modelo de ecossistema de espécie única de células de Ca. $D$. audaxviator (Figura 1). Considerando que se trata de uma espécie mantida prioritariamente por uma via de redução do sulfato produzido por radiólise (ver seção 1.6). Realizamos primeiramente, para desenvolver o modelo, o cálculo da produção de sulfato por radiólise aquosa usando condições geológicas de diferentes cenários de ambientes radioativos modelados com base em estudos e modelos geológicos já conhecidos; parâmetros experimentais da radiólise aquosa; e nos estudos microbiológicos realizados na região de Witwatersrand. Isto devido ao fato de que ainda não temos dados diretos ou indiretos do ambiente e da composição geológica da subsuperfície de Europa. A produção de sulfato calculada foi então comparada à sua demanda por célula, como apresentado no trabalho de Lin et al. (19). 
O sulfato é um produto secundário da radiólise, como ilustra a Figura 5, desta maneira, sua taxa de produção não pode ser calculada somente utilizando a relação apresentada pela equação (10). A partir do trabalho de Lefticariu et al. (13), os resultados demonstram a necessidade de adicionar fatores relativos ao mineral pirita, que é o substrato para a formação do sulfato a partir da radiólise aquosa, para o cálculo da taxa de produção anual do ânion (equação 19). O seu resultado experimental apresentou que a produção de sulfato via radiólise aquosa por energia de decaimento é igual a $G_{S O_{4}^{2-}}=2,1 \cdot 10^{-9} \mathrm{~mol} \cdot\left(\mathrm{m}^{2} \cdot G y\right)^{-1}$.

$$
P_{S O_{4}^{2-}}=Y_{S O_{4}^{2-}} \cdot S_{p y} \cdot w_{\%}
$$

Porém a dosagem incidente de radiação, $D_{n}$, é dada pela mesma equação (11), sendo que neste modelo simples consideramos parâmetros geológicos dos diferentes cenários considerados. Por fim, a produção anual de sulfato via radiólise aquosa, como citado, é dada pela equação (19), onde $S_{p y}$ em $\mathrm{m}^{2} / \mathrm{kg}$ é a área superficial da pirita por quilograma de material que, pelos dados experimentais dos autores, resultou no valor de $226.0 \pm 6.5 \mathrm{~cm}^{2} / \mathrm{g}$ para granulação dentro da faixa de 100 a $150 \mu \mathrm{m}$ de pirita; e $w \%$ é a porcentagem em massa de pirita na rocha sedimentar. A formação de sulfato ocorre por conta da oxidação e dissolução do mineral pirita por produtos formados na radiólise aquosa (11), como é o caso da reação representada pela equação (20). Sendo que o radical $\mathrm{HO}^{\bullet}$ é um dos produtos primários das reações de radiólise. (12)

$$
\mathrm{Fe}+4 \mathrm{HO} \rightarrow \mathrm{Fe}^{2+}+\mathrm{S}+\mathrm{SO}_{4}^{2-}+2 \mathrm{H}_{2}
$$

Além da produção calculada de sulfato, para o modelo de ecossistema, utilizamos do resultado microbiológico da taxa in situ de redução de sulfato microbiana apresentada no trabalho de Lin et al. (19) Como resultado deste trabalho, a taxa de redução de sulfato se encontra na faixa de $5,5.10^{-18}$ a $3,6.10^{-17}$ mol por célula por ano para amostras contendo espécies microbianas encontradas em Witwatersrand (13) (ver seção 1.6).

A Figura 5 apresenta um modelo de ambiente de subsuperfície em Europa, enfatizando sua analogia com ambientes radioativos na Terra. Assumimos, para o modelo, a presença de nichos de material radioativo na subsuperfície rochosa, em distância considerável de fontes hidrotermais que possam ser fontes alternativas de sulfato, mas em proximidade de formações 
de pirita. Este material é conhecido pela sua origem primordial em planetas rochosos. (102) Além de que há conhecidos modelos para origem, evolução da crosta e oceano de Europa (103) que apresentam hipóteses de formação de material como a pirita. Por fim, assumimos a presença de materiais radioativos de ${ }^{238} \mathrm{U}$ e ${ }^{232} \mathrm{Th}$ contido em rochas, e de ${ }^{40} \mathrm{~K}$ presente nos oceanos.

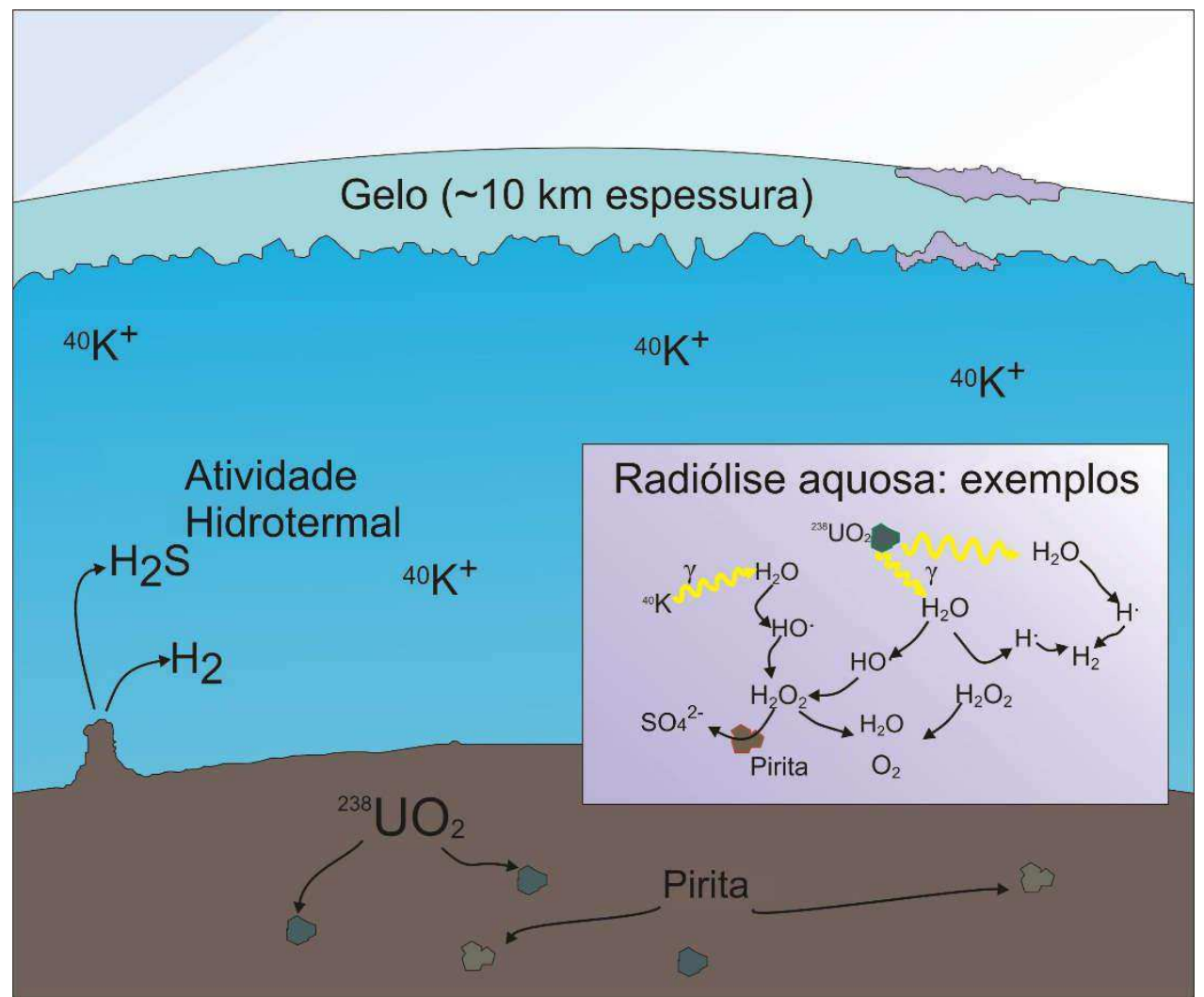

Figura 5 - Modelo de Europa ilustrando o material radiogênico e a radiólise aquosa que ocorre na subsuperfície. Assumimos a presença de ${ }^{238} \mathrm{U}$ e ${ }^{232} \mathrm{Th}$ presente em rochas da lua gelada e ${ }^{40} \mathrm{~K}$ dissolvido na água.

Fonte: Adaptada de CHYBA (100)

Para as concentrações de urânio e tório nos modelos, admitimos os valores atribuídos a três cenários a partir de resultados de análises geoquímicas: a) Zona vadosa (insaturada de água) marciana; b) Rochas de estrato geológico não mineralizado da região de Witwatersrand, onde há alta concentração de elementos radioativos; c) Rochas de estrato geológico mineralizado da região de Witwatersrand, onde há baixa concentração de elementos radioativos. Para o potássio, assumimos a faixa concentração entre 380 ppm (igual à concentração oceânica na Terra (104)) e 3800ppm (que estimam ser próximo ao valor do oceano em Europa (103). Sendo considerada a porcentagem isotópica correspondente a cada nuclídeo. 
A área superficial, como discutido, é um fator que influencia a produção de sulfato, portanto propomos calcular esta a partir de diferentes modelos de granulação que poderiam ocorrer na subsuperfície de Europa. Propomos variar a granulação a partir de um modelo de empacotamento esférico preenchendo um volume cúbico. Variando o tamanho do grão esférico, isto é, o diâmetro da esfera $(\phi)$, implica na variação da área superficial do mesmo grão, $\operatorname{Spy}(\phi)$. A partir do modelo, temos a relação inversamente proporcional entre a área superficial e o raio da esfera. Enfim, calculamos a produção de sulfato pela radiólise aquosa (Ps) para diferentes tamanhos de grãos, tendo como referência a escala granulométrica de Wentworth. (105) Para cada categoria de agregado (argila, silte, areia, seixos ou pedregulhos), consideramos uma distribuição homogênea de tamanho de grãos. 


\section{Resultados e discussões}

\subsection{Diversidade química pela radiólise}

Com o modelo cinético inspirado no trabalho experimental de Pastina e LaVerne (64), obtivemos o resultado relativo à diversidade química localmente a um ambiente de deposição radioativa em função do tempo em que o oceano primitivo sofre radiação. Similarmente ao resultado do trabalho citado, as figuras 6 e 7 demonstram que, a longo prazo, os efeitos da diferença de concentração dos radionuclídeos é balanceado pelos efeitos secundários da radiólise, que envolve o conjunto de reações químicas que acontece entre as espécies, conforme Tabela 6. Isto é, há um crescimento inicial da concentração das espécies, caracterizando o período onde o fenômeno radiolítico predomina, provendo os produtos primários até o momento em que começa a prevalecer os fenômenos químicos entre as espécies, formando produtos secundários e apresentando relativa estabilização das concentrações. Nas figuras 6 e 7, se demonstram os efeitos da radiólise aquosa a longo prazo considerando duas diferentes referências para a concentração de radionuclídeos, a região de Witwatersrand e o condrito carbonático. Os resultados se apresentam de acordo com as expectativas a partir da química do fenômeno e comparando com referências relativas aos ambientes modelo. Está apresentada na figura o resultado das espécies que apresentaram concentrações maiores do que $10^{-20} \mathrm{~mol}^{-1}{ }^{-1}$. Além disto, observamos a distribuição entre espécies químicas, onde o $\mathrm{H}_{2}$, assim como os íons $\mathrm{H}^{+}$e $\mathrm{OH}^{-}$, apresenta concentração bem superior às demais, que incluem espécies radicalares, o elétron (e-aq) e o peróxido de hidrogênio $\left(\mathrm{H}_{2} \mathrm{O}_{2}\right)$. Isto vai de acordo com à instabilidade química já conhecida entre espécies radicalares comparada às moleculares.

Comparando os resultados referente às duas referências de onde baseamos valores das concentrações de radionuclídeos, podemos notar alguns efeitos da diferença destas concentrações. Tal diferença esperada era significativa, uma vez que os elementos $U$ e Th contribuem fortemente com a emissão gama, que foi a que consideramos aos nossos cálculos, como pode ser observado a partir da Tabela 4. Além disto, pela Figura 7, que representa nossa referência para baixa concentração de radionuclídeos, vemos que o $\mathrm{H}_{2}$ atinge concentrações de até duas ordens de grandeza inferiores ao caso da Figura 6. E notável, comparando os modelos, os diferentes tempos para a estabilização das concentrações, enquanto que na figura 6 vemos este fenômeno após dezenas de milhares de anos, no caso da figura 7, este só acontece após um milhão de anos. 
Outra característica notável nos resultados representados pela Figura 6 foi a concentração de $\mathrm{H}_{2}$ que se estabilizou usando as concentrações de radionuclídeos associados após tempo próximo a um ano de radiação, chegando à ordem de $0,1 \mathrm{nM}$. Mesma ordem de grandeza dos resultados dos modelos de produção de $\mathrm{H}_{2}$ obtidos por Lin et al (16) usando parâmetros de diferentes ambientes em Witwatersrand. No modelo deste trabalho, Lin et al. (16) consideram apenas o efeito da radiólise para o cálculo, excluindo os fenômenos químicos que ocorrem $a$ posteriori, apesar de que dosagem efetiva foi calculada similarmente ao modelo de nosso trabalho, usando o modelo desenvolvido por Hoffmann (89). Pelos resultados das Figura 6 e 7, podemos notar que os valores das concentrações de $\mathrm{H}_{2}$ variam juntamente com os valores das concentrações de $\mathrm{OH}^{-}$quando estas decaem, o que se explica ao observamos os sistemas de reações químicas considerados, em que as reações 29 e 30 (ver Tabela 6 em Metodologia) têm $\mathrm{OH}^{-}$e $\mathrm{H}_{2}$ como produtos e alta constante de velocidade.

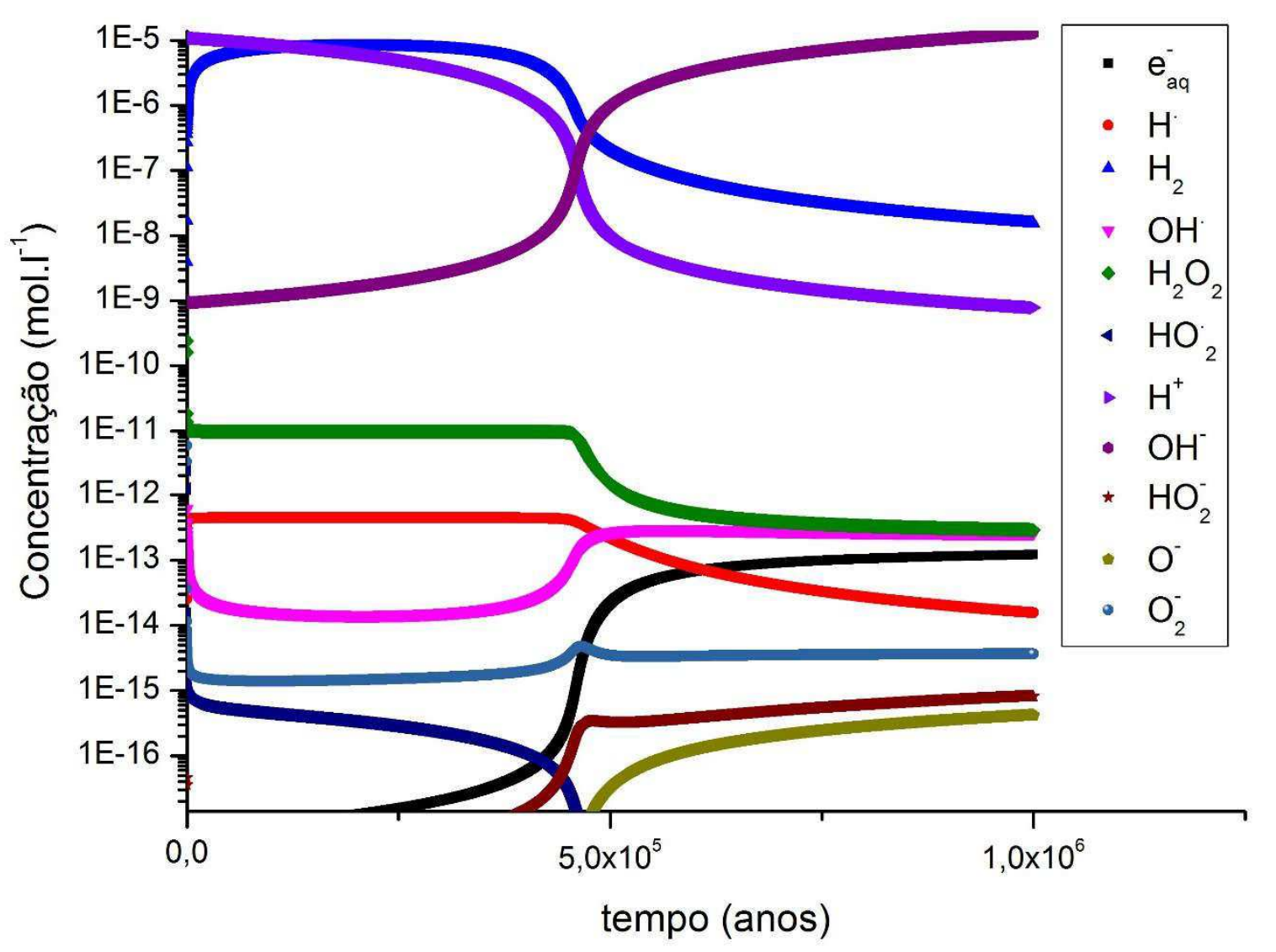

Figura 6 - Resultado do modelo cinético para produção de espécies químicas a partir da radiólise aquosa. As concentrações são apresentadas em função do tempo. Os cálculos da diversidade química efeito da radiólise aquosa foi feita considerando a concentração de ${ }^{238} \mathrm{U},{ }^{232} \mathrm{Th}$ e ${ }^{40} \mathrm{~K}$ associadas a estratos minerais mais concentrados em Witwatersrand - sendo a concentração e atividade de ${ }^{40} \mathrm{~K}$ relativos ao oceano primitivo, e considerando oceano primitivo moderadamente ácido $(\mathrm{pH}=5)$.

Fonte: Elaborada pelo autor 


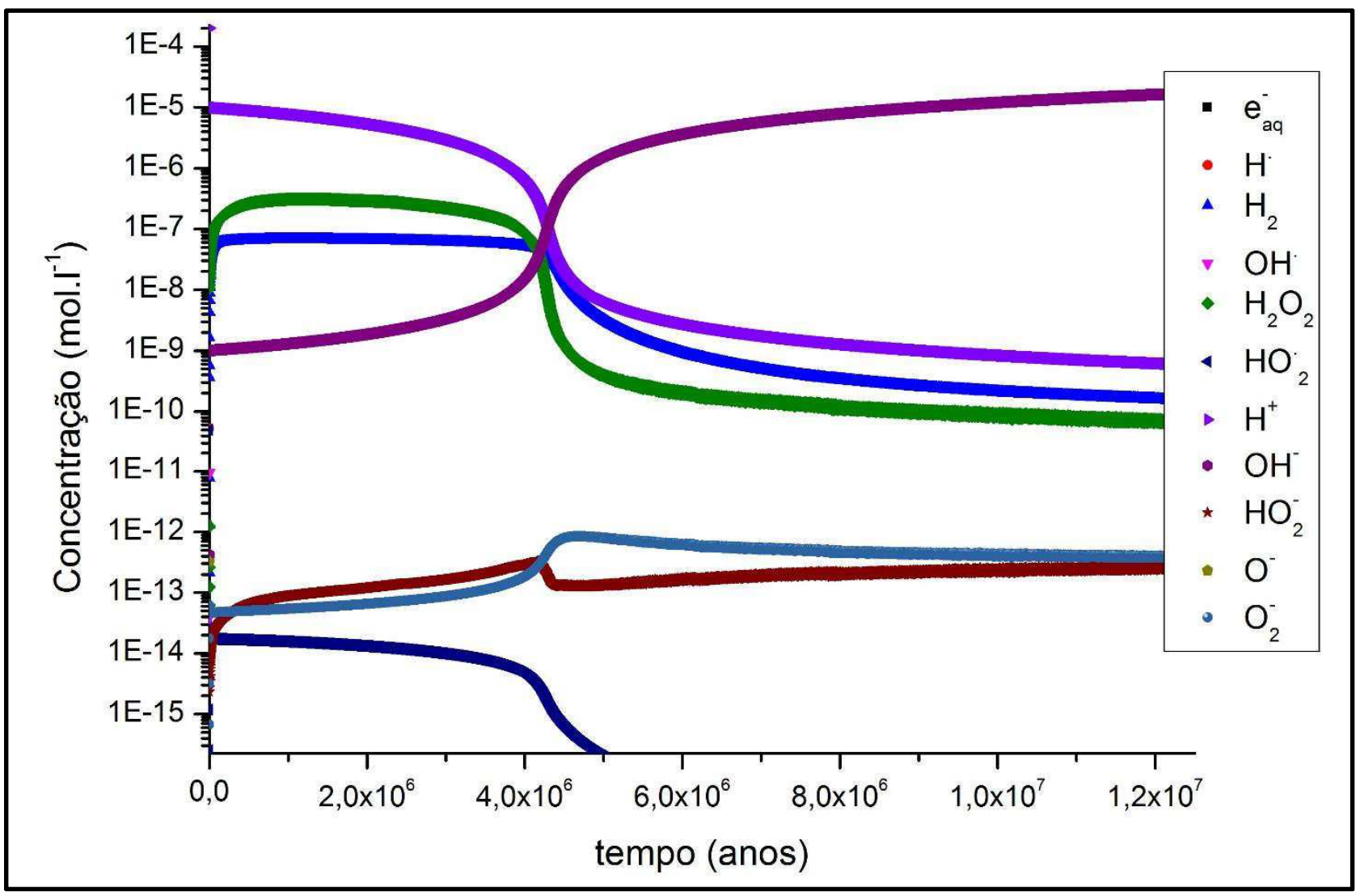

Figura 7 - Resultado do modelo cinético para produção de espécies químicas a partir da radiólise aquosa. As concentrações são apresentadas em função do tempo. Os cálculos da diversidade química efeito da radiólise aquosa foi feita considerando a concentração de ${ }^{238} \mathrm{U},{ }^{232} \mathrm{Th}$ e ${ }^{40} \mathrm{~K}$ associadas a condritos e considerando oceano primitivo moderadamente ácido $(\mathrm{pH}=5)$.

Fonte: Elaborada pelo autor

A característica alcalina constatada nos ambientes radioativos naturais estudados aqui parece ter a radiólise aquosa como principal influência, como podemos notar nos resultados. $\mathrm{O}$ efeito de alcalinidade pela radiólise aquosa é perceptível na Figura 6 e 7 em tempo após cerca de $460.10^{3}$ e $426.10^{4}$ anos considerando. Nestes dados momentos, há um crescimento da alcalinidade, com o aumento da concentração de $\mathrm{OH}^{-}$e o consequente abaixamento da concentração de $\mathrm{H}^{+}$dada a auto-hidrólise da água. A concentração final relativamente alta da concentração de $\mathrm{OH}^{-}$no cálculo do modelo de ambiente radioativo demonstra acordo com resultados geoquímicos das referências. Portanto, a radiólise aquosa do modelo se mostra promissora para explicar o $\mathrm{pH}$ que se constatou em análises in situ em ambientes radioativos que comportavam organismos da espécie Candidatus Desulforudis audaxviator (ver seção 1.6). Pelas figura 6 e 7, observamos que a concentração do íon hidroxila se mantém crescendo mesmo 
após uma estimativa na ordem dos milhões de anos. Até o período calculado, alcançou algo da ordem de $10^{-6} \mathrm{~mol}^{-1}$, e apresenta crescimento cada vez menor. Os perfis da diversidade química gerada pela radiólise aquosa em longo prazo mostra perfil muito similar em modelos nos demais cenários propostos, conforme foram apresentados no Apêndice C. Sendo assim, podemos concluir que temos uma boa representatividade em nosso modelo cinético relativo ao efeito da radiólise no meio aquoso observando os resultados que alcançamos de modo geral.

\subsection{Desequilíbrio químico pela radiólise}

Quanto a difusão das espécies químicas no espaço e no tempo, destacamos alguns resultados para algumas espécies que, além de apresentarem concentração final consideravelmente maior nos resultados do modelo cinético, consideramos de importância para os objetivos deste trabalho. São espécies que aparecem em referência na literatura sobre análises geoquímicas in situ em ambientes radioativos, ou espécies que participam da via metabólica de Wood-Ljungdahl, que é o caso do $\mathrm{H}_{2}$ (ver seção 1.1).

Com os resultados apresentados na Figura 8, temos noção dos efeitos do $\mathrm{pH}$ em região próxima a um ambiente radioativo, cujas concentrações se apresentaram na Figura 6 considerando o meio aquoso como o oceano primitivo, conforme modelos que o consideravam de característica moderadamente ácida (ver seção 1.3). Este gradiente de $\mathrm{pH}$ apresenta-se seguindo a difusão dos íons $\mathrm{H}^{+}$e $\mathrm{OH}^{-}$no tempo e no espaço. Podemos notar que, com o passar do tempo, a tendência é a convergência das linhas apresentadas na Figura 8.

Analogamente, se apresenta na Figura 9 a distribuição da concentração de $\mathrm{H}_{2}$, considerando o mesmo modelo de difusão unidimensional. 


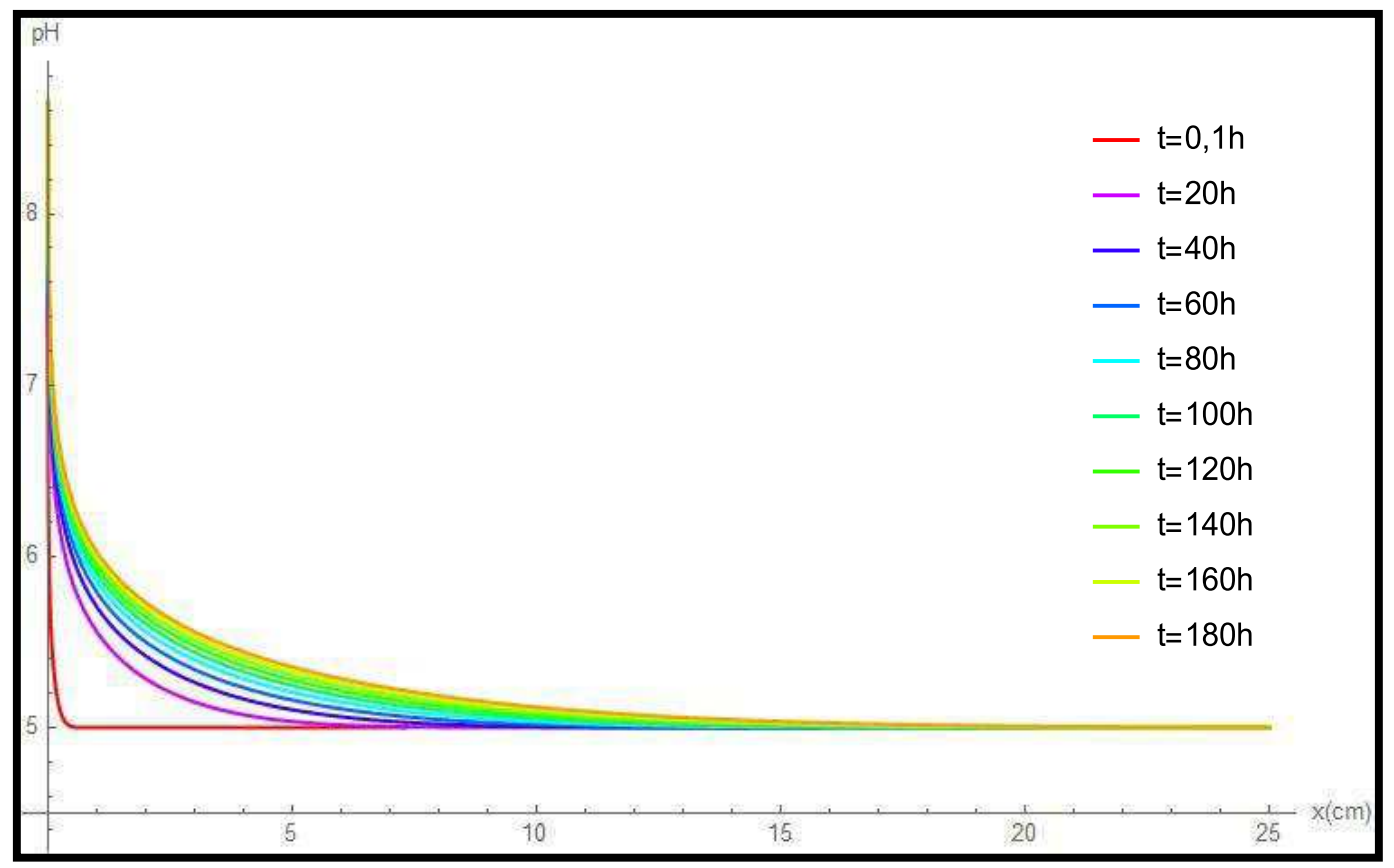

Figura 8 - Gradiente de $\mathrm{pH}$ em função do tempo e do espaço na interface entre um ambiente radioativo em $\mathrm{x}=0$ (origem espacial) e o oceano primitivo de $\mathrm{pH}=5$ e temperatura $\mathrm{T}=5^{\circ} \mathrm{C}$. Para tal gradiente, foi considerado modelo unidimensional de difusão dos íons $\mathrm{H}^{+}$e $\mathrm{OH}^{-}$pela lei de Fick e difusividade constante. Em $\mathrm{x}=0$, temos o pH relativo ao ambiente radioativo, utilizando as concentrações apresentadas na Tabela 4Valores associados ao radionuclídeos utilizados para o modelo de produção de espécies químicas por radiólise aquosa para região em Witwatersrand corrigidas para período anterior a $4 \mathrm{Ga}$.

Fonte: Elaborada pelo autor

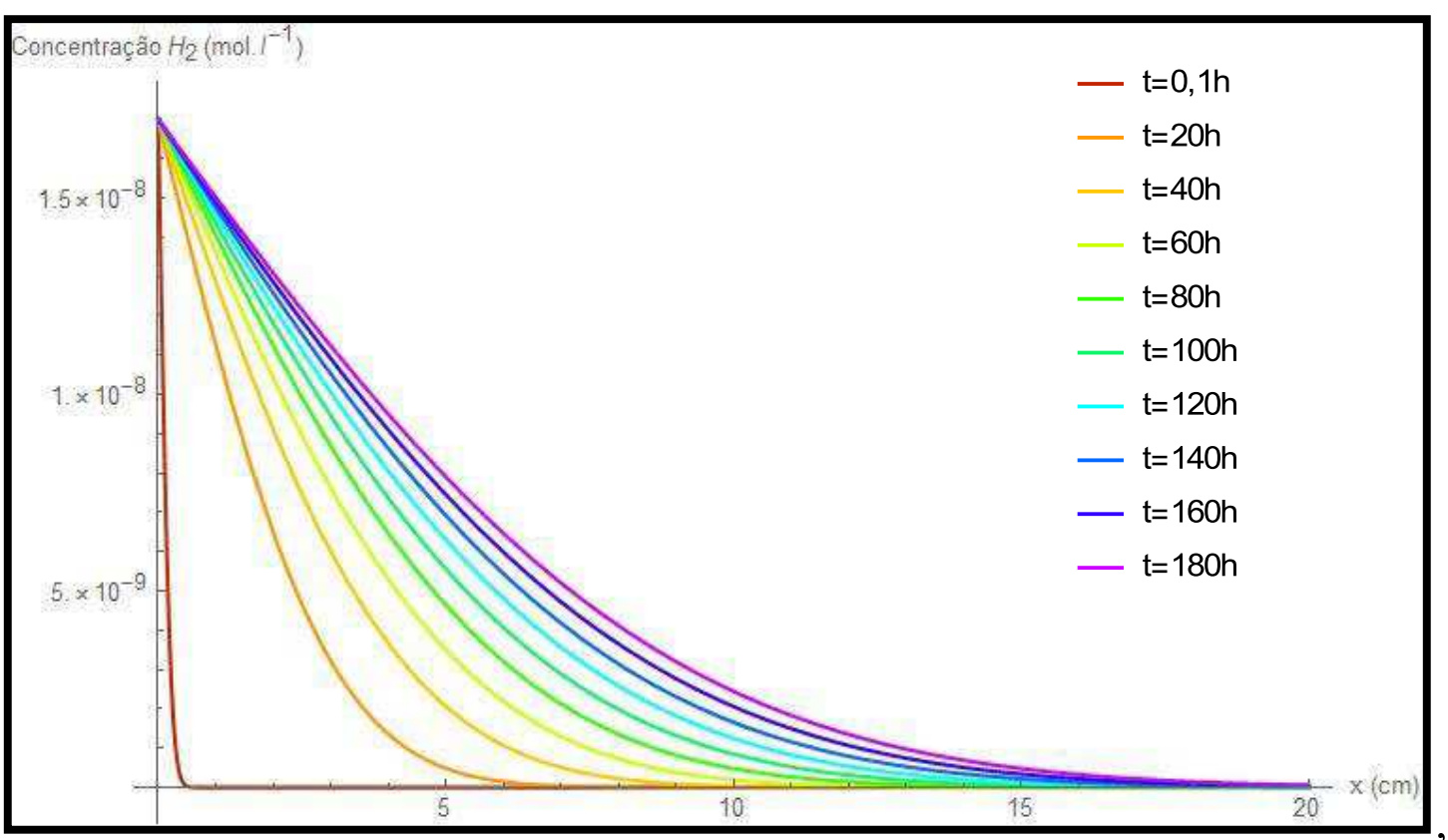

Figura 9 - Distribuição de $\mathrm{H}_{2}$ no tempo e no espaço a partir de modelo de difusão unidimensional pela lei de Fick, considerando o coeficiente de difusão constante relativo ao meio aquoso a $\mathrm{T}=5^{\circ} \mathrm{C}$. Neste modelo, em $\mathrm{x}=0$ está a concentração média do período de tempo em que a concentração de $\mathrm{H}_{2}$, na Figura 5 a), encerra sua oscilação -aproximadamente em $\mathrm{t}=7,5.10^{5}$ anos.

Fonte: Elaborada pelo autor 
Na Figura 10 superior estão apresentados os valores para o potencial eletroquímico resultante da produção das espécies químicas pela radiólise. Com isso, somado à presença de $\mathrm{H}_{2}$ produzido dissolvido no meio, concluímos primeiramente, que nosso modelo de ambiente radioativo natural se trata de um meio redutor. Seu potencial local apresenta valor de $230 \mathrm{mV}$ (Figura 10 superior), supera o potencial gerado pelos gradientes em fontes hidrotermais, na ordem de $200 \mathrm{mV}(21,26)$ e é comparável ao valor da força eletromotriz de uma mitocôndria, também de $200 \mathrm{mV}$. (30) $\mathrm{Na}$ imagem inferior da Figura 10, temos os valores relativos ao potencial químico consequência da radiólise e de sua consequente diversidade química em oceano primitivo em função do espaço e do tempo após a relativa estabilização da concentração das espécies produzidas pela radiólise aquosa. Com o valor do potencial químico em condição de temperatura e pressão constantes, como é o caso do modelo aqui desenvolvido, temos o valor associado à energia livre consequência do desequilíbrio formado pela radiólise aquosa.

Em conclusão, temos na Figura 10 o valor máximo possível de energia disponível pelo gradiente formado em efeito aos produtos da radiólise aquosa. Em outras palavras, temos calculado a energia máxima que pode ser transferida para um sistema vivo em região próxima à de um ambiente radioativo. Isto, evidentemente desconsiderando até então quaisquer mecanismos de transdução que atuariam transferindo parte destes valores de energia calculados.

Considerando os parâmetros termodinâmicos da etapa inicial e endergônica da via de síntese de Acetil-CoA, temos referência da suficiência do gradiente quimiosmótico na interface fluido radiolítico-oceano primitivo como possível força termodinâmica. Por fim, notamos que localmente o potencial gerado supera os $94 \mathrm{mV}$ que demanda a etapa do metabolismo citado considerando interface similar em termos de pH. (26) 

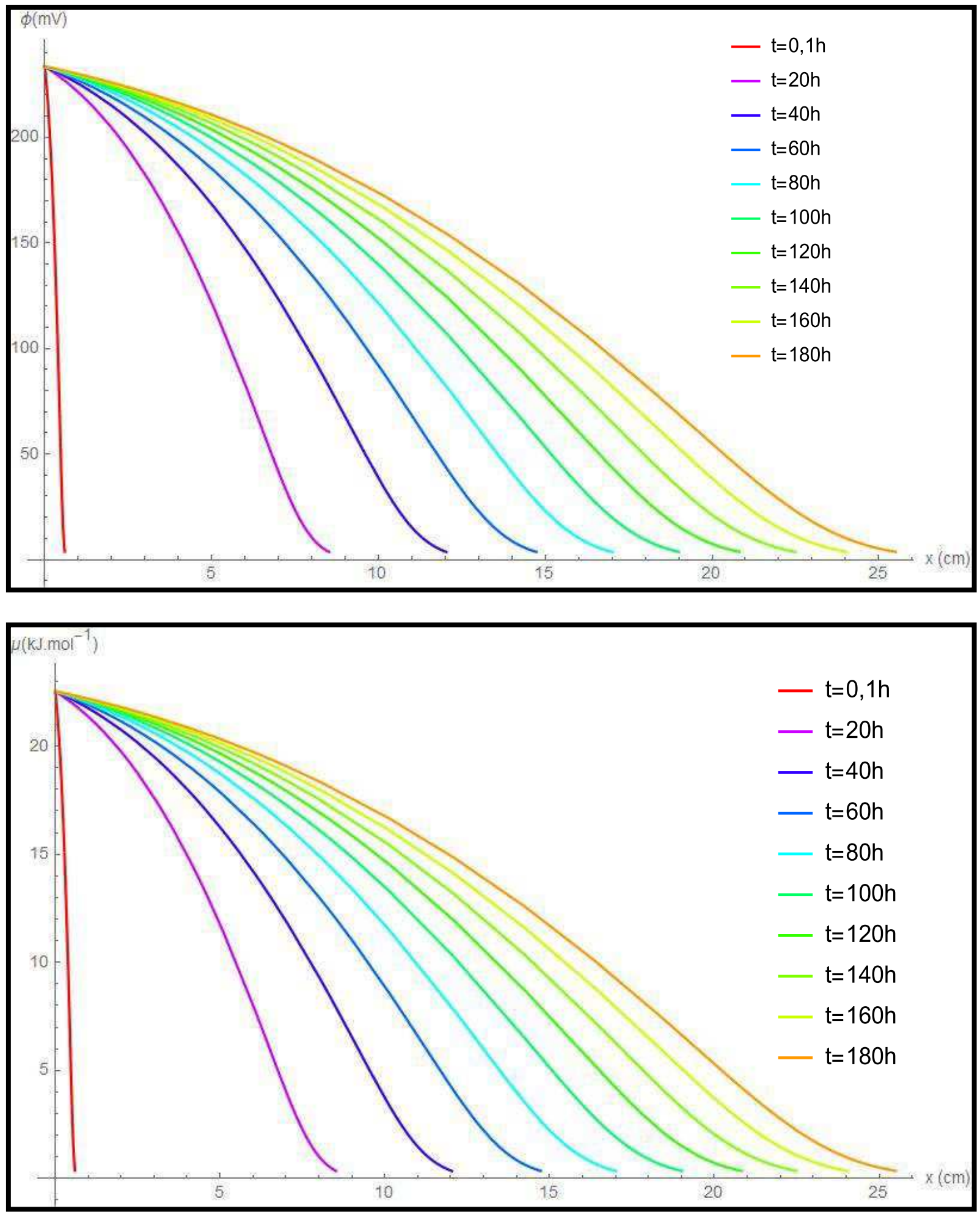

Figura 10 - Superior: Força eletromotriz associada ao espaço e tempo em decorrência ao gradiente quimiosmótico entre o ambiente radioativo - em $\mathrm{x}=0$ (origem espacial) - e oceano primitivo. Inferior: Potencial químico associada ao espaço e tempo em decorrência ao gradiente quimiosmótico entre o ambiente radioativo $-\mathrm{em} \mathrm{x}=0$ - e oceano primitivo. Para ambos os casos, consideramos que espécies estão se difundindo em oceano primitivo de temperatura $\mathrm{T}=5^{\circ} \mathrm{C}$ e $\mathrm{pH}=5$.

Fonte: Elaborada pelo autor 


\subsection{Condições para transdução da energia livre formada}

Os resultados do desequilíbrio químico gerado em ambiente radioativo apresentados nas seções anteriores apresentaram a contribuição da radiólise aquosa para a formação de gradientes quimiosmóticos locais e produção de energia livre. Assim como em ambiente das fontes hidrotermais de Lost City (ver seção 1.1) consequência do fenômeno químico da serpentinização, a radiólise aquosa gera, no ambiente radioativo, um meio localmente alcalino e redutor, em contraste com o oceano primitivo moderadamente ácido e oxidante. Deste modo, para concluir a comparação com os modelos de Lost City, necessitamos complementações geológicas de modo a avaliar possibilidade de precipitação de interface que frustraria os gradientes formados, isto é, limitaria a difusão das espécies produzidas, e discutir a possibilidade de formação de minerais de propriedade catalítica. Com isto, poderíamos discutir a viabilidade de aplicar hipóteses de transdução, tal como as relacionadas à via de síntese acetilCoA.

Se considerarmos as reações de precipitação de materiais carbonáticos, principalmente de minerais como calcita $\left(\mathrm{CaCO}_{3}\right)$, ou de sulfetos de ferro, como pirita e greigita temos a condição de avaliar possível formação destes nos arredores do ambiente radioativo, dentro distância de difusão a qual o desequilíbrio químico da radiólise possui efeito. A princípio, pirita e calcita são reportados na região de Witwatersrand, até mesmo próximos a região de deposição de minerais radioativos (ver seção 1.5). Levando em conta a estabilidade dos minerais citados, podemos estimar a possível precipitação de minerais carbonáticos, que seriam importantes para mediar o gradiente quimiosmótico na interface de fluídos vindos dos ambientes radioativos e do oceano primitivo. A princípio, considerando a solubilidade extremamente baixa (pK de precipitação igual a $-10,5$ e $-8,30$ para a calcita e siderita respectivamente), a presença de $\mathrm{Fe}^{2+}$, $\mathrm{Ca}^{2+} \mathrm{e} \mathrm{CO}_{3}{ }^{2-}$ no oceano primitivo (ver seção 1.3) é razoável a expectativa de precipitados de carbonatos de ferro e, prioritariamente, cálcio nas proximidades e induzidos por ambientes radioativos dentro da distância a qual calculamos os gradientes quimiosmóticos pela difusão das espécies produzidas pela radiólise aquosa.

A partir da análise de diagramas de estabilidade para estes minerais, das condições de $\mathrm{pH}$ e potencial de redução local e considerando as condições das amostras mais quentes encontradas na região com temperatura de $60^{\circ} \mathrm{C}$ e pressão de $0,25 \mathrm{kbar}$ (19), estimamos a presença predominante de calcita e dolomita e a ausência de aragonita em região de ambiente radioativo conforme diagrama de estabilidade destes minerais. E a partir da abrupta diferença de $\mathrm{pH}$ entre estes microambientes alcalinos por efeito da radiólise aquosa, e o meio oceânico 
primitivo, em torno de 4 valores de diferença, estimamos ser possível a presença de minerais de propriedade catalíticas como greigita e mackinawita. O que pode ser confirmado se considerarmos a possível contribuição da concentração alta de $\mathrm{Fe}^{2+}$ e $\mathrm{Mg}^{2+}$ (ver seção 1.3) no oceano primitivo e considerarmos a presença de sulfetos no ambiente de Witwatersrand, o que pode ser evidenciado pela presença de pirita $\left(\mathrm{FeS}_{2}\right)$ na região. (ver seção 1.5)

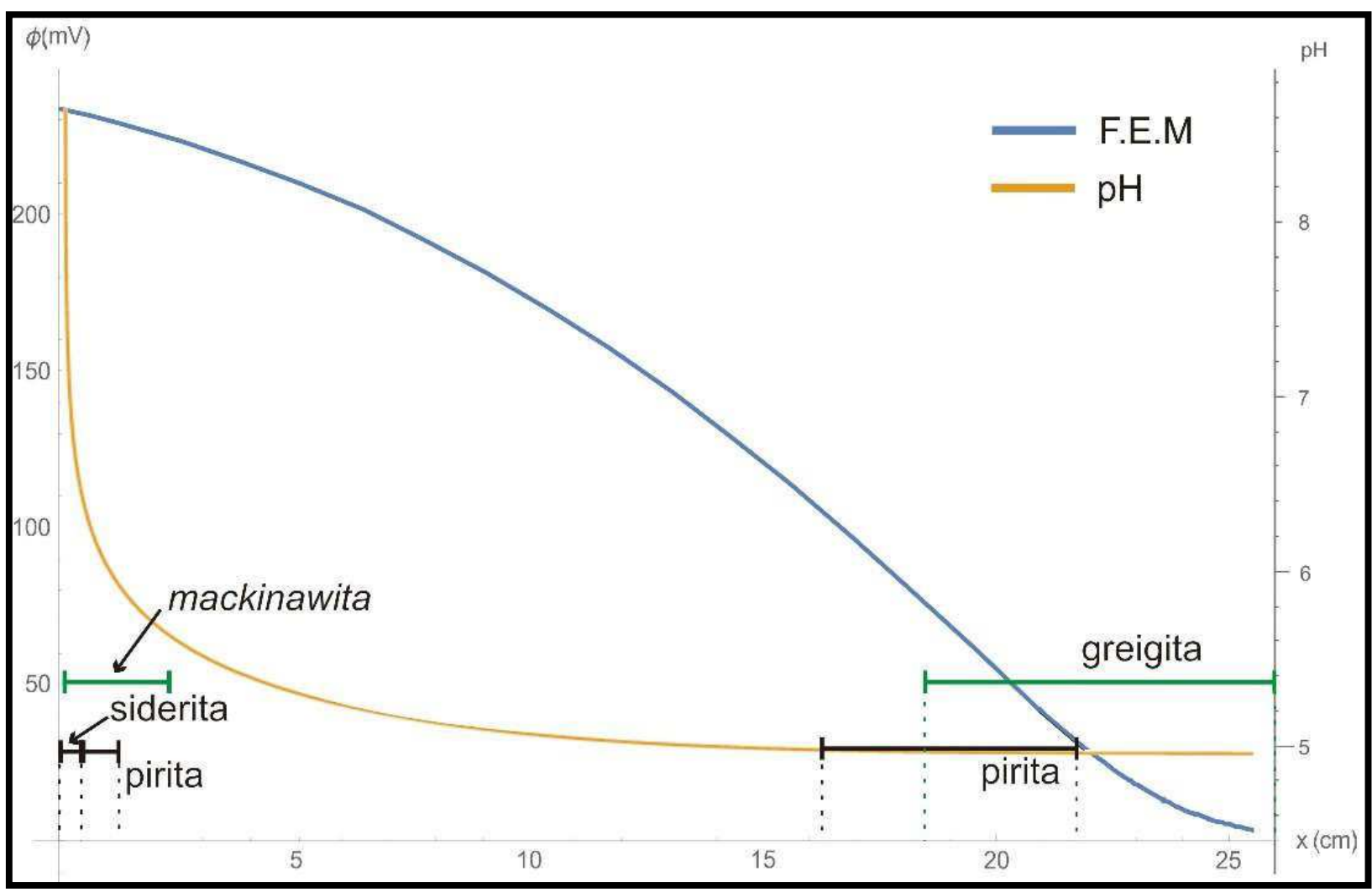

Figura 11 - Regiões de estabilidade de minerais de ferro e enxofre em região de interface entre ambiente radioativo natural e oceano primitivo moderadamente ácido $(\mathrm{pH}=5)$. Apresenta a variação de $\mathrm{pH}$ e força eletromotriz (F.E.M.) em função da distância em região de ambiente radioativo após estabilização dos valores (após $10^{4}$ segundos de difusão das espécies formadas). As barras horizontais apresentam a região onde cada mineral se mostra estável, considerando simultaneamente o $\mathrm{pH}$ e o potencial associado à faixa de distância representada. As estabilidades foram verificadas em duas referências; Linhas verdes: Estabilidades de óxidos, sulfetos e carbonatos de ferro em água a $25^{\circ} \mathrm{C}$ e 1 atm de pressão. Considerando concentração de enxofre dissolvido de $10^{-6} \mathrm{M}$, e de $\sum \mathrm{CO}_{2}=1 \mathrm{M}$; Linhas pretas: Estabilidades de carbonatos e pirita, considerando pressão de água como pressão total.

Fonte: Adaptada de GARRELS; CHRIST (106); HYNDMAN. (107).

A partir da comparação com diagramas Eh-pH, observa-se que mesmo em presença de baixa quantidade de enxofre, pirita é estável conforme as condições fortemente redutoras. A partir destes e conforme nossos resultados do efeito da difusão das espécies produzidas pela radiólise no potencial de redução do meio, vemos um limite em que podemos encontrar pirita 
e os minerais tais como greigita e mackinawita em intervalos de distância relativamente próximos ao do ambiente radioativo (ver Figura 11) considerando simultaneamente o potencial e o $\mathrm{pH}$ do intervalo. Desta maneira e considerando a potencialidade de se encontrar minerais carbonáticos em todo intervalo, podemos analisar os possíveis minerais catalíticos FeS que poderiam estar incrustados em carbonato. A partir de resultados como os apresentados em RICKARD e LUTHER (108) é perceptível que a greigita apresenta, sob as condições químicas específicas, estabilidade quando valores de $\mathrm{pH}$ e potencial de redução estão bem específicos. A distância a partir de 18,5 até $26 \mathrm{~cm}$ do ambiente radioativo em nosso modelo se encontra dentro dessas condições, analogamente até 2,5 cm notamos ser estável a forma da mackinawita, como apresentado na Figura 10. Tais estimativas foram feitas considerando a presença de enxofre no oceano primitivo na ordem de $10^{-3}$ a $10^{-2}$ mol.1 ${ }^{-1}(62,69)$, superior ao $10^{-6}$ mol. ${ }^{-1}$ que os diagramas de ferro-enxofre apresentam, o que pode ampliar pouco mais a faixa onde a gregita seria estável. Ou seja, há a possibilidade de existir clusters de greigita ou mackinawita agregados em precipitados de minerais carbonáticos, como calcita e siderita, que podem coexistir em diferentes regiões próximas. E pela formação de gás $\mathrm{H}_{2}$ pouco solúvel se difundindo, podemos esperar o aspecto de porosidade nesses minerais.

\subsection{Possibilidade de vida mantida a partir de decaimento radioativo em subsuperfície da lua gelada Europa}

Apresentamos, na Tabela 7, a área total calculada para a pirita em diferentes tipos de agregados sedimentares. Baseado nos valores desta tabela, calculamos não apenas a produção de sulfato por ano como função da massa de rocha presente, como também calculamos a quantidade de células de Ca. D. audaxviator que sobreviveria por quilograma de rocha presente no meio local nos distintos cenários propostos, como apresentado na Figura 12. Sendo assim, a oxidação de vastas quantidades de pirita proveria muito mais sulfato do que o necessário para suprir a demanda da via metabólica das células redutoras bacterianas.

A Figura 12 apresenta uma visão geral dos resultados calculados para a densidade de célula bacteriana que sobreviveria por massa de rocha. Pela mesma figura vemos que uma diferença em 10 vezes na concentração de ${ }^{40} \mathrm{~K}$ pode aumentar a quantidade de células que se mantém em até 1000 vezes. Além do que, se considerarmos $1 \mathrm{~kg}$ de material rochoso em nosso sistema, e um meio aquoso tão pequeno quanto $2 \mathrm{ml}$ (amostra aquosa usada nos experimentos de Lefticariu et al. 2010 (13)), os cenários b e c (ver seção 4.4) excedem significativamente a densidade de células mantidas ao valor referência de $4.10^{7}$ células por litro, como apresentou a análise 
microbiológica em Witwatersrand. (ver seção 1.6) Esta referência vem da densidade média que estava presente em amostras de inclusão fluida na região de Witwatersrand.

Tabela 7 - Resultados do cálculo da área superficial de pirita com base em diferentes tipos de agregados conforme a escala de Wentworth (105) usando modelo de empacotamento esférico.

\begin{tabular}{lll}
\hline $\begin{array}{c}\text { Tipo de } \\
\text { agregado }\end{array}$ & $\boldsymbol{\phi ( \mu \mathbf { m } )}$ & \multicolumn{1}{c}{$\begin{array}{c}\mathbf{S p y}(\boldsymbol{\phi}) \\
\left(\mathbf{m}^{\mathbf{2}} \cdot \mathbf{K g}^{-\mathbf{1}}\right)\end{array}$} \\
\hline Argila & 2 & $1,41 \times 10^{3}$ \\
\hline Silte & 10 & $2,83 \times 10^{2}$ \\
& 60 & $4,71 \times 10^{1}$ \\
\hline \multirow{2}{*}{ Areia } & 125 & $2,26 \times 10^{1}$ \\
& 500 & 5,65 \\
\hline Seixos & 1000 & 2,83 \\
& 10000 & $2,83 \times 10^{-1}$ \\
\hline Pedregulhos & 100000 & $2,83 \times 10^{-2}$ \\
& 200000 & $1,41 \times 10^{-2}$ \\
\hline
\end{tabular}

Fonte: Elaborada pelo autor 


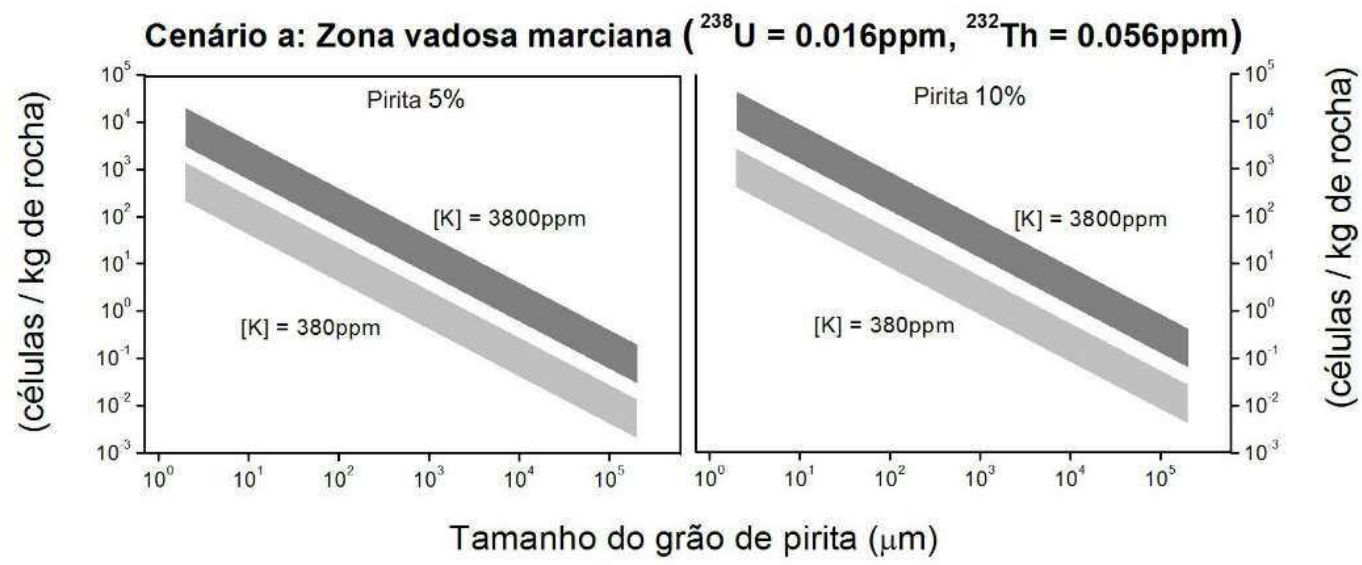

Cenário b: região de Witwatersrand de baixa concentração $\left({ }^{238} \mathrm{U}=3 \mathrm{ppm},{ }^{232} \mathrm{Th}=11 \mathrm{ppm}\right)$
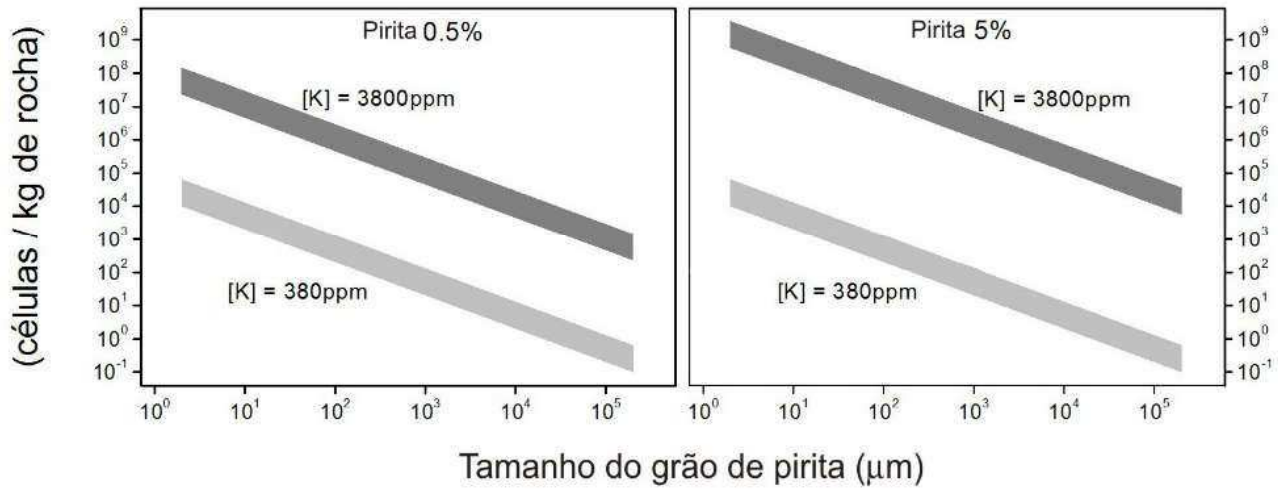

\begin{tabular}{l}
$\frac{\pi}{0}$ \\
$\frac{0}{0}$ \\
$\frac{0}{0}$ \\
0 \\
0 \\
0 \\
$\frac{1}{0}$ \\
0 \\
$\frac{\pi}{5}$ \\
$\frac{0}{0}$ \\
\hline 0
\end{tabular}

Cenário c: região de Witwatersrand de baixa concentração $\left({ }^{238} \mathrm{U}=271 \mathrm{ppm},{ }^{232} \mathrm{Th}=15 \mathrm{ppm}\right)$
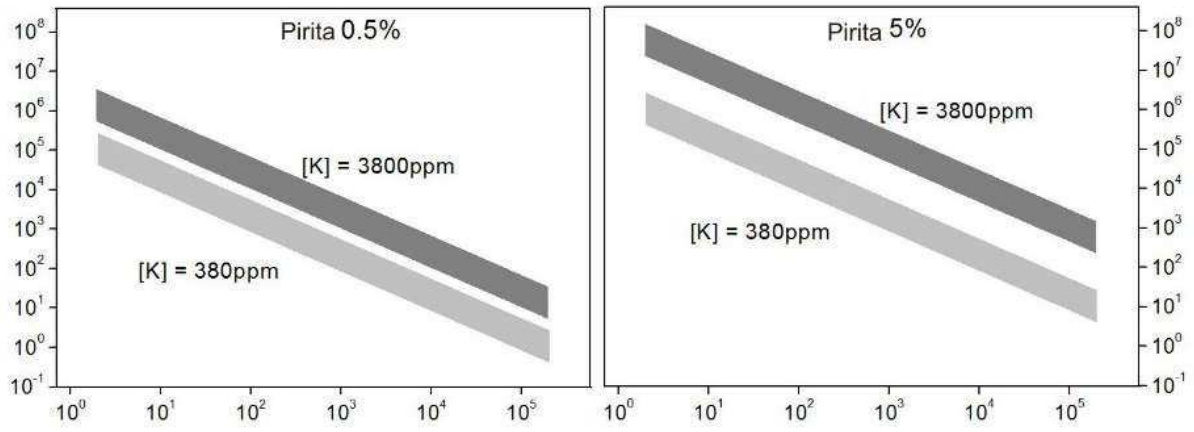

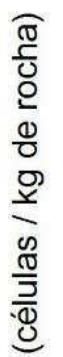

Tamanho do grão de pirita $(\mu \mathrm{m})$

Figura 12 - Relação entre densidade celular que sobreviveria por massa de rocha em função da variação do tamanho de grão de pirita para os diferentes cenários. A espessura das faixas representa os valores entre o máximo da densidade que sobreviveria, enquanto os diferentes cenários são representados nas variações de concentração de ${ }^{238} \mathrm{U},{ }^{232} \mathrm{Th},{ }^{40} \mathrm{~K}$ em meio aquoso e de pirita no meio rochoso.

Fonte: Elaborada pelo autor 


\section{Conclusões}

Ambientes radioativos naturais têm como principal recurso energético a longo prazo os fenômenos de decaimento radioativo de materiais físseis - predominantemente os compostos de radionuclídeos de longa vida, como ${ }^{238} \mathrm{U},{ }^{232} \mathrm{Th}{ }^{40} \mathrm{~K}$. Esse decaimento resulta em liberação de partículas alfa, beta e gama ( $\alpha, \beta$ e $\gamma)$, que interagem com o material aquoso, resultando na radiólise aquosa, e com o material rochoso do meio. Modelamos os efeitos da radiólise aquosa de raios gama em possíveis sistemas na Terra primitiva do Hadeano (4Ga) de modo a analisar as implicações de ambientes radioativos naturais na Terra primitiva e possíveis análogos na lua gelada Europa, respectivamente. Para ambas análises, os modelos numéricos ficaram restritos a dados geológicos de ambientes radioativos conhecidos, principalmente ambientes onde se constatou a presença do organismo Candidatus Desulforudis audaxviator, dependente de produtos de radiólise para as principais vias metabólicas e encontrado em bacia do Arqueano. No entanto, levantamos informações sobre os efeitos locais da radiólise em oceano primitivo para gerar diversidade química, desequilíbrio e energia livre. Com estes resultados, tivemos base para avaliar a adequação da estrutura onde poderia se estabelecer mecanismo de transdução com base no conhecido metabolismo de síntese do Acetil-CoA. Enquanto para Europa, onde as informações geológicas da subsuperfície ainda se apresentam restritas, obtivemos resultados para possibilidade de sobrevivência de células do Ca. D. audaxviator para diversos cenários candidatos a análogos geológicos da subsuperfície de Europa.

Os cálculos da diversidade química que a radiólise aquosa gera a longo prazo em um oceano primitivo demonstrou condição comparável a resultados analíticos de ambientes atuais, meio redutor, da ordem de centenas de $\mathrm{mV}$, e alcalino de $\mathrm{pH}$ local estabilizado a longo prazo em aproximadamente 9; assim como demonstrou a geração de desequilíbrio e gradientes químicos com o mesmo oceano, capaz de gerar energia livre da ordem de dezenas de kJ por mol de espécie formada. Tais gradientes demonstram-se comparáveis também ao caso dos formados em Lost City, diferenciando pela taxa de produção das espécies e de estabilização de meio alcalino, sendo a serpentinização que é mantida nesse ambiente possui taxas de formação das espécies maiores e é um fenômeno quimicamente mais simples comparado aos fenômenos químicos envolvendo a radiólise aquosa. Além de ser condição termodinamicamente interessante para fazer acontecer a reação protometabólica análoga à síntese de Acetil-CoA.

Apesar de resultados experimentais e geoquímicos disponíveis na literatura serem ainda pouco detalhados quanto à possibilidade de criação de barreiras semipermeáveis formando 
gradientes quimiosmóticos, a análise termodinâmica se demonstrou promissora para esse tipo de estudo. Inclusive quanto à possibilidade de presença de clusters de minerais com propriedades catalíticas como os de $\mathrm{Fe}(\mathrm{Ni}) \mathrm{S}$. Para o caso dos sulfetos e carbonatos de ferro, detalhes das regiões de maior probabilidade de se encontrar os minerais de ferro, onde há superior a estabilidade dos minerais em diferentes condições redox e de $\mathrm{pH}$ não chegam a ser contemplados nas análises da fontes hidrotermais. Se tal tipo de arranjo mineralógico se demonstrar existente, teremos um meio de condições hidrotermais em ambientes radioativos tão promissores para a bioenergética da emergência da vida quanto o de fontes hidrotermais alcalinas.

Com os resultados apresentados para a diversidade química produzida pela radiólise química do oceano primitivo, observamos comportamento dinâmico das concentrações das espécies químicas envolvidas. O modelo cinético que desenvolvemos para os efeitos químicos a longo prazo da radiólise aquosa, apresentou comportamento numericamente estável, apesar de nem sempre apresentar-se estacionário, e resultados promissores quando comparado às análises reportadas na literatura. Procuramos usar destes resultados para uma nova publicação, que já se encontra em desenvolvimento. Está fora do escopo deste trabalho realizar uma análise detalhada do processo dinâmico das soluções do sistema, porém parâmetros relacionados à estabilidade dos valores de concentração são interessantes a se explorar em um trabalho futuro. Conhecendo tais parâmetros, estimamos que seria possível analisar por quanto tempo estruturas minerais, como a que propomos para a transdução, se manteriam; assim como poderia averiguar-se se a condição físico-química ao qual concluímos - meio básico e redutor- seria esperada em qualquer ambiente radioativo, desconsiderando peculiaridades geológicas, como minerais que interagiriam modificando esta condição.

Para a estrutura macroscópica que propomos, apesar das nossas estimativas do arranjo mineral, ainda se espera detecção de indicativos da presença dos minerais em casos geológicos com constatada presença de material radioativo. Caso estes forem detectados, é estimamos ser possível associa-los ao período de atividade do ambiente radiativo natural. Dado que as condições promissoras à estabilidade dos minerais citados se dão após o período de aumento do $\mathrm{pH}$, que varia conforme concentrações locais de radionuclídeos. Além destas questões, em nosso caso específico, apesar de nossas expectativas positivas quanto à característica porosa da membrana, a formação deste tipo de estrutura ainda deve ser melhor modelada, de modo a prover conclusões mais assertivas. 
Por fim, considerando que as condições para o arranjo de um ambiente radioativo dependem de radionuclídeos que se acumulam em corpos celestes no processo de acreção, e presença de água, que se acumula em certos corpos, como luas geladas no Sistema Solar, existe a possibilidade de análogos extraterrestres, como já discutimos. Com base no modelo de Lefticariu et al. (14) da produção de sulfato como produto secundário da radiólise aquosa, escolhemos um modelo biológico para analisar a disponibilidade de energia química de diferentes cenários possíveis análogos ao ambiente de subsuperfície da lua Europa. Com isto, analisamos a habitabilidade e a importância de diferentes fatores para esta na subsuperfície da lua gelada. Todos os cenários propostos foram analisados com ferramentas teóricas propícias à análise de desequilíbrio de ambientes radioativos em profundidade, objetivo principal deste projeto de pesquisa. A ideia e os resultados desta parte da pesquisa foram apresentados em um manuscrito intitulado Microbial habitability of Europa sustained by radioactive sources recentemente publicado no periódico internacional Nature Scientific Reports. Tal trabalho se encontra anexado no Apêndice A, com material suplementar apresentado no Apêndice B. Por fim, estimamos que este método de modelagem, adequado à diferentes parâmetros e considerando outros fatores locais, possa nos dar indícios de formação de espécie química biologicamente interessante a partir de materiais que carreguem elementos fundamentais para a vida como conhecemos, tais como fósforo e nitrogênio. Porém, de modo geral, visamos que com resultados que possam vir a ser obtidos em missões que visam a exploração de Europa, pode-se restringir o leque de cenários os quais propomos, criando restrições às condições de habitabilidade da lua gelada. 


\section{REFERÊNCIAS}

1 LABONTÉ, J. M. et al. Single cell genomics indicates horizontal gene transfer and viral infections in a deep subsurface Firmicutes population. Frontiers in Microbiology, v. 6, p. 111, 2015. doi: 10.3389/fmicb.2015.00349.

2 WHITMAN, W. B.; COLEMAN, D. C.; WIEBE, W. J. Prokaryotes: the unseen majority. Proceedings of the National Academy of Sciences, v. 95, n. 12, p. 6578-6583, 1998.

3 ONSTOTT, T. C. Deep gold mines of South Africa: windows into the subsurface biosphere. Proceedings of SPIE, v. 3111, p. 344-357, 1997.

4 LIPPMANN, J. et al. Dating ultra-deep mine waters with noble gases and $36 \mathrm{Cl}$, Witwatersrand Basin, South Africa. Geochimica et Cosmochimica Acta, v. 67, n. 23, p. 4597-4619, 2003.

5 CHIVIAN, D. et al. Environmental genomics reveals a single-species ecosystem deep within earth. Science, v. 322, n. 5899, p. 275-278, 2008.

6. DRAGANIĆ, I. G.; DRAGANIĆ, Z. D.; ALTIPARMAKOV, D. Natural nuclear reactors and ionizing radiation in the Precambrian. Precambrian Research, v. 20, n. 2-4, p. 283-298, 1983.

7 DUBESSY, J. et al. Radiolysis evidenced by $\mathrm{H} 2-\mathrm{O} 2$ and $\mathrm{H} 2$-bearing fluid inclusions in three uranium deposits. Geochimica et Cosmochimica Acta, v. 52, n. 5, p. 1155-1167, 1988.

8 DOMAGAL-GOLDMAN, S. D. et al. The astrobiology primer v2.0. Astrobiology, v. 16, n. 8, p. 561-653, 2016.

9 BLAIR, C. C. et al. Radiolytic hydrogen and microbial respiration in subsurface sediments. Astrobiology, v. 7, n. 6, p. 951-970, 2007.

10 BOUQUET, A. et al. Alternative energy: production of $\mathrm{H} 2$ by radiolysis of water in the rocky cores of icy bodies. Astrophysical Journal, v. 840, n. 1, p. L8, 2017.

11 EBISUZAKI, T.; MARUYAMA, S. Nuclear geyser model of the origin of life: driving force to promote the synthesis of building blocks of life. Geoscience Frontiers, v. 8, n. 2, p. 275-298, 2017.

12 OGG, J. G.; OGG, G. M.; GRADSTEIN, F. M. Precambrian. In: A concise geologic time scale. Amsterdam: Elsevier, 2016. p. 19-28.

13 LEFTICARIU, L. et al. Anoxic pyrite oxidation by water radiolysis products - a potential source of biosustaining energy. Earth and Planetary Science Letters, v. 292, n. 1-2, p. 5767, 2010.

14 SAVARY, V.; PAGEL, M. The effects of water radiolysis on local redox conditions in the Oklo, Gabon, natural fission reactors 10 and 16. Geochimica et Cosmochimica Acta, v. 61, n. 21, p. 4479-4494, 1997. 
$15 \mathrm{LIN}, \mathrm{L}$. H. et al. The yield and isotopic composition of radiolytic H2, a potential energy source for the deep subsurface biosphere. Geochimica et Cosmochimica Acta, v. 69, n. 4, p. 893-903, 2005.

16 LIN, L. H. et al. Radiolytic H2 in continental crust: nuclear power for deep subsurface microbial communities. Geochemistry, Geophysics, Geosystems, v. 6, n. 7, p. 1-13, 2005.

17. DRAGANIC, I. G.; DRAGANIC, Z. D. The radiation chemistry of water. New York: Academic Press Inc, 1971. v. 26.

18 OMAR, G. I.; ONSTOTT, T. C.; HOEK, J. The origin of deep subsurface microbial communities in the witwatersrand basin, South Africa as deduced from apatite fission track analyses. Geofluids, v. 3, n. 1, p. 69-80, 2003.

19 LIN, L.-H. et al. Long-Term sustainability of a high-energy, low-diversity crustal biome. Science, v. 314, n. 5798, p. 479-482, 2006.

20 BRANSCOMB, E.; RUSSELL, M. J. Turnstiles and bifurcators: the disequilibrium converting engines that put metabolism on the road. Biochimica et Biophysica Acta bioenergetics, v. 1827, n. 2, p. 62-78, 2013.

$21 \mathrm{SOJO}, \mathrm{V}$. et al. The origin of life in alkaline hydrothermal vents. Astrobiology, v. 16, n. 2, p. 181-197, 2016.

22 HOEHLER, T. M. An energy balance concept for habitability. Astrobiology, v. 7, n. 6, p. 824-838, 2007.

23 KELLEY, D. S. et al. An off-axis hydrothermal vent field near the mid-Atlantic Ridge at $30^{\circ}$ N. Nature, v. 412, n. 6843, p. 145-149, 2001.

24 MARTIN, W. et al. Hydrothermal vents and the origin of life. Nature Reviews Microbiology, v. 6, n. Ii, p. 805-814, 2008.

25 BURCAR, B. T. et al. In situ imidazole activation of ribonucleotides for abiotic RNA oligomerization reactions. Origins of Life and Evolution of Biospheres, v. 45, n. 1-2, p. 3140, 2015.

26 HERSCHY, B. et al. An origin-of-life reactor to simulate alkaline hydrothermal vents. Journal of Molecular Evolution, v. 79, n. 5-6, p. 213-2272014.

27 RUSSELL, M. J.; ARNDT, N. T. Geodynamic and metabolic cycles in the Hadean. Biogeosciences Discussions, v. 2, n. 1, p. 97-111, 2005.

28 YAMAMOTO, M. et al. Spontaneous and widespread electricity generation in natural deep-sea hydrothermal fields. Angewandte Chemie International Edition, v. 56, n. 21, p. 5725-5728, 2017.

29 LANE, N.; ALLEN, J. F.; MARTIN, W. How did LUCA make a living? chemiosmosis in the origin of life. BioEssays, v. 32, n. 4, p. 271-280, 2010. 
30 BARGE, L. M. et al. Characterization of iron-phosphate-silicate chemical garden structures. Langmuir, v. 28, n. 8, p. 3714-3721, 2012.

31 KELLEY, D. S. A serpentinite-hosted ecosystem: the lost city hydrothermal field. Science, v. 307, n. 5714, p. 1428-1434, 2005.

32 GRASSET, O. et al. Jupiter ICy moons Explorer (JUICE): an ESA mission to orbit Ganymede and to characterise the Jupiter system. Planetary and Space Science, v. 78, p. 121, 2013.

33 ORO, J.; MILLER, S. L.; LAZCANO, A. The origin and early evolution of life on earth. Annual Review of Earth and Planetary Sciences, v. 18, n. 1, p. 317-356, 1990.

34 RUIZ-MIRAZO, K.; BRIONES, C.; DE LA ESCOSURA, A. Prebiotic systems chemistry: new perspectives for the origins of life. Chemical Reviews, v. 114, n. 1, p. 285-366, 2014.

35 KAUFFMAN. S. A. The origins of order: self-organization and selection in evolution. New York: Oxford University Press, 1993.

36 PROSS, A.; PASCAL, R. The origin of life: what we know, what we can know and what we will never know. Open Biology, v. 3, n. 3, p. 120190-120190, 2013.

37 WÄCHTERSHÄUSER, G. In praise of error. Journal of Molecular Evolution, v. 82, n. 2-3, p. 75-80, 2016.

38 GILBERT, W. Origin of life: the RNA world. Nature, v. 319, n. 6055, p. 618-618, 1986.

39 RUSSELL. M. J.; NITSCHKE. W.; BRANSCOMB. E. The inevitable journey to being. Philosophical Transactions of the Royal Society B: biological sciences, v .368, n. 20, p.20120254, 2013.

40 BARGE, L. M. et al. Thermodynamics, disequilibrium, evolution: far-from-equilibrium geological and chemical considerations for origin-of-life research. Origins of Life and Evolution of Biospheres, v. 47, n. 1, p. 39-56, 2017.

41 E. BRANSCOMB, E. et al. Escapement mechanisms and the conversion of disequilibria; the engines of creation. Physics Reports, v. 677, p. 1-60, 2017.

doi:/10.1016/j.physrep.2017.02.001.

42 RUSSELL, M. J.; HALL, A. J.; TURNER, D. In vitro growth of iron sulphide chimneys: possible culture chambers for origin $\square$ of $\square$ life experiments. Terra Nova, v. 1, n. 3, p. 238$241,1989$.

43 KONDEPUDI. D. K.; PRIGOGINE. I. Modern thermodynamics : from heat engines to dissipative structures. 2nd ed. New York: John Wiley \& Sons, 2015.

44 CASTELLAN, G. Fundamentos de físico-química. 2nd ed. Rio de Janeiro: LTC, 1994.

45 DILL, K.; BROMBERG, S. Molecular driving forces: statistical thermodynamics in biology, chemistry, physics and nanoscience. 2nd ed. New York: Garland Science, 2010. v. 2. 
46 PULSELLI, R. M.; SIMONCINI, E.; TIEZZI, E. Self-organization in dissipative structures: a thermodynamic theory for the emergence of prebiotic cells and their epigenetic evolution. BioSystems, v. 96, n. 3, p. 237-241, 2009.

47 LANE, N.; MARTIN, W. F. The origin of membrane bioenergetics. Cell, v. 151, n. 7, p. 1406-1416, 2012.

48 BOYER, P. D. The Atp Synthase-a splendid molecular machine. Annual Review of Biochemistry, v. 66, n. 1, p. 717-749, 1997.

49 JACKSON, J. B. Natural pH gradients in hydrothermal alkali vents were unlikely to have played a role in the origin of life. Journal of Molecular Evolution, v. 83, n. 1-2, p. 1-11, 2016.

50 NITSCHKE, W.; RUSSELL, M. J. Beating the acetyl coenzyme A-pathway to the origin of life. Philosophical Transactions of the Royal Society of London B: biological sciences, v. 368, n. 1622, p. 20120258-20120258, 2013.

51 WÄCHTERSHÄUSER, G. The Origin of life and its methodological challenge. Journal of Theoretical Biology, v. 187, n. 4, p. 483-494, 1997.

52 BARGE, L. M. et al. The fuel cell model of abiogenesis: a new approach to origin of-life simulations. Astrobiology, v. 14, n. 3, p. 254-270, 2014.

53 MCCOLLOM, T. M. Methanogenesis as a potential source of chemical energy for primary biomass production by autotrophic organisms in hydrothermal systems on Europa. Journal of Geophysical Research: planets, v. 104, n. E12, p. 30729-30742, 1999.

54 MARTIN, W. F.; SOUSA, F. L.; LANE, N. Energy at life's origin. Science, v. 344, n. 6188, p. 1092-1093, 2014.

55 FERRY, J. G.; HOUSE, C. H. The stepwise evolution of early life driven by energy conservation. Molecular Biology and Evolution, v. 23, n. 6, p. 1286-1292, 2006.

56 NITSCHKE, W.; RUSSELL, M. J. Hydrothermal focusing of chemical and chemiosmotic energy, supported by delivery of catalytic $\mathrm{Fe}, \mathrm{Ni}, \mathrm{Mo} / \mathrm{W}, \mathrm{Co}, \mathrm{S}$ and $\mathrm{Se}$, forced life to emerge. Journal of Molecular Evolution, v. 69, n. 5, p. 481-496, 2009.

57 WOESE, C. R. Interpreting the universal phylogenetic tree. Proceedings of the National Academy of Sciences, v. 97, n. 15, p. 8392-8396, 2000.

58 JACKSON, J. B. The origin-of-life reactor and reduction of $\mathrm{CO} 2$ by $\mathrm{H} 2$ in inorganic precipitates. Journal of Molecular Evolution, v. 85, n. 1-2, p. 1-7, 2017.

59 ORGEL, L. E. The implausibility of metabolic cycles on the prebiotic earth. PLoS Biology, v. 6, n. 1, p. 0005-0013, 2008.

60 DRAGANIC, I. G.; DRAGANIĆ, I. G. Radiolysis of water: a look at its origin and occurrence in the nature. Radiation Physics and Chemistry, v. 72, n. 2-3, p. 181-186, 2005. 
61 WATANABE, R.; SAITO, K. Monte Carlo simulation of water radiolysis in oxygenated condition for monoenergetic electrons from $100 \mathrm{eV}$ to $1 \mathrm{MeV}$. Radiation Physics and Chemistry, v. 62, n. 2-3, p. 217-228, 2001.

62 SPINKS, J.W.T.; WOODS, R. J. An introduction to radiation chemistry. New York: Wiley, 1964.

63 LE CAËR, S. Water radiolysis: influence of oxide surfaces on h2 production under ionizing radiation. Water, v. 3, n. 4, p. 235-253, 2011.

64 PASTINA, B.; LAVERNE, J. A. Effect of molecular hydrogen on hydrogen peroxide in water radiolysis. Journal of Physical Chemistry A, v. 105, n. 40, p. 9316-9322, 2001.

65 ZAIA, D. A. M. Adsorption of amino acids and nucleic acid bases onto minerals: a few suggestions for prebiotic chemistry experiments. International Journal of Astrobiology, v. 11, n. 4, p. 229-234, 2012.

66 PINTI, D. L. The origin and evolution of the oceans. Lectures in Astrobiology, v. 1, p. 83-112, 2005; doi: 10.1007/10913406_4.

67 RUSSELL, M. J. et al. The drive to life on wet and Icy worlds. Astrobiology, v. 14, n. 4, p. 308-343, 2014.

68 MAISONNEUVE, J. The composition of the precambrian ocean waters. Sedimentary Geology, v. 31, n. 1, p. 1-11, 1982.

69 HOLLAND, H. D. The geologic history of sea water-an attempt to solve the problem. Geochimica et Cosmochimica Acta, v. 36, n. 6, p. 637-651, 1972.

70 IZAWA, M. R. M. et al. Composition and evolution of the early oceans: evidence from the Tagish Lake meteorite. Earth and Planetary Science Letters, v. 298, n. 3-4, p. 443-449, 2010 .

71 GROTZINGER, J. P.; KASTING, J. F. New constraints on precambrian ocean composition. Journal of Geology, v. 101, n. 2, p. 235-243, 1993.

72 KRAMER, J. R. History of sea water: constant temperature-pressure equilibrium models compared to liquid inclusion analyses. Geochimica et Cosmochimica Acta, v. 29, n. 8, p. 921-945, 1965.

73 ROTHSCHILD, L. J.; MANCINELLI, R. L. Life in extreme environments. Nature, v. 409, n. 6823, p. 1092-1101, 2001.

74 COCKELL, C. S. et al. Habitability: a review. Astrobiology, v. 16, n. 1, p. 89-117, 2016.

75 SVERDRUP, H.; JOHNSON, M.; FLEMING, R. H. General distribution of temperature, salinity and density. In: The oceans: their physics, chemistry and general biology.

Englewood Cliffs: Prentice-Hall, INC, 1970. 
76 DE RONDE, C. E. J. et al. Fluid chemistry of Archean seafloor hydrothermal vents: implications for the composition of circa 3.2 Ga seawater. Geochimica et Cosmochimica Acta, v. 61, n. 19, p. 4025-4042, 1997.

77 WALKER, J. C. G. Possible limits on the composition of the Archaean ocean. Nature, v. 302, n. 5908, p. 518-520, 1983.

78 SLEEP, N. H.; ZAHNLE, K.; NEUHOFF, P. S. Initiation of clement surface conditions on the earliest earth. Proceedings of the National Academy of Sciences of the United States of America, v. 98, n. 7, p. 3666-3672, 2001.

79 CHESTER, R. Marine geochemistry. Oxford: Blackwell Science, 2010.

80 SVERJENSKY, D. A.; LEE, N. The great oxidation event and mineral diversification. Elements, v. 6, n. 1, p. 31-36, 2010.

81 HAZEN, R. M.; EWING, R. C.; SVERJENSKY, D. A. Evolution of uranium and thorium minerals. American Mineralogist, v. 94, n. 10, p. 1293-1311, 2009.

82 KASTING, J. F.; CATLING, D. Evolution of a habitable planet. Annual Review of Astronomy and Astrophysics, v. 41, n. 1, p. 429-463, 2003.

83 SIMONCINI, E. et al. Thermodynamics of chemical free energy generation in off-axis hydrothermal vent systems and its consequences for compartmentalization and the emergence of life. 2010. Disponível em:

$<$ https://pdfs.semanticscholar.org/d407/cea1053c802322c8fe0451198ffa73b83467.pdf>. Acesso em 23 jan. 2017.

84 LOWELL, R. P.; RONA, P. A. Seafloor hydrothermal systems driven by the serpentinization of peridotite. Geophysical Research Letters, v. 29, n. 11, p. 0-3, 2002.

85 MÖLLER, F. M. et al. Steep pH Gradients and directed colloid transport in a microfluidic alkaline hydrothermal pore. Angewandte Chemie International Edition, v. 56, n. 9, p. 2340-2344, 2017.

86 BARRIGA, F. et al. Discovery of the saldanha hydrothermal field on the FAMOUS segment of the MAR (36 30 N). Eos Transactions American Geophysical Union, v. 79, n. 45 , p. $67,1998$.

87 ROBB, L. J.; MEYER, F. M. The Witwatersrand basin, South Africa: geological framework and mineralization processes. Ore Geology Reviews, v. 10, n. 2, p. 67-94, 1995.

88 HALLBAUER, D. The minerelogy and geochemistry of Witwatersrand pyrite, gold, uranium, and carbonaceous matter. In: Mineral deposits of Southern Africa. Johannesburg: Geological Society of South Africa, 1986. p. 731-752.

89 HOFFMANN, B. A. Isolated reduction phenomenon in red beds: aresult of porewater radiolysis. In: KHARAKA, Y. K.; MAEST, A. S. (Ed.). Water-rock interaction. Berlin, Heidelberg: Springer, 1992. p. 503-506. 
90 EYERS, L. et al. Environmental genomics: Exploring the unmined richness of microbes to degrade xenobiotics. Applied Microbiology and Biotechnology, v. 66, n. 2, p. 123-130, 2004.

91 SCHLOSS, P. D.; HANDELSMAN, J. Biotechnological prospects from metagenomics. Current Opinion in Biotechnology, v. 14, n. 3, p. 303-310, 2003.

92 ITÄVAARA, M. et al. Characterization of bacterial diversity to a depth of $1500 \mathrm{~m}$ in the Outokumpu deep borehole, Fennoscandian shield. FEMS Microbiology Ecology, v. 77, n. 2, p. 295-309, 2011.

93 LERM, S. et al. Thermal effects on microbial composition and microbiologically induced corrosion and mineral precipitation affecting operation of a geothermal plant in a deep saline aquifer. Extremophiles, v. 17, n. 2, p. 311-327, 2013. doi: 10.1007/s00792-013-0518-8.

94 JUNGBLUTH, S. P. et al. Microbial diversity within basement fluids of the sedimentburied Juan de Fuca Ridge flank. The ISME Journal, v. 7, n. 1, p. 161-172, 2013. doi: 10.1038/ismej.2012.73.

95 LIDE, D. R. CRC handbook of chemistry and physics. Boca Raton: CRC Press, 2003.

96 WAITE, J. H. et al. Cassini finds molecular hydrogen in the Enceladus plume: evidence for hydrothermal processes. Science, v. 356, n. 6334, p. 155-159, 2017. doi: 10.1126/science.aai8703.

97 VANCE, S. et al. Hydrothermal systems in small ocean planets. Astrobiology, v. 7, n. 6, p. 987-1005, 2007.

98 BYRNE, G. D.; HIINDMARSH, A. C. Stiff ODE solvers: a review of corning attractions. Journal Computational Physics, v. 70, n. 1, p. 1-62, 1987.

99 FREITAS, S. R.; LONGO, K. M.; RODRIGUES, L. F. Modelagem numérica da composição química da atmosfera e seus impactos no tempo, clima e qualidade do ar. Revista Brasileira de Meteorologia, v. 24, n. 2, p. 188-207, 2009.

100 FROMENT, G.; BISCHOFF, K. Chemical reactor analysis and design. 2nd ed. New York: Wiley, 1990.

101 CRANK, J. The mathematics of diffusion. 2nd ed. Oxford: Clarendon, 1975.

102 KARGEL, J. S. et al. Europa's crust and ocean: origin, composition, and the prospects for life. Icarus, v. 148, n. 1, p. 226-265, 2000.

103 CHYBA, C. F. Planetary science: enhanced: life without photosynthesis. Science, v. 292, n. 5524, p. 2026-2027, 2001.

104 DRAGANIĆ, I. G. et al. Decomposition of ocean waters by potassium-40 radiation 3800 Ma ago as a source of oxygen and oxidizing species. Precambrian Research, v. 52, n. 3-4, p. 337-345, 1991. 
105 WENTWORTH, C. K. A Scale of grade and class terms for clastic sediments. Journal of Geology, v. 30, n. 5, p. 377-392, 1922. doi: 10.1086/622910.

106 GARRELS, R. M.; CHRIST, C. Solutions, minerals, and equilibria. New York: Harper \& Row, 1965.

107 DONALD W. HYNDMAN. Petrology of igneous and metamorphic rocks. New York: McGraw-Hill, 1972.

108 RICKARD, D.; LUTHER, G. W. Chemistry of iron sulfides. Chemical Reviews, v. 107, n. 2, p. 514-562, 2007. doi: 10.1021/cr0503658. 
APÊNDICE A - Artigo publicado na Scientific Reports em 2018.

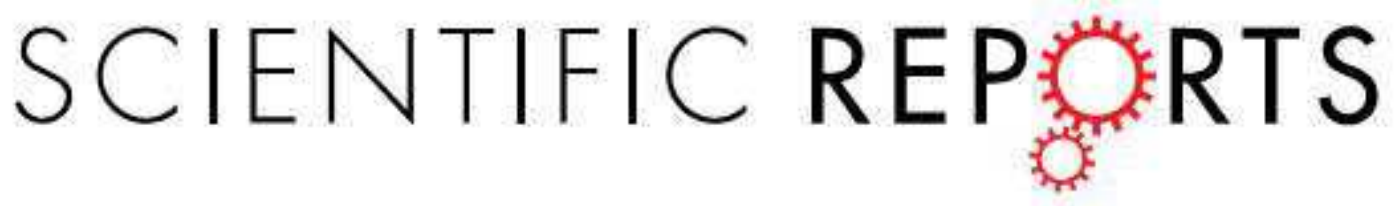

OPEN Microbial habitability of Europa sustained by radioactive sources

\author{
Thiago Altairid ${ }^{1,4}$, Marcio G. B. de Avellar ${ }^{2}$, Fabio Rodrigues ${ }^{3}$ \& Douglas Galante ${ }^{1 / 4}$
}

Received: 4 Jaly 2017

Acopted: 12 Decomber 2017

Published:onitux $x$ hedatuary 2018
There is an increasing interest in the icy moons of the Solar System due to their potential habitability and as targets for future exploratory missions, which indude astrobiological goals. Several studies have reported new results describing the details of these moons' geological settings; however, there is still a lack of information regarding the deep subsurface environment of the moons. The purpose of this artide is to evaluate the microbial habitability of Europa constrained by terrestrial analogue environments and sustained by radioactive energy provided by natural unstable isotopes. The geological scenarios are based on known deep environments on Earth, and the bacterial ecosystem is based on a suffatereducing bacterialecosystem found $2.8 \mathrm{~km}$ below the surface in a basin in South Africa. The results show the possibility of maintaining the modeled ecosystem based on the proposed scenarios and provides directions for future modds and exploration missions for a more complete evaluation of the habitability of Europa and of icy moons in generd.

Except for Earth, the monns of the giant planets, especially the icy moons such as Enceladus, Europa, Ganymede and Callisto, are the only other places in the Solar System with considerahle evidence of the existence of liquid water in aburdance. The decans under the icy crusts on these moons may be able to host living organisms ${ }^{-1}$ and thes be abfe to bost habitable environmenis. Tws critical factors that can make these moons compeling, enviroaments for living systems, besides the presence of water, are the avalability of energy and a chemtcal disequilibriam based on reductant-oxidant pairs for biologicel processes'. 'The surface of the Javian mona Europa ss young, with a resurfacing age determined to be approximately $30-70$ Myr, and it represents one of the most important targets for astrobiology research in the Solar System 10 . Studies also ind cate actiwe geological processes on a global scalo on this icy moon such ss the movement of lithospheric blocks and the upwelling of material that fills the rocky core 11,1 . These aspects could hetp to maintain the chemical disequibibrium in the oceans under its scy layer, which is penwered by tidal and radiolysis phenonena (the batter is emphasized in this paper)

Radiolysis has already been progosed for the Europan framework. However, it was mainly focused on radoolysis caused by the buenbardment of the superlicjal ice with energetic charged particles, such as electrons ar ions, that are acceleraled by the magnetic field of a nearby planes (in this case, Jupiter) ${ }^{3,13}$. Another possibality for the ratiolysis on Eumpa comes from the botton of the ocean, where there is a water rack interlace. Radioactive decay also occurs from fssionable rmaterials that exist in every rocky celestial body in the Solar System. These materials, primordial radioactive elements, enit ionizing radiation that can zoteract with the ocean water that breaks its molecules, causes excitation and ionization, and consequently and locally forms very resctive iosized or radical speciest, This defines the water radisolysis, the focus of this work. Research on the radiation efiects on water and mainly radical formation induced by radiolysss increased largely in the mid- $20^{4}$ century $y^{4} ;$ however, the association of radiation from nuclear decay as a possible source of energy for a living syssem was proposed near the end of the century ${ }^{1 *}$ Recent stodies of the sir-called fossal matural teacters on firth" have provided a basis for the debate on the importance of ionizing energy from radioactive decay zs a localized source of energy for biological processes. Notwithstanding, the recent disconcry of pecutiar ecosystems in decp sutisurface environments, which are maintained by nutrents produced vas radionuclide radiolysis ${ }^{\text {thail }}$, has garnered attention for its feasibilaty.

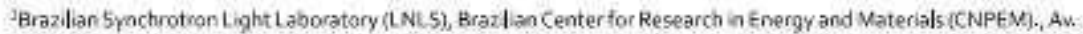
Giuseppe Máwo scolfaro, 20000, 13083-100, Campinas, SP; Brazil. Tnstituto de Astranamia, Geofísica e Ciéncias. Atmosfericas, Universidade de 5á Paula. Rua do Matá, 1226, 05508-090, 5ao Paulo, SP, Brazil. 'Departamento de Ouimica Fundamental Instituto de Quimica, Universidade de Sá Paulo. Av. Prof. Lineu Prestes, 748, 05508000, São Paulo, SP, Brazil. ^Programe de Pôs-Graduaçăo em Fisica Biomolecular, Instituto de Fisica de 5 áo Carlos, Universidade de Säo Paolo, Så Carlos, SP, Brazil. Correspandence and requests for materials should be addressed to M.G.B.U.A. (email: mgb.avellar@ag.usp.br) 
On Earth, water radiolyss is sagnificant in the deep environments where water and fissionable materials $\operatorname{exist}^{12,15 * 23}$ and consequently form several chemical species that contribute to microbial activity ${ }^{2221}$, Chivian et $\mathrm{dl}^{2}$ and Lin et al." reported an important occurrence in nature of metabolism dependent on this type of radioactivity interaction. In the depths of the Mponeng gold mine in South Africa ${ }^{301}$ and located at the region of the Witwatersrand basin, it was found that a single-species ecosystem based an the bacterium Candidatus Desulforadis andaxviator, which uses this saurce of energy, was independent of sunlight. This discovery opened newr ventses to the studf of other non-illuminated envionments of the Solar System and the Universe, induding. Furopa and wher icy monas.

Recently, the debate on radiolysis under the surface of Puropa has gained new perspectives. Atri ${ }^{21}$ discusses the importance of galactic cosmic rays (GCR), which are primary charged particles, mostly protons, that originated beyond the Solar System. If a celestial body has a teasonably thick atmosphere, primary GCR particles strike the atmospheric molecules, producting becondary particles such as kavos, pions and muons that can propagate decp anderground and are highly unstable, quickly decaying to produce particles such as $\beta$ and $\gamma$ particles and possibly triggering radiolysis. The radiolysis discussed in that work ${ }^{34}$ is galactic cosmic ray-indeced and may be important when considering imall rocky bodies such as planets not tied to any planetary system or comet. but it depends on the presence of an atmosphere. However, radiolysis from radioactive isotope decay has stionn potential importance in powering life on the deep subsurface of icy moons where solar energy cannot reach and galactic cosmic rays cannot provide enough energy. Considering charged particles of reasionable primary energy. only muns could reach $3 \mathrm{~km}$ below the surface level of an icy moon, and the energy deposition rate would still become nearly zero below this depth sisi

However, there is still a modest number of references in the literature related to the effect of water radiolysis as s coosequence of radioactive minerals in the desp sibstarface icy mooos and its implications for habitability. Fecently, the radiolytic production of $\mathrm{H}_{2}$ in the subsurface of several of the Solar System's icy moons was pro-

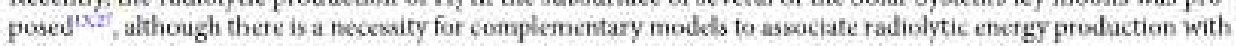
biological metabolism to assess the actual habitability of extensive extratertestrial water bonties.

Models relased to the survival of bacterial cells based on radiolysis-produced chemical species, sach as $\mathrm{H}_{3}$, have been proposed ${ }^{3}$. This model focuses on terrestrial context and on the pritary tadiolysis product. In contrast, in this study, we present the model hased an the production of a secondary chemical spectes, sulfate, and apply it to the extraterrestrial context. For this model, we compared the radiolysis produced sulfate rate to in size sulfate demand for a deep subsurface emvironment where Ca. D. addaxviator was found.

Thus, thes paper approaches the possibility of maintaining an ecosystem hased on the chemical energy provided as a consequence of the direct radiolysis of water by primordial long-living radionaclides such as $2 \mathrm{U}$, $22 \mathrm{Th}$ and "K on a modeled setung for Earopa. This bypothesis was based on the importance of sach species for the natural radioactivity on Earth and assuming a similar elemental distribution on rocky planets abd on Earopa. The potential babitability of Europa is the main reason for the choice of this moon for the model in addition to the reasonable and growing body of information on its subsurface occan and crust ${ }^{4}$ as well as for its importance for future space missions stich as the ESA mission JUpiter ICY moons Explorer (fUICE) ${ }^{n}$. Is was possible to showe the avalability, under certain conditions, of enough chemical energy to sustain an ecosystem of chemoautotrophic extrempphilic candidate spectes such is $\mathrm{Cl}$. D audaviator, which has a metabolism hased on sulfur reduction. Sach an energy source could be used to sustain basic metabolssm and/or repair damage caused by ratiation expo: sure" , thus creating a habitahle environment, from the energetic point of viev. $C a$. $D$, aliaxviaior was found in fractured water in the gold mine of Mponeng. located in the Witwalerstand basig region ${ }^{2}$, South Africa, surviving at depths ap $t 02.8 \mathrm{~km}$ belose the surface with temperatures between $40^{\circ} \mathrm{C}$ and $60^{\circ} \mathrm{C}$, a pH of 9.3 . pressures comparable to those of the abyssal regions of Earth's eceans, low availability of nutrients and some concentration

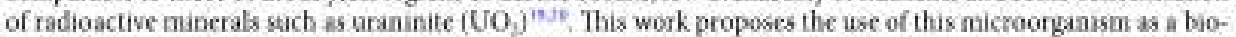
fogical model and doep tetrestrial environments as analogues to better understand the limits of habitability on deep, non-illuminated environments of the Solat System, although this scenarto ss stall poorly explored for this purpose.

\section{Biological Energy Transduction}

Since the first examples of a single-species microblal ecosystem were reported from decp subsurface environments ${ }^{\text {ths }}$, attention has been drawn to bacteria simblar to Ca. D. andasvietor on other extreme regions. Figure 1 illustrates a simplified model of the metabolic pathway of $C a$. D. asdarviatar, which obtains energy from the radiolysts of water. The bacterium extracts encrgy from the sulfate $\left(\mathrm{SO}_{4}^{-2}\right)$ reduction reaction, as shown in reaction $(1)^{21}$.

$$
\mathrm{HH}_{3}+\mathrm{H}^{+}+\mathrm{SO}_{4}^{2-} \rightarrow \mathrm{HS}^{-}+\mathrm{AH}_{2} \mathrm{O}
$$

The bacterial salfate consumption model calculations depend on the presence of $\mathrm{H}_{2}$ in such a way that sulfate is the limiting reactunt of reaction (1). Dissolved $\mathrm{H}_{2}$ may exist on icy moons such as Enceladus as a result of radiolysis or bydrotbermal activity. The presence of this gas in the subsurface ocean has been reported for Enceladus"' On Europa, there are also speculations related to this component ${ }^{\text {tis }}$,

\section{Physicochemical Basis For Radiolysis}

As a henchmark for this work, the experimental results of Lefticaria ef al. ". and Lin et al. "were used for the calculations. The fist study provided a model for the rate of radiolytic sulfate production by the exposare of water and pynte to a source of gamma radiation. The secood notk presents the in situ rate of microbual sulfute reduction between 0.22 and $1.45 \mathrm{nM}$ pet year for a cell dessity of $4 \times 10^{7}$ cells per liter of $5,5 \times 10^{-18}$ to $3.6 \times 10^{-15}$ mols per cell per year in the case of the deep subsurface of the Wirwaterstand lossin ${ }^{30}$. 


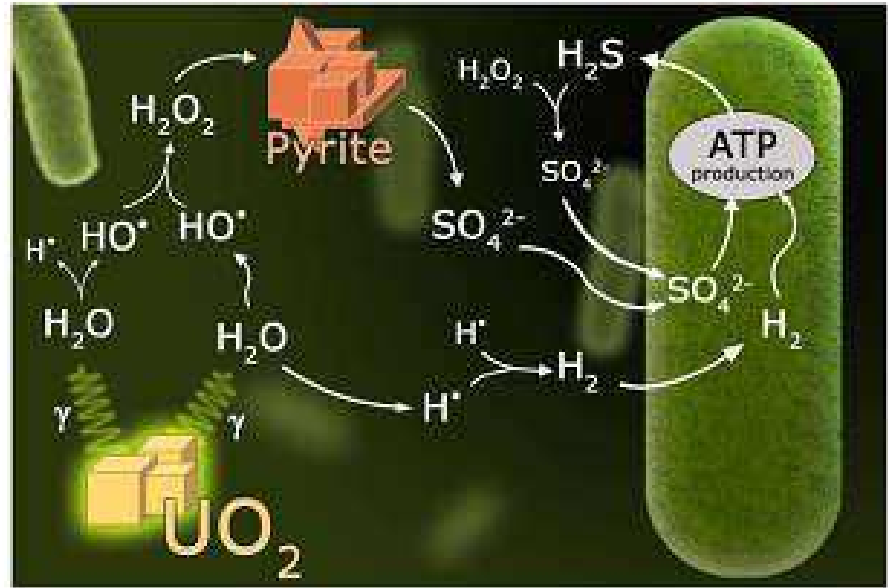

Figure 1. Model of the single species ecospstem of the fractured Mponeng gold mine in South Airncz. $\mathrm{Ca} . D$ awdituiator's pathway for abtaning energy from the decay of uranium of ${ }^{2 U} \mathrm{VO}_{2}$ (uraninite) is shown, induding the pathway of sulfate reduction. Adapted from Chivan et al.

The experimental wotk conducted by Lefticariu of al ${ }^{\text {i" }}$ showed that she sulfate production via radiolysis is

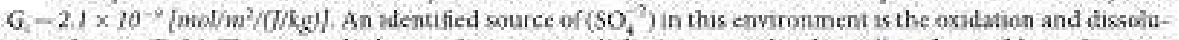

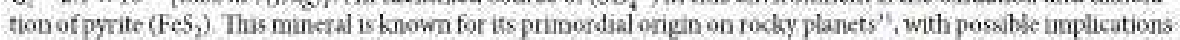
on preobistic chenistry and early metstolism. It can seact with a radiolysis protuct of water doe to the ractiation.

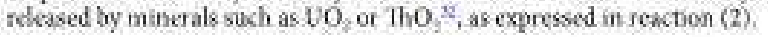

$$
\mathrm{FiS}_{2}+4 \mathrm{HO} \rightarrow \mathrm{Fe}^{2+}+\mathrm{S}+\mathrm{SO}_{4}^{-2}+2 \mathrm{H}_{2}
$$

The HO ndical is one of the products of the primary reactivas of the radialysis of water ${ }^{31,3}$ (3).

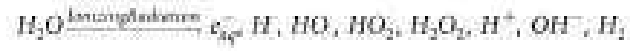

The productiou rate of $\mathrm{SO}_{4}^{2}$ as a finction of the dose $\mathrm{D}$, of (gamma) radiation from different apecies is then givei by $Y_{1}=\Sigma D_{2} \times G_{3}$ in units of mol/ $m^{2} / y$ ar $A$ direct relationship between $G_{1}$ and $Y_{\text {, and }}$ the exposed surface area of pyrite exists which is a feature that is exploted forther in section 5 and in the supplementary material. The

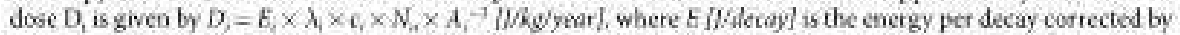

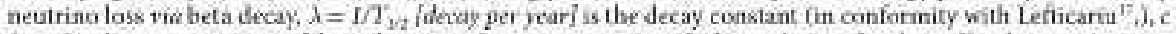
$[\mathrm{ppm}]$ is the concentration of the radjoactive element, $N_{a}$ is Avogadros number, and $A_{1}$ ( $\left.\mathrm{g} / \mathrm{w} w i\right)$ is the atomic mass. The index $i$ stands for the radioactive species involved in the process. Finally, the annual production of radiolytic

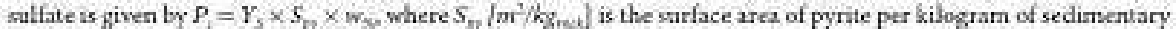
mek which, fint pyrite in the authars experiment, was measured to be $226.0+6.5 \mathrm{~cm}^{2} / g_{\mathrm{g}}$ and $w_{\mathrm{s}}$ is the pyrite mass percentuge tor the rock.

\section{Abundances Of Radioactive Materials And Pyrite Granulometry}

The results for radiolysis produced salfate, which was induced by natural radioactive decay in the Mponeng mine fracture water, suggests the possibility of an analogoas process pocuering in the subsurface environment of Furopa, as sctiematized in Fig. 2. This work assumes that there are clumps of radioactive materials an the seabed, proximate to pyrite formations and far from hydrothermal vents that could be another source of sulfate and significantly increase the temperature of the medium. Models for the ongin, composition and evolution of the crust and ecean of Europa" suggest the farmation of prrite-like materiats, which ate a najor component. Is was assumed that the niches of radioactive materials contain ${ }^{78} \mathrm{U}$ and ${ }^{20} \mathrm{Th}$ and that ${ }^{40} \mathrm{~K}$ is present in the ocean in concentrations that are expected to be higher than what is found in modern terrestrial oceans ${ }^{34}$

For uranium and thorium, the concentration from three subsurface scenarios 7 was used because the actual concentrations on the Europa seabed are still anknown: a) Martian deep vadose (water-unsaturated yone). b) rocks from non-mineralized strata hiving low concentrations of radioactive elements from the Witwatersrand basin, and c) racks from mineralized stratz having high concentrations af radinactive elements on the Witwatersrand hasin. For potassium, it was assumed that concentrations were in the range of 380 ppm (2s in Farth's ocean 4 ) to 3500 ppm (which may be closer to that of the Furopan ocean'), with the unstable " $\mathrm{K}$ isotopes. accounting for $0.0117 \%$.

For the pyrite sites, the presence of homogeneous pyrite grains covering parts of the niches was assumed. We use the experimental value of the surface area of prrite. $S_{s y}=226 \mathrm{~cm}^{2} / \mathrm{s}^{17}$, telated to grains in the range of 100 to 150 pm in the size as a base to calculate other plausible scenarios for the granulometry that could posstbly exist on Eurogi. These grasus of pyrite were modeled as sanall spheres that fill a culhic space, just as a typical 


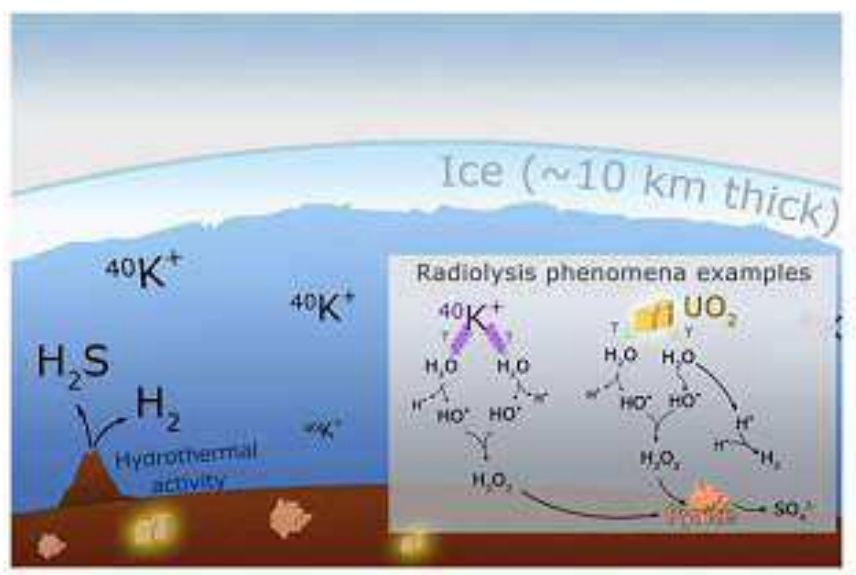

Figure 2. Model of Europa enphasizing the radiogenic material and the gamma-ray radiolysis phenomena

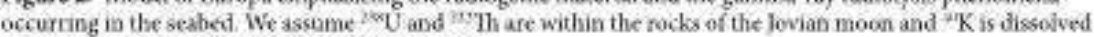
in the watet. Adapted from Chyma \& Hand $(2001)$

\begin{tabular}{|c|c|c|}
\hline Typrof azirifale & Cetant finm) & Sprifici $\left(\mathbf{m}^{2} \cdot \mathbf{q}^{-1}\right)$ \\
\hline Cley & 2 & $1.4 \times 10^{3}$ \\
\hline \multirow{2}{*}{ sith } & 10 & $283 \times 10^{2}$ \\
\hline & $\omega$ & $471 \times 10^{2}$ \\
\hline \multirow{3}{*}{ Sint } & 125 & $226 \times 10$ \\
\hline & 500 & 565. \\
\hline & 1060 & $2 \times 3=$ \\
\hline \multirow{2}{*}{ Trboles. } & 10009 & $2.83 \times 10^{-1}$ \\
\hline & 5000 & $565 \times 10^{-1}$ \\
\hline \multirow{2}{*}{ Ciebles. } & 100050 & $283 \times 15^{-1}$ \\
\hline & 200050 & $1.41 \times 10^{-1}$ \\
\hline
\end{tabular}

Table 1: Sphere-packing model tesults for the surface area of pyrile from different types of aggregates, based on the Wentworth scales"

sphere packing model. Varying the spherical grain sixe, ie., the diameter of the sphere (p), implies a variation of the surface area of the gran, $\$,\{(\varphi)$. Considering this medel, the total surface area of the sphere packing is inversely proportional to the gphere radias. Thes, the sulfate production (P.) was estimated for different possibje grais sizes based on the Wentworth" grade scale, considering the concentrations of radionucludes and pyrite for the different scenarios described earlier. Fot each type of aggregate, a bomogeneous grain size distribution was considered. In other words, every grain bas the sume netrage stas.

\section{Results}

Table 1 shows the calculated total surface arca of pyrite for the ditierent types of aggregates. Based on the values in Table t, the sulfate production per year as a function of the yrite rock mass (presented on Table S1) was calculated as well as the cell-carcying capacisy fthe quantity of cells that could survive of $C$ a. D. avilaxviatio per kilogram of tock present on the losal site for the proposed aralogue scenarios summarized in Fig 3 and furthez

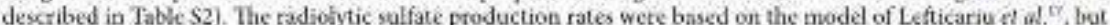
greater values for the rates were obtained, not only due to the addition of the +O $\mathrm{K}$ source hat also slue to a revision of the previous calculations.

The difference in the K concentration for the Europan and the terrestrial ocean had an important outenme. Figure 3 shows that 310 times grezter concentration of $\mathrm{K}$ an provide enough sultate for 21000 - fold increase in cell number. Tahle $\$ 2$ shows that if we consider $1 \mathrm{~kg}$ of racky material with an aqueous mediun 15 small as $2 \mathrm{ml}$, as in the samples in the experimental wvik of water radiolysis ${ }^{17}$, scenarios $b$ and $c$ (described on section 4 ) signifi. cantly exceed the necessity to maintain a cell density of $4 \times 10$ cells per liter. which is the average density abat was peesent in samples of fracturc water from the Witwatesstand basin region ${ }^{\text {? }}$.

Once more information regardiog the esistence, concentration and grasuhometry of prrite and the presence of radioactive isotopes on the seabed of Faropa is obtained frum models, experiments or directindirect measurements by space missions, the results presented is Fig 3 may be useful to estimate the habitability of the moon in terans od biologically usefal energy sources. 


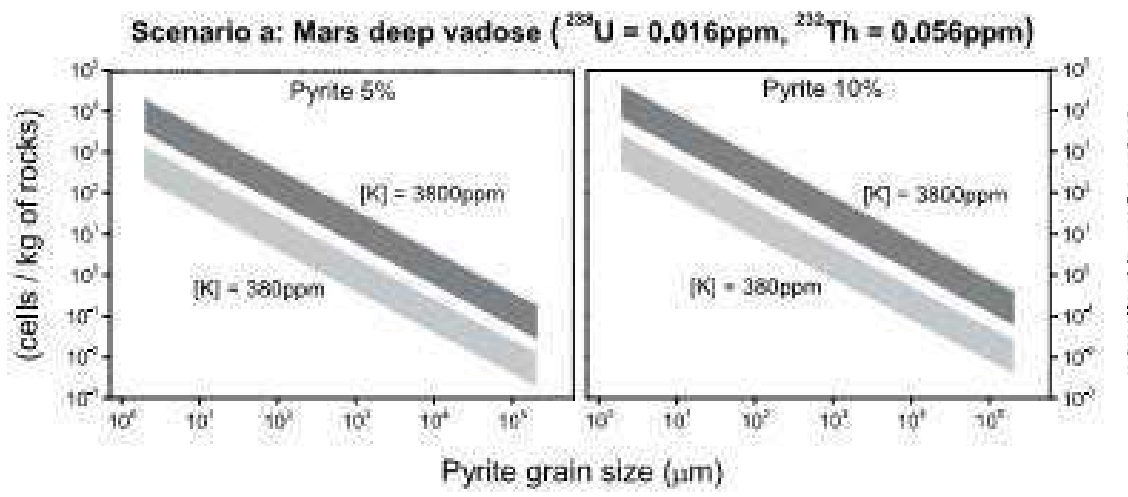

Scenario b: Witwatersrand low concentration $\left({ }^{211} \mathrm{U}=3 \mathrm{ppm},{ }^{237} \mathrm{Th}=11 \mathrm{ppm}\right)$

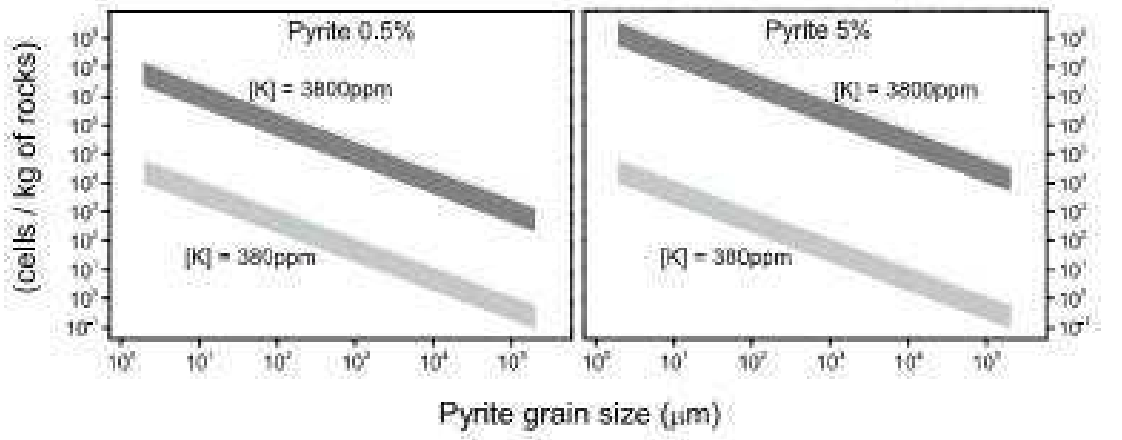

Scenario c: Witwatersrand high concentration $\left({ }^{258} \mathrm{U}=271 \mathrm{ppm},{ }^{232} \mathrm{Th}=15 \mathrm{ppm}\right)$

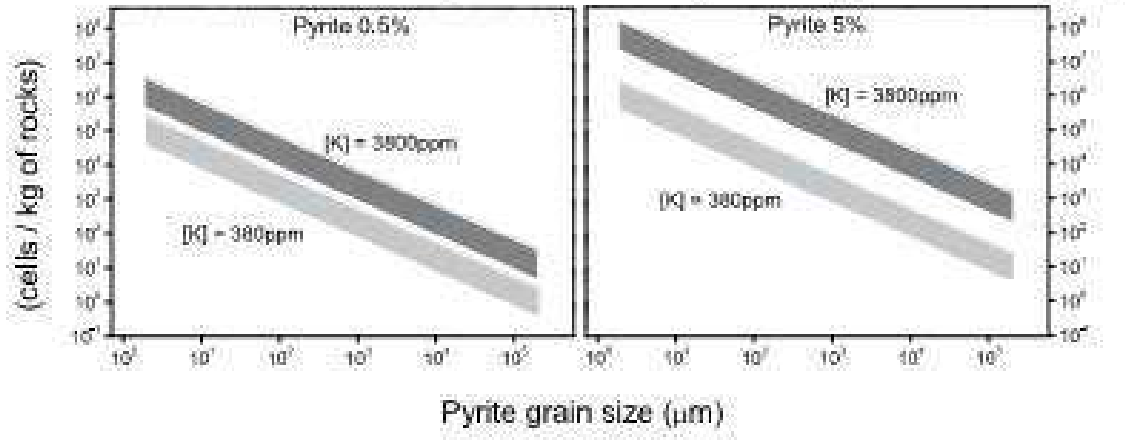

Figure 3. Log-Log plot of the cell-carrying capacity per mass of rocks that contains pyrite compared to the results for the different uranium and tharium scenarios ( $\mathrm{a}, \mathrm{b}$ and $\mathrm{c}$, as descrihed in section 4 ) and the ussumed minimum (light gray) and maximum (darlt grayl potassium concentrations. The $\mathrm{X}$-2xis represents the vanatson in grain size of pyrite based on the classification and based on the Wentworth scale (see Table \$2), which is inversely proportional to the surface area available for oxidation.

\section{Discussion}

In this work, deep terrestral enviohments, stuch as the Mponeng gold mine, and selected Martian peological settings were evaluated as reasonable analogues for the undericrust ocesnic non illuminated and non-photosynthetic environment of Europa. In this context, the Ciesdidatis Desulforidis andaxviatar extremephile was used as a model organisim because it is prominent from fracture water sampled from depths greater than $1.5 \mathrm{~km}$ across the Witwatersrand basin and is dominates the bioca discovered $2.8 \mathrm{~km}$ below the land surface The envitonmestal conditions of Mponeng mine as w deep subsurface environment cobsidering the lack of $\mathrm{O}_{2}$ and high temperatures can be considered similar to those of the seabed of Europa ${ }^{3 t}$. which is heated by tidal: 
Internction with Jupiter. Because it is shemoautotrophas, this bacterium candidate species bas the capacity to fix its own carbon (thus reducing the necessity of reduced organies) and to shrive in regions with a cbernical disequilibrium produced by waser radiolysis.

Our calculation assumes that there is enough radiolytic endogenous sulfate production to enter the mictootganism metabolisen even if we restrict the results to gamma-ray radiolysis. This simplification wax based on the fact that the rate of radiolytic production of $\mathrm{HO}$ from water, which reacts with prrite to form sulfate, is at least one order of mapnitude higher than the rate dae to other decay channels, such as alphas (per electron-Volt) ${ }^{\text {ID }}$. Despite the fact that rock porosity and space constraints wese not considered in our calculations, those prarame ters were included in models to calculate the production far from the solid water interface of radioactive mineral $^{23}$. Here, a simple model considered local radiolysis in the aquecous environment, and this model showed enough to provide some reference to the objectives estahlished for this work. In aditition, considering the possibility for existence of hydrothermal systems on the Europa seahed", these can be another endogenous source of sulfate\%. These sources wefe assamed to exist far from our radiolytic system, and for the survival of s species such as $C$ a. D andusvintor, is is neccessary that the enviromment is depleted of oxygen and has a high $\mathrm{pH}^{20}$ - a coodition. notmally not matched by nearby hydrothermal vents preseat on Earth". More observational data from space missicans are needed tis constrain this information for the case of Europa. fi has also been proposed that salfate could have an exogenous source $e^{3,0}$, namely, from lo ${ }^{10}$. We argue that although this could be a source, the icy crust would prevent efficient mixing, made even bess probabje when associated with the abyssal depths of the ocean. It was assumed that sulfate is not used in uther reactions that could prevent its availability for the microorganism. The main route for the depletion of sulfate could be, under Europan conditions, the precipitation of sulfate in the form of non soluble salts such as $\mathrm{BaSO}_{4}$ and/or CaSO, Howerer, to study these possihle sinks, more information is needed regarding the abundances of $\mathrm{Ca}^{+}$and $\mathrm{Ba}^{+}$and their equilibrium reactions under Europan condusions. especially pH and temperature. Additionally, reactions witb silica can occior depending on the temperature, for example, $2 \mathrm{CaSO}_{4}+2 \mathrm{SiO}_{2}+\mathrm{C} \rightarrow 2 \mathrm{CuSiO}_{3}+2 \mathrm{SO}_{2}+\mathrm{CO}_{2}$. releasing ealfur in the form of gas. Thus, as the dynamics of cryotectonism is not completely understood and the rate of sulfate delivery or sanking remains. poorly constraned, these effects were not taken into account in the present work. Future direct measorements and modcls are still needed to better constrain the habitability of Europd.

Other open-questions atise, such as the unknown distribution of " $\mathrm{K}$ on the ocean. If it is unformly distributed, then the release of $\mathrm{O}_{2}$ by the radiolysis of warer would have oxidised the oxean over time, which could balt sulfale production. However, a non-uniform distribution would place some restrictions on the present results, and although it is easy to imagine niches of uranium and thorium, it is difficult to imagine that there would also be a clump of $\mathrm{K}$ together with the niches of ${ }^{25} \mathrm{U}$ and ${ }^{23} \mathrm{Th}$. An example of this clumping wasld be due to the

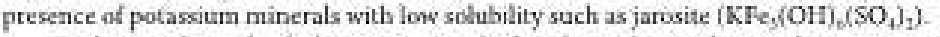

Another product of radiolysis is $\mathrm{H}_{2} \mathrm{O}_{1}$, which is formed according to the reaction $\mathrm{HO}+\mathrm{HO} \rightarrow \mathrm{H}_{2} \mathrm{O}_{7}$. The sterilizing power of the peroxide could be a caveat. Too mach peroxade near the microorganisms conld minimize the habitability of the environment when considering the case of $C a . D$ arafaxcialar, whose genes lack functional peroxidase homologs $5^{14}$. However, we suppose that this situation would not occur in a system such as the one modeled here, since $\mathrm{H}_{2} \mathrm{O}_{1}$ is a kinetically unstable chemical species and the rate of water formation from the same reagent $\mathrm{HO}$ is dauble the hydrogen peroxide formatioa rate $e^{\mathrm{ik}} 17$ Similarly, the presence of $\mathrm{O}_{2}$ as a product of radiolysis coald be important considering its sterilizing power for $C a, D$ audexviator, as it also lacks a complete system for oxygen resistance". However, deep environments such as the Mponeng gold mine and others are depleted of $\mathrm{O}_{2}$ and are reductant-rich's $x \mathrm{w}_{2} \mathrm{x}$, which suggests that molecular oxygen and $\mathrm{H}_{2} \mathrm{O}_{3}$ bave a relevant sink that may be the pyrite mineral itself, and the same may occur for the deep subsurace of Europa.

The resulis for the Europar framemork are also useful fok studies involving other Solar System icy moons that pres.

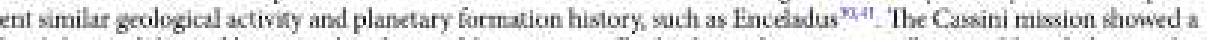
local themical disequilibrism and evidence of the existence of hydrothermal systerns as well as possitble radiolysis under

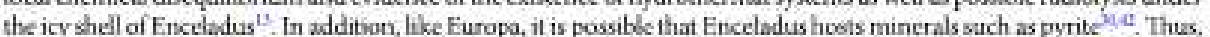
this moon is also a propitiaus celestial body to host life ${ }^{\circ}$. In other words, the habitability question addressed here cuuld provide an znalogue epplicatinn foe Fncelautus, which is another promisiag target for astrobiology studies.

\section{Conclusions}

Our results contribute to the evolving picture of Faropa and other icy meons, such as Enceladas, ws promising habitable environments. Sulfate production via $\rightarrow$ ray radiolysis was shown to be enough to sappty the minimum energy required to mantain a considerable cell mass of the salfate-reducing bacterium $\mathrm{Ca}$. D. audaxviafor used as a model organism. The cell quantity was shown to be comparable to that found in decp terrestrial etsvironmenis if one assumes conditions similar to that in experimental work on radiolysis-produced sulfate. The tolal alusence of salfate sinks that could compete with a bacterial single-species ecosystem was assumed. However, as uranium also decrys by $\mathrm{c}$ and 3 decay, the released energy sbosild be greater than that calculated here, more water radjolysis would occur, and more pyrite would suffer oxidation. Therefore, this resalt can represent a lower limit for var sulfate-dependent ecosystem energy requirement. Othervise, there would be no bacterial activity living in a suhsarface environment such 25 that of the Mponeng gold nine. In fact, these and other deep and inhahited eavironments on Earth represent good analogues for Europa and could be further explored for this application. induding serving as the basis for future space missions.

Our model for Europa can provide more energy than necessary to sustain the modeled microbial life even only by the gamma decay of ${ }^{21} \mathrm{~K}$, since its abundance can be 10 times (or morel greater than that found in Earth's oceans. This result makes Europa a propitions place for the development of an ecosystem that sustans forms of life such as the sulfate-reducing bacterna Candiduaus Desulforadis awiloxviator, ahthough this cstimate needs more constraints from experimental data. An important observation based on our results may be the relevance of the 
"K concentration in the Furopan oceas. As shows in Fig. 1, it creates a considurable difference in the range of the cell-carrying capacity based on the sulfate metabolism. The same dependency exists with pyrite grain size, and direct or indirect measurements of this chatacteristic are important to better constrain the model.

\section{References}

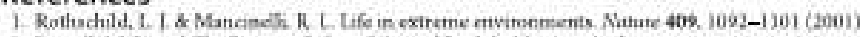

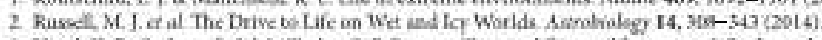

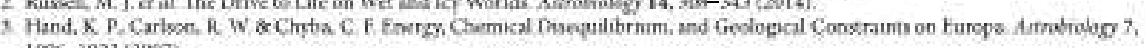
$1006-\ln 22(2007)$

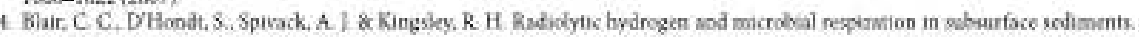
Asirotichugy 7.951-570(2007)

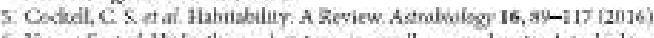

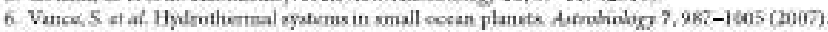

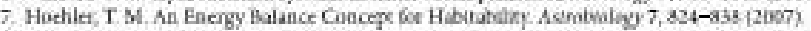

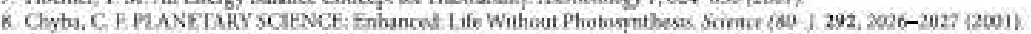

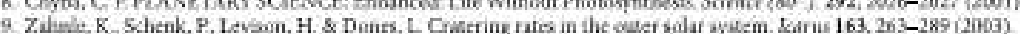

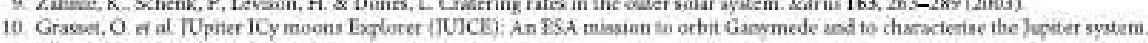
Manst. 5 pace Sci. $78,1-21$ (2013)

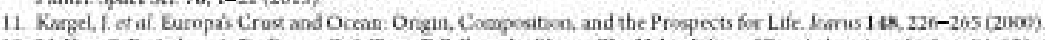

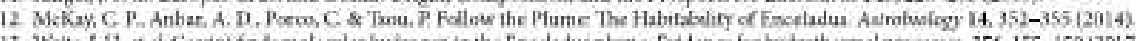

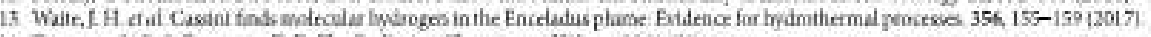

14. Draganic, I. G. \& Dreganse, Z D. The Radiaion Chemisiry of Wher 26 \&19711.

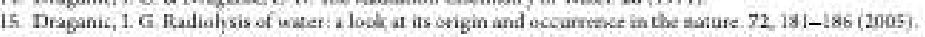

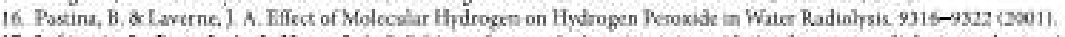

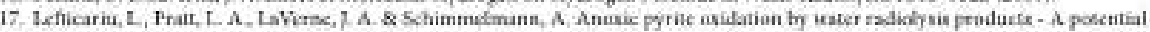

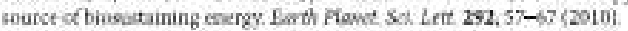

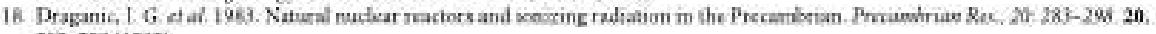
$283-29 \mathrm{~d}(1993)$

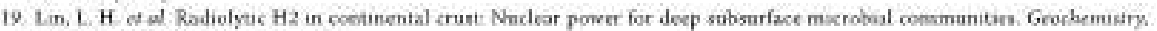

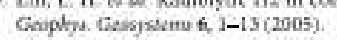

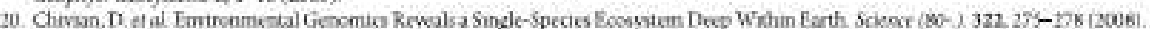

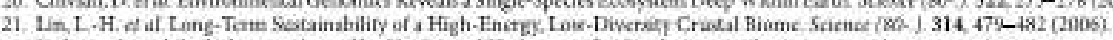

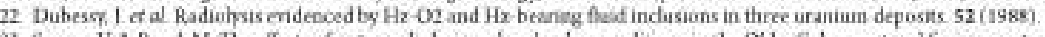

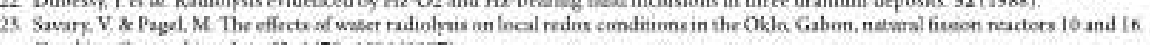

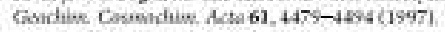

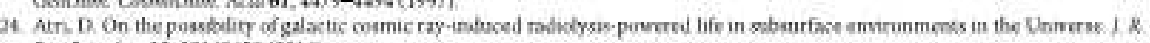
Sox. Interjase 13, 20160459 (2016).

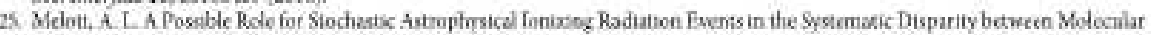

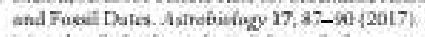

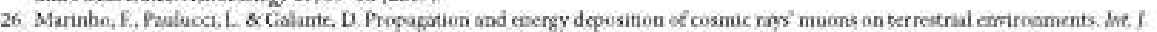
Astroḱi, $13,1-502014$

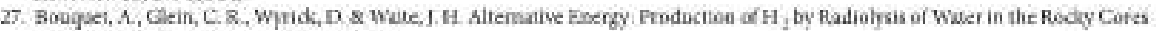

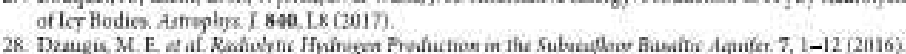

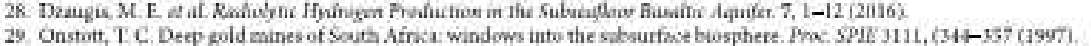

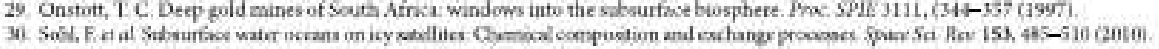

31. Hexen, R. M. Af al Mineral emblution Am Mitieral. 93, 1843-1720 \{2008).

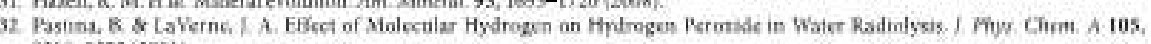
$9316-9322(2001)$

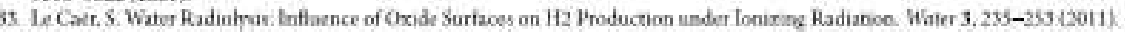

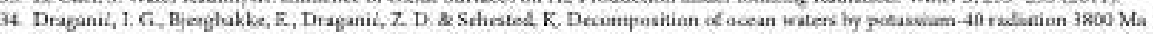

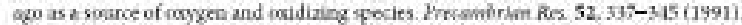

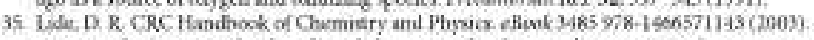

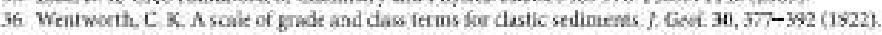

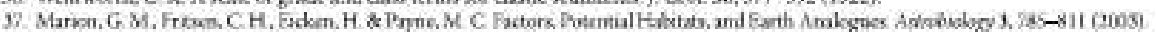

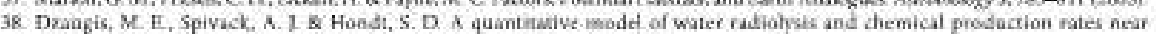

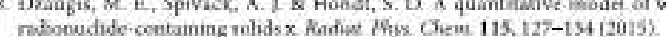

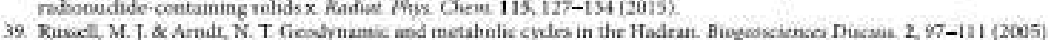

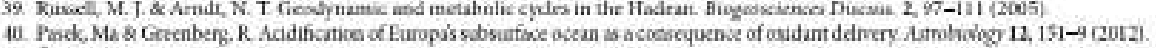

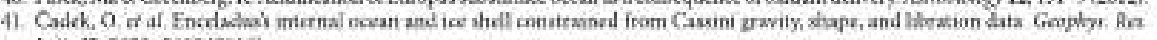
Lett. $43,565,-5660120168$

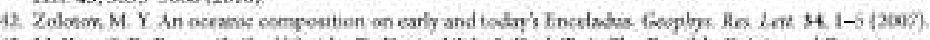

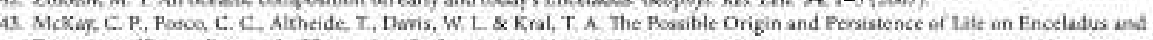

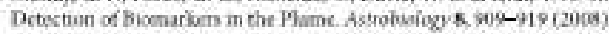

\section{Acknowledgements}

The authors thank FAPESP (project 2016/06114-6), CAPES and CNPq (project 424367/2016-5) for the finaacial support and the Research Unit in. Astrobsology (NAP/Astrobio - PRPRUSP) for the institutional support. MGBA also acknowledges EAPESP project 2011/23996-9 and FAPESP Thematic Project 2013/26258-4. The authors also thank Serrapilheira Project number G-1709-20205.

\section{Author Contributions}

T.A. reviewed and expanded the calculations and was responstble for the writing of the main body of the matsuscript: M.G.B.A was responsible for the first version of the calculations and manuscript writing and revision; FR. contributed to the discussion of the physicochemical models, a discussion of the results and final review of the munuscript and figures, D.G. was responsible for the initial idez for the article, proposed the model for the reactions and the use of the terrestrial analogue for Europa, and contributed to the writing of the manuscript and discussion of the implication of the results. 


\section{Additional Information}

Supplementary information accompanies this paper at larps:Hdou.org/10.1038is41598-017-18470- $z$.

Competing Interests: The authors declare that they have no competing interests.

Publisher's note: Springer Nature remains neutral with regard to jurisctictional daims in published maps and institutional affiliations.

(c) Open Access This article is licessed under a Creative Commons Attribution 4.0 International License, which permits use, sharing, alaptatavn, distribution and reproduction in any medium or format, as long as you give appropriate credit to the original author(s) and the source, provide a link to the Creative Commons license, and indicate if changes were made. The imzges or other third party material in this article are included in the article's Creative Commons license, unless indicated otherwise in a credit line to the material. If materiat is not included in the article's Creative Commons license and your intended use is not per mitted by statatery regulation or exceeds the permitted ase, you will need to obtain permission directly from the copyright holiler. To view a copy of this license, visit http $/$ /creativecommons.sig/icenses/ly/4.A\%.

6 The Author(s) 2018 


\title{
APÊNDICE B - Material Suplementar do artigo publicado na Scientific Reports.
}

Supplementary Online material for

\section{Microbial habitability of Europa sustained by radioactive sources}

\author{
Thiago Altair ${ }^{1,4}$, Marcio G. B. de Avellar ${ }^{2}$, Fabio Rodrigues ${ }^{3}$, Douglas Galante ${ }^{1,4}$
}

${ }^{1}$ Brazilian Synchrotron Light Laboratory (LNLS), Brazilian Center for Research in Energy and Materials (CNPEM), Campinas/SP, Brazil.

${ }^{2}$ Instituto de Astronomia, Geofísica e Ciências Atmosféricas, Universidade de São Paulo, São Paulo/SP, Brazil.

${ }^{3}$ Departamento de Química Fundamental Instituto de Química, Universidade de São Paulo, São Paulo/SP, Brazil.

${ }^{4}$ Programa de Pós-Graduação em Física Biomolecular, Instituto de Física de São Carlos, Universidade de São Paulo, São Carlos/SP, Brazil.

\section{Sulfate production by water radiolysis from alpha emission}

In our calculation for radiolysis-produced sulfate, we have considered the gamma radiolysis as the start point, based on the argument presented in the conclusions of the main manuscript. Regardless of our conclusions, there is the possibility of considering other emission particles, such as alphas, for sulfate production, which is another important emission channel for the long-lived radionuclides considered for our calculations, ${ }^{238} \mathrm{U},{ }^{232} \mathrm{Th}$ and ${ }^{40} \mathrm{~K}$. For this purpose, experimental data related to this alpha emission is necessary. Based on a table of isotopes (119) and on results for water radiolysis presented on the main manuscript's references such as the work of Pastina and LaVerne (2001) (12) and Lefticariu et al. (2010) (11) the alpha emission-water radiolysis for sulfate production was disconsidered for this work. Basically, for extrapolating the results for radiolysis-produced sulfate, one needs a measurement for the constant Gs presented in the section 3 of the main manuscript, however one needs this measurement related to alpha-induced water radiolysis, which is not reliably available.

One can compare the sulfate production via gamma radiolysis and via alpha radiolysis by the simplification of considering only $\mathrm{HO}$ as the radical that oxides pyrite just as presented in work of Lefticariu et al. (2010). This is expressed on the equation $\mathrm{FeS}_{2}+4 \mathrm{HO}^{\bullet} \rightarrow \mathrm{Fe}^{2+}+$ $\mathrm{S}+\mathrm{SO}_{4}^{-2}+2 \mathrm{H}_{2}$. We can summarize the comparison of gamma radiation to other channels of decay with the result that the rate of $\mathrm{HO}$ produced via gamma ray radiolysis is one order of magnitude higher than its production via alpha particle radiolysis (12).

\section{Wentworth granular scale}

As a reference for the selected range of pyrite grain size for sulfate production, it is used the granular size classification proposed by Wentworth (1922). In this scheme, the names applied to the different grades carry no lithologic, mineralogic or chemical significance 
as far as the present work is concerned. The author considers that such uniformity in each sediment does not occur in nature, as on the example of clay particles that are not usually composed of the same material. Regardless of this and other possible caveats, the work that presents the classification was cited more than four thousand times until the submission of our paper, according to public databases of academic journals. This grain scale classification and these terms are now generally followed as a reference $(120,121)$. The scale is based on the geometric distribution of grain size extending from 1/256 to $256 \mathrm{~mm}$. From its establishment until now, it was reviewed, adopting the so called $\varphi$-scale, which has a logarithm relationship with the grain size (121). On the main manuscript, it was considered as just another expression for the grain size. This commonly adopted size scale is presented on figure $\mathrm{S} 1$.

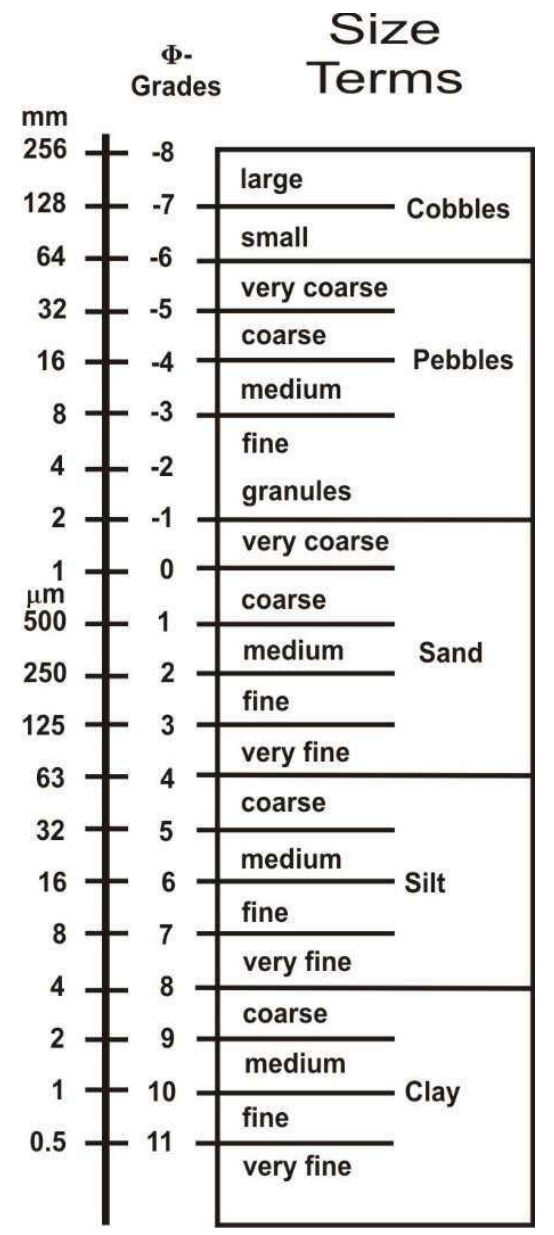

Figure S1- Wentworth grain-size scale and grain-size-based terms commonly used for differentiating sedimentary grains (adapted from Flügel 2010 [7]).

As long that there is still a lack of detailed information or modelling about the possible presence of pyrite in Europa subsurface environment - which includes its granulation setting it is reasonable to evaluate a range of possible granulations, based on the Wentworth scale. 
Based on Lefticariu et al. (2010), we proposed the calculations for sulfate production for each scenario proposed. However, to adequate the terrestrial and martian scenarios proposed as analogues for subsurface environments of Europa, we have considered not only ${ }^{238} \mathrm{U}$ and ${ }^{232} \mathrm{Th}$, but also ${ }^{40} \mathrm{~K}$. And, as mentioned in the main manuscript, we have proposed to calculate sulfate using the concentrations for ${ }^{238} \mathrm{U}$ and ${ }^{232} \mathrm{Th}$ constrained to each scenario, as suggested in the work of Lefticariu et al. and the ${ }^{40} \mathrm{~K}$ concentration suggested for terrestrial ocean (122) and for an estimation for Europan ocean (95). The results in detail for sulfate production are shown in table $\mathrm{S} 1$.

Table S1. Estimated radiolytic sulfate production for different proposed scenarios. Each scenario represents a local composition for ${ }^{238} \mathrm{U}$ and ${ }^{232} \mathrm{Th}$. Concentration for each scenario: Mars deep vadose: ${ }^{238} \mathrm{U}=0.016 \mathrm{ppm}$, ${ }^{232} \mathrm{Th}=0.056 \mathrm{ppm}$; Witwatersrand with low concentration: ${ }^{238} \mathrm{U}=3 \mathrm{ppm},{ }^{232} \mathrm{Th}=11 \mathrm{ppm}$; Witwatersrand with high concentration: ${ }^{238} \mathrm{U}=271 \mathrm{ppm},{ }^{232} \mathrm{Th}=15 \mathrm{ppm}$. For each, it is considered a specific grain size of pyrite in the classification based on Wentworth scale and it is considered ${ }^{40} \mathrm{~K}$ concentration as $0.0117 \%$ of total potassium (87).

\begin{tabular}{|c|c|c|c|c|c|c|c|}
\hline & & \multicolumn{6}{|c|}{ Mars deep vadose } \\
\hline & & \multicolumn{3}{|c|}{$[\mathrm{K}]=380 \mathrm{ppm}$} & \multicolumn{3}{|c|}{$[\mathrm{K}]=3800 \mathrm{ppm}$} \\
\hline & & & $\begin{array}{l}\text { Pyrite } \\
\text { wt. } 5 \%\end{array}$ & $\begin{array}{c}\text { Pyrite } \\
\text { wt. } 10 \% \\
\end{array}$ & & $\begin{array}{l}\text { Pyrite } \\
\text { wt. 5\% }\end{array}$ & $\begin{array}{c}\text { Pyrit } \\
\text { wt. } 10 \% \\
\end{array}$ \\
\hline $\begin{array}{l}\text { Wentwort } \\
\text { h scale }\end{array}$ & $\begin{array}{l}\text { Grain } \\
\varphi / \mu \mathrm{m}\end{array}$ & $\begin{array}{c}\text { Dose } \\
\text { (J/Kg.yr) }\end{array}$ & $\begin{array}{c}\text { Sulfate } \\
\text { production } \\
\text { Rate } / \mathrm{mol} \\
(\mathrm{kg} \text { year })^{-1}\end{array}$ & $\begin{array}{c}\text { Sulfate } \\
\text { production } \\
\text { Rate } / \mathrm{mol} \\
(\mathrm{kg} \text { year })^{-1}\end{array}$ & $\begin{array}{c}\text { Dose } \\
(\mathrm{J} / \mathrm{Kg} . \mathrm{yr})\end{array}$ & $\begin{array}{c}\text { Sulfate } \\
\text { production } \\
\text { Rate } / \mathrm{mol} \\
(\mathrm{kg} \text { year })^{-1}\end{array}$ & $\begin{array}{c}\text { Sulfate } \\
\text { production } \\
\text { Rate } / \mathrm{mol} \\
(\mathrm{kg} \text { year })^{-1}\end{array}$ \\
\hline Clay & 2 & $\begin{array}{c}5.24 \times 10 \\
-5\end{array}$ & $7.77 \times 10^{-12}$ & $1.55 \times 10^{-11}$ & $4.03 \times 10^{-4}$ & $1.20 \times 10^{-7}$ & $2.39 \times 10^{-7}$ \\
\hline \multirow{2}{*}{ Silt } & 10 & $\begin{array}{c}5.24 \times 10 \\
-5\end{array}$ & $1.55 \times 10^{-12}$ & $3.11 \times 10^{-12}$ & $4.03 \times 10^{-4}$ & $2.39 \times 10^{-8}$ & $4.78 \times 10^{-8}$ \\
\hline & 60 & $\begin{array}{c}5.24 \times 10 \\
-5\end{array}$ & $2.59 \times 10^{-13}$ & $5.18 \times 10^{-13}$ & $4.03 \times 10^{-4}$ & $3.99 \times 10^{-9}$ & $7.97 \times 10^{-9}$ \\
\hline \multirow{3}{*}{ Sand } & 125 & $\begin{array}{c}5.24 \times 10 \\
-5\end{array}$ & $1.24 \times 10^{-13}$ & $2.49 \times 10^{-13}$ & $4.03 \times 10^{-4}$ & $1.91 \times 10^{-9}$ & $3.83 \times 10^{-9}$ \\
\hline & 500 & $\begin{array}{c}5.24 \times 10 \\
-5\end{array}$ & $3.11 \times 10^{-14}$ & $6.22 \times 10^{-14}$ & $4.03 \times 10^{-4}$ & $4.78 \times 10^{-10}$ & $9.57 \times 10^{-10}$ \\
\hline & 1000 & $\begin{array}{c}5.24 \times 10 \\
-5\end{array}$ & $1.55 \times 10^{-14}$ & $3.11 \times 10^{-14}$ & $4.03 \times 10^{-4}$ & $2.39 \times 10^{-10}$ & $4.78 \times 10^{-10}$ \\
\hline \multirow{2}{*}{ Pebbles } & 10000 & $\begin{array}{c}5.24 \times 10 \\
-5\end{array}$ & $1.55 \times 10^{-15}$ & $3.11 \times 10^{-15}$ & $4.03 \times 10^{-4}$ & $2.39 \times 10^{-11}$ & $4.78 \times 10^{-11}$ \\
\hline & 50000 & $\begin{array}{c}5.24 \times 10 \\
-5\end{array}$ & $3.11 \times 10^{-16}$ & $6.22 \times 10^{-16}$ & $4.03 \times 10^{-4}$ & $4.78 \times 10^{-12}$ & $9.57 \times 10^{-12}$ \\
\hline \multirow{2}{*}{ Cobbles } & 100000 & $\begin{array}{c}5.24 \times 10 \\
-5\end{array}$ & $1.55 \times 10^{-16}$ & $3.11 \times 10^{-16}$ & $4.03 \times 10^{-4}$ & $2.39 \times 10^{-12}$ & $4.78 \times 10^{-12}$ \\
\hline & 200000 & $\begin{array}{c}5.24 \times 10 \\
-5\end{array}$ & $7.77 \times 10^{-17}$ & $1.55 \times 10^{-16}$ & $4.03 \times 10^{-4}$ & $1.20 \times 10^{-12}$ & $2.39 \times 10^{-12}$ \\
\hline
\end{tabular}

\begin{tabular}{|c|c|l|l|c|}
\hline \multicolumn{3}{|c|}{ Witwatersrand low concentration } \\
\hline \multicolumn{3}{|c|}{$[\mathrm{K}]=380 \mathrm{ppm}$} & \multicolumn{2}{|c|}{$[\mathrm{K}]=3800 \mathrm{ppm}$} \\
\hline $\begin{array}{c}\text { Pyrite } \\
\text { wt. } 0.5 \%\end{array}$ & & $\begin{array}{c}\text { Pyrite } \\
\text { wt. } 0.5 \%\end{array}$ & & $\begin{array}{c}\text { Pyrite } \\
\text { wt. } 0.5 \%\end{array}$ \\
\hline
\end{tabular}




\begin{tabular}{|c|c|c|c|c|c|c|c|}
\hline $\begin{array}{c}\text { Jentworth } \\
\text { scale }\end{array}$ & $\begin{array}{l}\text { Grain } \\
\varphi / \mu \mathrm{m}\end{array}$ & $\begin{array}{c}\text { Dose } \\
\text { (J/Kg.yr) }\end{array}$ & $\begin{array}{c}\text { Sulfate } \\
\text { production } \\
\text { Rate } / \mathrm{mol}(\mathrm{kg} \\
\text { year })^{-1}\end{array}$ & $\begin{array}{c}\text { Sulfate } \\
\text { production } \\
\text { Rate } / \mathrm{mol}(\mathrm{kg} \\
\text { year })^{-1}\end{array}$ & $\begin{array}{c}\text { Dose } \\
(\mathrm{J} / \mathrm{Kg} . \mathrm{yr})\end{array}$ & $\begin{array}{c}\text { Sulfate } \\
\text { production } \\
\text { Rate } / \mathrm{mol} \\
(\mathrm{kg} \text { year) }\end{array}$ & 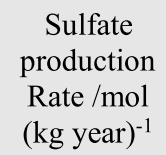 \\
\hline Clay & 2 & $\begin{array}{c}2.62 \times 10 \\
-3\end{array}$ & $3.89 \times 10^{-10}$ & $3.89 \times 10^{-10}$ & $2.97 \times 10^{-3}$ & $8.81 \times 10^{-7}$ & $2.20 \times 10^{-5}$ \\
\hline \multirow{2}{*}{ Silt } & 10 & $\begin{array}{c}2.62 \times 10 \\
-3\end{array}$ & $7.77 \times 10^{-11}$ & $7.77 \times 10^{-11}$ & $2.97 \times 10^{-3}$ & $1.76 \times 10^{-7}$ & $4.41 \times 10^{-6}$ \\
\hline & 60 & $\begin{array}{c}2.62 \times 10 \\
-3\end{array}$ & $1.30 \times 10^{-11}$ & $1.30 \times 10^{-11}$ & $2.97 \times 10^{-3}$ & $2.94 \times 10^{-8}$ & $7.34 \times 10^{-7}$ \\
\hline \multirow{3}{*}{ Sand } & 125 & $\begin{array}{c}2.62 \times 10 \\
-3\end{array}$ & $6.22 \times 10^{-12}$ & $6.22 \times 10^{-12}$ & $2.97 \times 10^{-3}$ & $1.41 \times 10^{-8}$ & $3.53 \times 10^{-7}$ \\
\hline & 500 & $\begin{array}{c}2.62 \times 10 \\
-3\end{array}$ & $1.55 \times 10^{-12}$ & $1.55 \times 10^{-12}$ & $2.97 \times 10^{-3}$ & $3.53 \times 10^{-9}$ & $8.81 \times 10^{-8}$ \\
\hline & 1000 & $\begin{array}{c}2.62 \times 10 \\
-3\end{array}$ & $7.77 \times 10^{-13}$ & $7.77 \times 10^{-13}$ & $2.97 \times 10^{-3}$ & $1.76 \times 10^{-9}$ & $4.41 \times 10^{-8}$ \\
\hline \multirow{2}{*}{ Pebbles } & 10000 & $\begin{array}{c}2.62 \times 10 \\
-3\end{array}$ & $7.77 \times 10^{-14}$ & $7.77 \times 10^{-14}$ & $2.97 \times 10^{-3}$ & $1.76 \times 10^{-10}$ & $4.41 \times 10^{-9}$ \\
\hline & 50000 & $\begin{array}{c}2.62 \times 10 \\
-3\end{array}$ & $1.55 \times 10^{-14}$ & $1.55 \times 10^{-14}$ & $2.97 \times 10^{-3}$ & $3.53 \times 10^{-11}$ & $8.81 \times 10^{-10}$ \\
\hline \multirow{2}{*}{ Cobbles } & 100000 & $\underset{-3}{2.62 \times 10}$ & $7.77 \times 10^{-15}$ & $7.77 \times 10^{-15}$ & $2.97 \times 10^{-3}$ & $1.76 \times 10^{-11}$ & $4.41 \times 10^{-10}$ \\
\hline & 200000 & $\begin{array}{c}2.62 \times 10 \\
-3\end{array}$ & $3.89 \times 10^{-15}$ & $3.89 \times 10^{-15}$ & $2.97 \times 10^{-3}$ & $8.81 \times 10^{-12}$ & $2.20 \times 10^{-10}$ \\
\hline
\end{tabular}

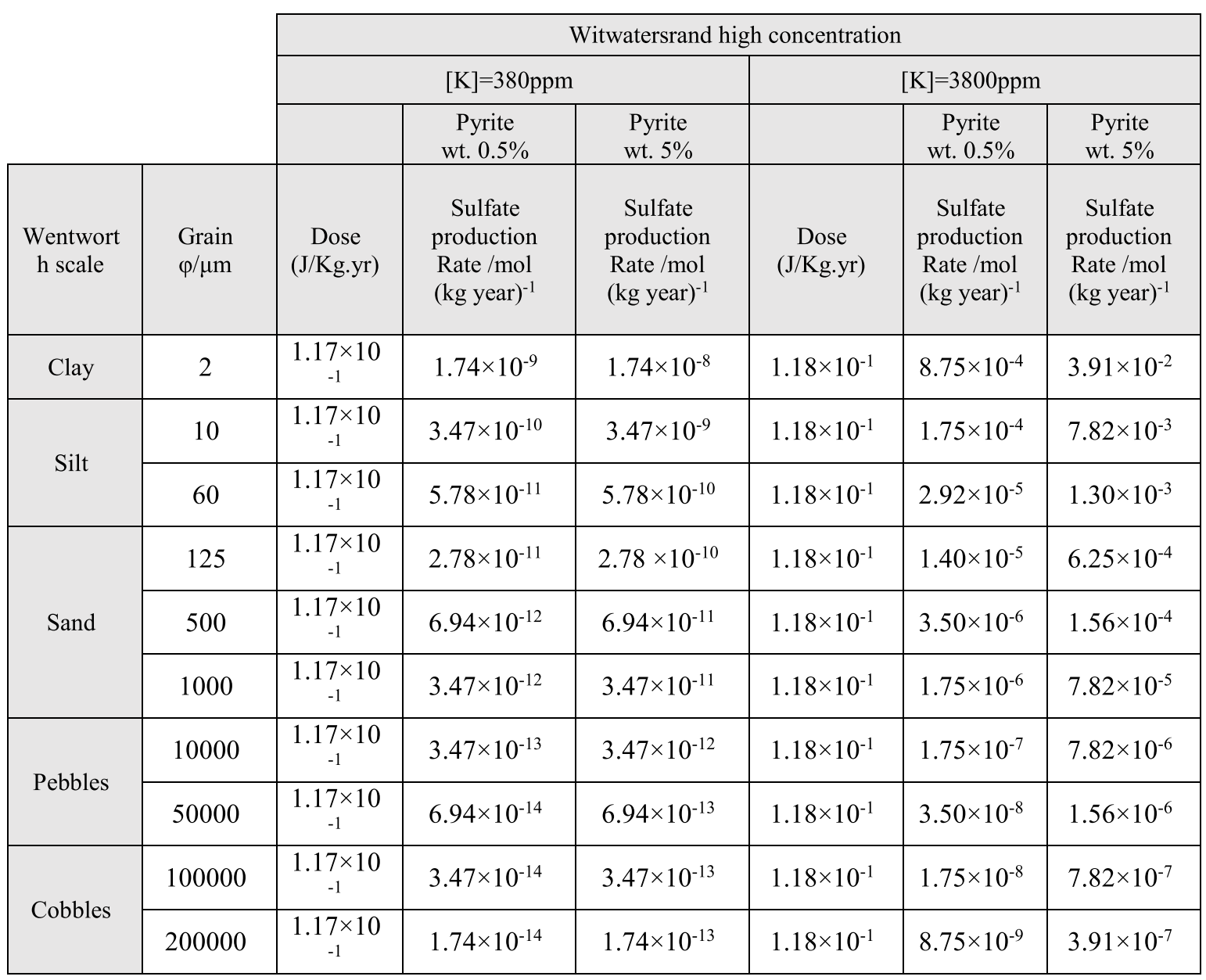




\section{Results for the cell holding capacity per kilogram of rock}

Table S2. Estimated cell holding capacity for $C a$. D. audaxviator for different scenarios and considering different possible pyrite aggregates. Each scenario represents a local composition for ${ }^{238} \mathrm{U}$ and ${ }^{232} \mathrm{Th}$.

Concentration for each scenario: Mars deep vadose: ${ }^{238} \mathrm{U}=0.016 \mathrm{ppm},{ }^{232} \mathrm{Th}=0.056 \mathrm{ppm}$; Witwatersrand with low concentration: ${ }^{238} \mathrm{U}=3 \mathrm{ppm},{ }^{232} \mathrm{Th}=11 \mathrm{ppm}$; Witwatersrand with high concentration: ${ }^{238} \mathrm{U}=271 \mathrm{ppm}$,

${ }^{232} \mathrm{Th}=15 \mathrm{ppm}$. For each, it is considered a specific grain size of pyrite in the classification based on Wentworth scale and it is considered ${ }^{40} \mathrm{~K}$ concentration as $0,0117 \%$ of total potassium (87).

\begin{tabular}{|c|c|c|c|c|c|c|c|c|c|}
\hline \multirow[b]{3}{*}{$\begin{array}{r}\text { Types of } \\
\text { aggregate }\end{array}$} & \multirow[b]{3}{*}{$\begin{array}{l}\text { Grain } \\
\varphi / \mu \mathrm{m}\end{array}$} & \multicolumn{4}{|c|}{ Mars with $[\mathrm{K}]=380 \mathrm{ppm}$} & \multicolumn{4}{|c|}{ Mars with $[\mathrm{K}]=3800 \mathrm{ppm}$} \\
\hline & & \multicolumn{2}{|c|}{ Pyrite wt. 5\% } & \multicolumn{2}{|c|}{ Pyrite wt. $10 \%$} & \multicolumn{2}{|c|}{ Pyrite wt. 5\% } & \multicolumn{2}{|c|}{ Pyrite wt. $10 \%$} \\
\hline & & $\begin{array}{c}\text { Cell } \\
\text { holding } \\
\text { capacity } \\
\text { per } \\
\text { kilogram } \\
\text { of rock } \\
\text { (minimum } \\
\text { ) }\end{array}$ & $\begin{array}{l}\text { Cell holding } \\
\text { capacity per } \\
\text { kilogram of } \\
\text { rock } \\
\text { (maximum) }\end{array}$ & $\begin{array}{l}\text { Cell holding } \\
\text { capacity per } \\
\text { kilogram of } \\
\text { rock } \\
\text { (minimum) }\end{array}$ & $\begin{array}{l}\text { Cell holding } \\
\text { capacity per } \\
\text { kilogram of } \\
\text { rock } \\
\text { (maximum) }\end{array}$ & $\begin{array}{l}\text { Cell holding } \\
\text { capacity per } \\
\text { kilogram of } \\
\text { rock } \\
\text { (minimum) }\end{array}$ & $\begin{array}{l}\text { Cell holding } \\
\text { capacity per } \\
\text { kilogram of } \\
\text { rock } \\
\text { (maximum) }\end{array}$ & $\begin{array}{l}\text { Cell holding } \\
\text { capacity per } \\
\text { kilogram of } \\
\text { rock } \\
\text { (minimum) }\end{array}$ & $\begin{array}{l}\text { Cell holding } \\
\text { capacity per } \\
\text { kilogram of } \\
\text { rock } \\
\text { (maximum) }\end{array}$ \\
\hline Clay & 2 & $2.16 \times 10^{5}$ & $1.41 \times 10^{6}$ & $2.13 \times 10^{2}$ & $1.40 \times 10^{3}$ & $4.26 \times 10^{2}$ & $2.79 \times 10^{3}$ & $3.28 \times 10^{3}$ & $2.15 \times 10^{4}$ \\
\hline \multirow{2}{*}{ Silt } & 10 & $4.32 \times 10^{4}$ & $2.83 \times 10^{5}$ & $4.26 \times 10^{1}$ & $2.79 \times 10^{2}$ & $8.53 \times 10^{1}$ & $5.58 \times 10^{2}$ & $6.56 \times 10^{2}$ & $4.29 \times 10^{3}$ \\
\hline & 60 & $7.20 \times 10^{3}$ & $4.71 \times 10^{4}$ & 7.11 & $4.65 \times 10^{1}$ & $1.42 \times 10^{1}$ & $9.30 \times 10^{1}$ & $1.09 \times 10^{2}$ & $7.15 \times 10^{2}$ \\
\hline \multirow{3}{*}{ Sand } & 125 & $3.45 \times 10^{3}$ & $2.26 \times 10^{4}$ & 3.41 & $2.23 \times 10^{1}$ & 6.82 & $4.46 \times 10^{1}$ & $5.25 \times 10^{1}$ & $3.43 \times 10^{2}$ \\
\hline & 500 & $8.64 \times 10^{2}$ & $5.65 \times 10^{3}$ & $8.53 \times 10^{-1}$ & 5.58 & 1.71 & $1.12 \times 10^{1}$ & $1.31 \times 10^{1}$ & $8.58 \times 10^{1}$ \\
\hline & 1000 & $4.32 \times 10^{2}$ & $2.83 \times 10^{3}$ & $4.26 \times 10^{-1}$ & 2.79 & $8.53 \times 10^{-1}$ & 5.58 & 6.56 & $4.29 \times 10^{1}$ \\
\hline \multirow{2}{*}{ Pebbles } & 10000 & $4.32 \times 10^{1}$ & $2.83 \times 10^{2}$ & $4.26 \times 10^{-2}$ & $2.79 \times 10^{-1}$ & $8.53 \times 10^{-2}$ & $5.58 \times 10^{-1}$ & $6.56 \times 10^{-1}$ & 4.29 \\
\hline & 50000 & $8.64 \times 10$ & $5.65 \times 10^{1}$ & $8.53 \times 10^{-3}$ & $5.58 \times 10^{-2}$ & $1.71 \times 10^{-2}$ & $1.12 \times 10^{-1}$ & $1.31 \times 10^{-1}$ & $8.58 \times 10^{-1}$ \\
\hline \multirow{2}{*}{ Cobbles } & 100000 & 4.32 & $2.83 \times 10^{1}$ & $4.26 \times 10^{-3}$ & $2.79 \times 10^{-2}$ & $8.53 \times 10^{-3}$ & $5.58 \times 10^{-2}$ & $6.56 \times 10^{-2}$ & $4.29 \times 10^{-1}$ \\
\hline & 200000 & 2.16 & $1.41 \times 10^{1}$ & $2.13 \times 10^{-3}$ & $1.40 \times 10^{-2}$ & $4.26 \times 10^{-3}$ & $2.79 \times 10^{-2}$ & $3.28 \times 10^{-2}$ & $2.15 \times 10^{-1}$ \\
\hline
\end{tabular}

\begin{tabular}{|c|c|c|c|c|c|c|c|c|c|}
\hline & \multicolumn{4}{|c|}{$\begin{array}{l}\text { Witwatersrand low concentration with } \\
\qquad[\mathrm{K}]=380 \mathrm{ppm}\end{array}$} & \multicolumn{4}{|c|}{$\begin{array}{l}\text { Witwatersrand low concentration with } \\
{[\mathrm{K}]=3800 \mathrm{ppm}}\end{array}$} \\
\hline & & \multicolumn{2}{|c|}{ Pyrite wt. $5 \%$} & \multicolumn{2}{|c|}{ Pyrite wt. $10 \%$} & \multicolumn{2}{|c|}{ Pyrite wt. $5 \%$} & \multicolumn{2}{|c|}{ Pyrite wt. $10 \%$} \\
\hline $\begin{array}{l}\text { Types of } \\
\text { aggregate }\end{array}$ & $\begin{array}{l}\text { Grain } \\
\varphi / \mu \mathrm{m}\end{array}$ & $\begin{array}{c}\text { Cell } \\
\text { holding } \\
\text { capacity } \\
\text { per } \\
\text { kilogram } \\
\text { of rock } \\
\text { (minimum } \\
\text { ) } \\
\end{array}$ & $\begin{array}{l}\text { Cell holding } \\
\text { capacity per } \\
\text { kilogram of } \\
\text { rock } \\
\text { (maximum) }\end{array}$ & $\begin{array}{l}\text { Cell holding } \\
\text { capacity per } \\
\text { kilogram of } \\
\text { rock } \\
\text { (minimum) }\end{array}$ & $\begin{array}{l}\text { Cell holding } \\
\text { capacity per } \\
\text { kilogram of } \\
\text { rock } \\
\text { (maximum) }\end{array}$ & $\begin{array}{l}\text { Cell holding } \\
\text { capacity per } \\
\text { kilogram of } \\
\text { rock } \\
\text { (minimum) }\end{array}$ & $\begin{array}{l}\text { Cell holding } \\
\text { capacity per } \\
\text { kilogram of } \\
\text { rock } \\
\text { (maximum) }\end{array}$ & $\begin{array}{l}\text { Cell holding } \\
\text { capacity per } \\
\text { kilogram of } \\
\text { rock } \\
\text { (minimum) }\end{array}$ & $\begin{array}{l}\text { Cell holding } \\
\text { capacity per } \\
\text { kilogram of } \\
\text { rock } \\
\text { (maximum) }\end{array}$ \\
\hline Clay & 2 & $1.02 \times 10^{4}$ & $6.70 \times 10^{4}$ & $1.02 \times 10^{4}$ & $6.70 \times 10^{4}$ & $2.42 \times 10^{7}$ & $1.58 \times 10^{8}$ & $5.80 \times 10^{8}$ & $3.80 \times 10^{9}$ \\
\hline \multirow{2}{*}{ Silt } & 10 & $2.05 \times 10^{3}$ & $1.34 \times 10^{4}$ & $2.05 \times 10^{3}$ & $1.34 \times 10^{4}$ & $4.83 \times 10^{6}$ & $3.16 \times 10^{7}$ & $1.16 \times 10^{8}$ & $7.60 \times 10^{8}$ \\
\hline & 60 & $3.41 \times 10^{2}$ & $2.23 \times 10^{3}$ & $3.41 \times 10^{2}$ & $2.23 \times 10^{3}$ & $8.06 \times 10^{5}$ & $5.27 \times 10^{6}$ & $1.93 \times 10^{7}$ & $1.27 \times 10^{8}$ \\
\hline \multirow{3}{*}{ Sand } & 125 & $1.64 \times 10^{2}$ & $1.07 \times 10^{3}$ & $1.64 \times 10^{2}$ & $1.07 \times 10^{3}$ & $3.87 \times 10^{5}$ & $2.53 \times 10^{6}$ & $9.29 \times 10^{6}$ & $6.08 \times 10^{7}$ \\
\hline & 500 & $4.09 \times 10^{1}$ & $2.68 \times 10^{2}$ & $4.09 \times 10^{1}$ & $2.68 \times 10^{2}$ & $9.67 \times 10^{4}$ & $6.33 \times 10^{5}$ & $2.32 \times 10^{6}$ & $1.52 \times 10^{7}$ \\
\hline & 1000 & $2.05 \times 10^{1}$ & $1.34 \times 10^{2}$ & $2.05 \times 10^{1}$ & $1.34 \times 10^{2}$ & $4.83 \times 10^{4}$ & $3.16 \times 10^{5}$ & $1.16 \times 10^{6}$ & $7.60 \times 10^{6}$ \\
\hline \multirow{2}{*}{ Pebbles } & 10000 & 2.05 & $1.34 \times 10^{1}$ & 2.05 & $1.34 \times 10^{1}$ & $4.83 \times 10^{3}$ & $3.16 \times 10^{4}$ & $1.16 \times 10^{5}$ & $7.60 \times 10^{5}$ \\
\hline & 50000 & $4.09 \times 10^{-1}$ & 2.68 & $4.09 \times 10^{-1}$ & 2.68 & $9.67 \times 10^{2}$ & $6.33 \times 10^{3}$ & $2.32 \times 10^{4}$ & $1.52 \times 10^{5}$ \\
\hline \multirow{2}{*}{ Cobbles } & 100000 & $2.05 \times 10^{-1}$ & 1.34 & $2.05 \times 10^{-1}$ & 1.34 & $4.83 \times 10^{2}$ & $3.16 \times 10^{3}$ & $1.16 \times 10^{4}$ & $7.60 \times 10^{4}$ \\
\hline & 200000 & $1.02 \times 10^{-1}$ & $6.70 \times 10^{-1}$ & $1.02 \times 10^{-1}$ & $6.70 \times 10^{-1}$ & $2.42 \times 10^{2}$ & $1.58 \times 10^{3}$ & $5.80 \times 10^{3}$ & $3.80 \times 10^{4}$ \\
\hline
\end{tabular}




\begin{tabular}{|c|c|c|c|c|c|c|c|c|c|}
\hline \multirow[b]{3}{*}{$\begin{array}{l}\text { Types of } \\
\text { aggregate }\end{array}$} & \multirow[b]{3}{*}{$\begin{array}{l}\text { Grain } \\
\varphi / \mu \mathrm{m}\end{array}$} & \multicolumn{4}{|c|}{$\begin{array}{l}\text { Witwatersrand high concentration with } \\
\qquad[\mathrm{K}]=380 \mathrm{ppm}\end{array}$} & \multicolumn{4}{|c|}{$\begin{array}{l}\text { Witwatersrand high concentration with } \\
{[\mathrm{K}]=3800 \mathrm{ppm}}\end{array}$} \\
\hline & & \multicolumn{2}{|c|}{ Pyrite wt. $5 \%$} & \multicolumn{2}{|c|}{ Pyrite wt. $10 \%$} & \multicolumn{2}{|c|}{ Pyrite wt. 5\% } & \multicolumn{2}{|c|}{ Pyrite wt. $10 \%$} \\
\hline & & $\begin{array}{c}\text { Cell } \\
\text { holding } \\
\text { capacity } \\
\text { per } \\
\text { kilogram } \\
\text { of rock } \\
\text { (minimum } \\
\text { ) } \\
\end{array}$ & $\begin{array}{l}\text { Cell holding } \\
\text { capacity per } \\
\text { kilogram of } \\
\text { rock } \\
\text { (maximum) }\end{array}$ & $\begin{array}{l}\text { Cell holding } \\
\text { capacity per } \\
\text { kilogram of } \\
\text { rock } \\
\text { (minimum) }\end{array}$ & $\begin{array}{l}\text { Cell holding } \\
\text { capacity per } \\
\text { kilogram of } \\
\text { rock } \\
\text { maximum) }\end{array}$ & $\begin{array}{l}\text { Cell holding } \\
\text { capacity per } \\
\text { kilogram of } \\
\text { rock } \\
\text { (minimum) }\end{array}$ & $\begin{array}{l}\text { Cell holding } \\
\text { capacity per } \\
\text { kilogram of } \\
\text { rock } \\
\text { (maximum) }\end{array}$ & $\begin{array}{c}\text { Cell holding } \\
\text { capacity per } \\
\text { kilogram of } \\
\text { rock } \\
\text { (minimum) }\end{array}$ & $\begin{array}{l}\text { Cell holding } \\
\text { capacity per } \\
\text { kilogram of } \\
\text { rock } \\
\text { (maximum) }\end{array}$ \\
\hline Clay & 2 & $4.82 \times 10^{7}$ & $4.33 \times 10^{4}$ & $2.83 \times 10^{5}$ & $4.33 \times 10^{5}$ & $2.83 \times 10^{6}$ & $5.54 \times 10^{5}$ & $3.63 \times 10^{6}$ & $2.34 \times 10^{7}$ \\
\hline \multirow{2}{*}{ Silt } & 10 & $9.64 \times 10^{6}$ & $8.66 \times 10^{3}$ & $5.67 \times 10^{4}$ & $8.66 \times 10^{4}$ & $5.67 \times 10^{5}$ & $1.11 \times 10^{5}$ & $7.25 \times 10^{5}$ & $4.69 \times 10^{6}$ \\
\hline & 60 & $1.61 \times 10^{6}$ & $1.44 \times 10^{3}$ & $9.44 \times 10^{3}$ & $1.44 \times 10^{4}$ & $9.44 \times 10^{4}$ & $1.85 \times 10^{4}$ & $1.21 \times 10^{5}$ & $7.81 \times 10^{5}$ \\
\hline \multirow{3}{*}{ Sand } & 125 & $7.71 \times 10^{5}$ & $6.92 \times 10^{2}$ & $4.53 \times 10^{3}$ & $6.92 \times 10^{3}$ & $4.53 \times 10^{4}$ & $8.87 \times 10^{3}$ & $5.80 \times 10^{4}$ & $3.75 \times 10^{5}$ \\
\hline & 500 & $1.93 \times 10^{5}$ & $1.73 \times 10^{2}$ & $1.13 \times 10^{3}$ & $1.73 \times 10^{3}$ & $1.13 \times 10^{4}$ & $2.22 \times 10^{3}$ & $1.45 \times 10^{4}$ & $9.37 \times 10^{4}$ \\
\hline & 1000 & $9.64 \times 10^{4}$ & $8.66 \times 10^{1}$ & $5.67 \times 10^{2}$ & $8.66 \times 10^{2}$ & $5.67 \times 10^{3}$ & $1.11 \times 10^{3}$ & $7.25 \times 10^{3}$ & $4.69 \times 10^{4}$ \\
\hline \multirow{2}{*}{ Pebbles } & 10000 & $9.64 \times 10^{3}$ & 8.66 & $5.67 \times 10^{1}$ & $8.66 \times 10^{1}$ & $5.67 \times 10^{2}$ & $1.11 \times 10^{2}$ & $7.25 \times 10^{2}$ & $4.69 \times 10^{3}$ \\
\hline & 50000 & $1.93 \times 10^{3}$ & 1.73 & $1.13 \times 10^{1}$ & $1.73 \times 10^{1}$ & $1.13 \times 10^{2}$ & $2.22 \times 10^{1}$ & $1.45 \times 10^{2}$ & $9.37 \times 10^{2}$ \\
\hline \multirow{2}{*}{ Cobbles } & 100000 & $9.64 \times 10^{2}$ & $8.66 \times 10^{-1}$ & 5.67 & 8.66 & $5.67 \times 10^{1}$ & $1.11 \times 10^{1}$ & $7.25 \times 10^{1}$ & $4.69 \times 10^{2}$ \\
\hline & 200000 & $4.82 \times 10^{2}$ & $4.33 \times 10^{-1}$ & 2.83 & 4.33 & $2.83 \times 10^{1}$ & 5.54 & $3.63 \times 10^{1}$ & $2.34 \times 10^{2}$ \\
\hline
\end{tabular}

Figure 3 on the main manuscript illustrates the result for our calculation of the cell holding capacity as on Table S2 for each proposed scenario. For Figure 3, we have plotted these results in a log-log scale graph, once the results in normal scale showed an exponential-like distribution. We have highlighted the region between the maximum and minimum for the cell holding capacity per kilogram of rock to illustrate the range of the results for each scenario.

\section{References}

1. Folk, R. L. A REVIEW OF GRAIN-SIZE PARAMETERS. Sedimentology 6, 73-93 (1966).

2. Flügel, E. Microfacies of Carbonate Rocks. Climate Change 2013 - The Physical Science Basis 1, (Springer Berlin Heidelberg, 2010).

3. Stumm, W. \& Morgan, J. J. Aquatic Chemistry. (Wiley, 1981).

4. Chyba, C. F. PLANETARY SCIENCE: Enhanced: Life Without Photosynthesis. Science (80-. ). 292, 2026-2027 (2001).

5. Lide, D. R. CRC Handbook of Chemistry and Physics. eBook 3485 (2003). doi:9781466571143 


\section{APÊNDICE C - Resultados de modelo cinético de radiólise aquosa em diversos cenário}
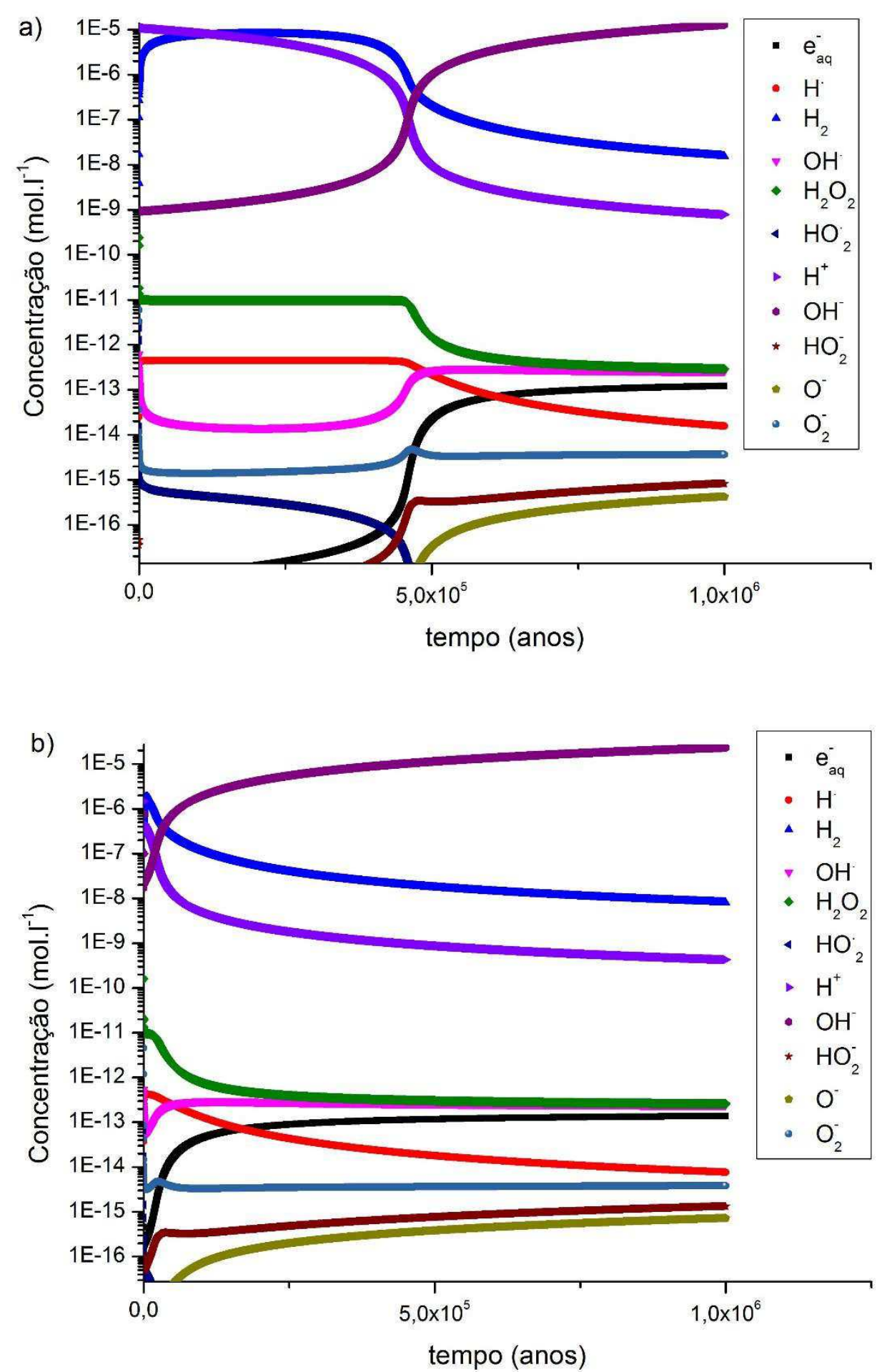

Figura C.1 - Resultado modelo cinético para concentração de radionuclídeo de condritos. $\left[{ }^{238} \mathrm{U}\right]=12$ $\mathrm{ppb} ;\left[{ }^{232} \mathrm{Th}\right]=40 \mathrm{ppb} ;\left[{ }^{40} \mathrm{~K}\right]=105 \mathrm{ppb}$. Em modelos de oceanos primitivos a) de $\mathrm{pH}=5$; b) de $\mathrm{pH}=7$. 

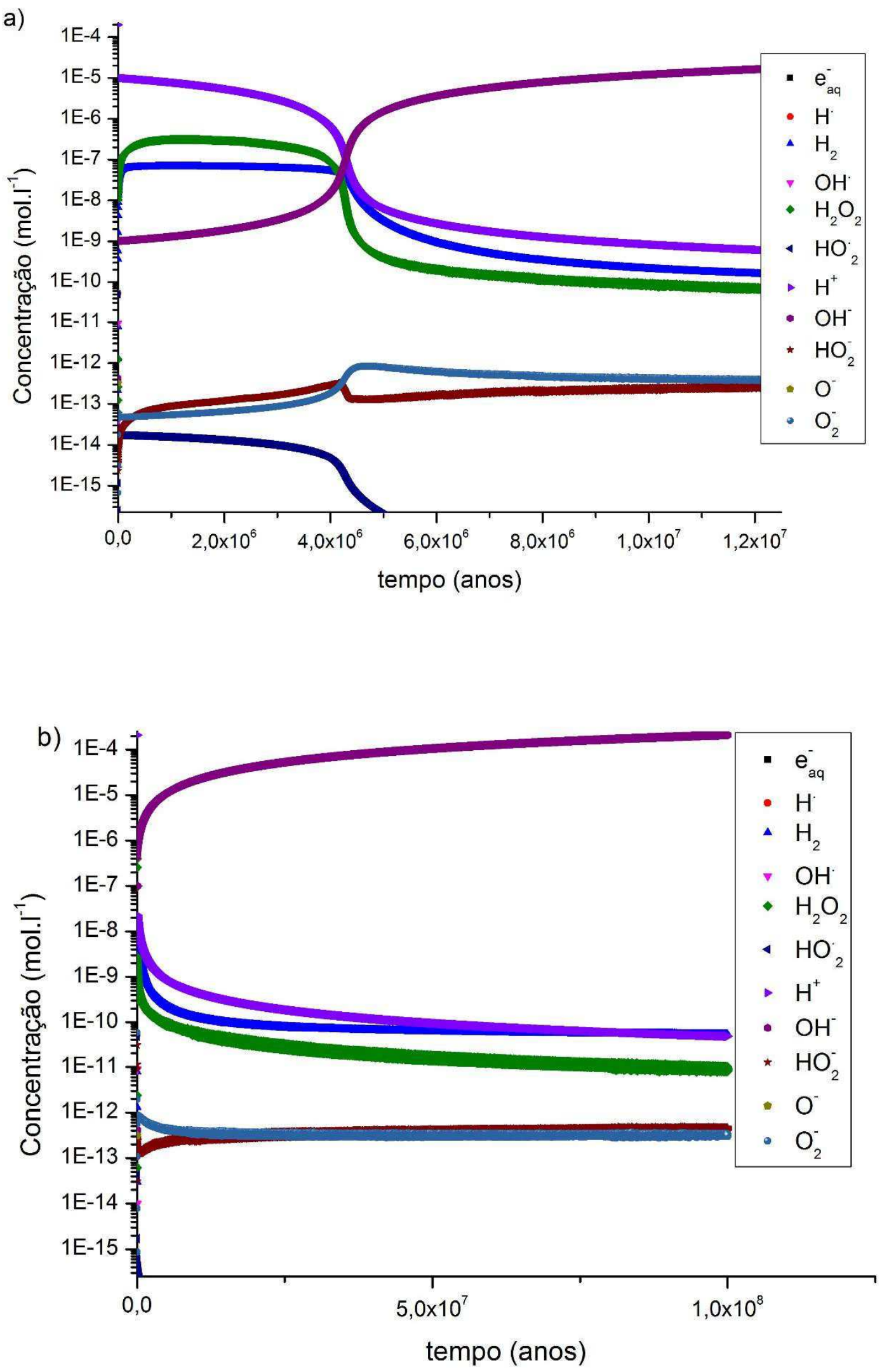

Figura C. 2 - Resultado modelo cinético para concentração de radionuclídeo de Witwatersrand. $\left.{ }^{238} \mathrm{U}\right]=271$ ppm; $\left[{ }^{232} \mathrm{Th}\right]=15 \mathrm{ppm} ;\left[{ }^{40} \mathrm{~K}\right]=380 \mathrm{ppm}$. Em modelos de oceanos primitivos a) de $\left.\mathrm{pH}=5 ; \mathrm{b}\right)$ de $\mathrm{pH}=7$. 


\section{APÊNDICE D - Equações Diferenciais Ordinárias (EDOs) stiff e princípios de método Rosenbrock de integração numérica.}

Equações stiff são EDOs para as quais a tentativa de resolução por alguns métodos numéricos resulta em instabilidade numérica. Enquanto para integrar equações diferenciais, é normal que intervalos sejam relativamente menores em regiões de alta variação da curva, e intervalos maiores onde a variação é menor. Há os casos de intervalos menores sejam usados para a solução em curvas com pouca variação, o que se pode ser associado ao termo stiffness, característica própria das EDOs stiff. Há ainda grande dificuldade em se definir precisamente o termo stiffness, associado a essas equações. Tentaremos, por tanto, com base em textos de revisões da literatura que abordam experimentos numéricos, desenvolver uma noção do termo e do método Rosenbrock, considerado adequado, dada tolerância de erros.

Considerando uma EDO com valor inicial canônico

$\boldsymbol{y}^{\prime}=\boldsymbol{f}(t, \boldsymbol{y}) t_{0} \leq t \leq t_{\text {final }}$,

$\boldsymbol{y}\left(t_{0}\right)=\boldsymbol{y}_{0}$

Sendo N, o número de EDOs escalares de primeira ordem; $\mathrm{t}$ a variável horária independente; $\boldsymbol{y}=\left[\mathrm{y}^{1}, \mathrm{y}^{2}, \ldots, \mathrm{y}^{\mathrm{N}}\right]^{\mathrm{T}}$ a coluna de vetores de dimensão $\mathrm{N}$ de variáveis dependentes; $\boldsymbol{f}$ é um vetor de dimensão $\mathrm{N}$ relativo à função y e $\mathrm{t}$; $\mathrm{t}_{0}$ é a condição inicial; $t_{\text {final}}$, o valor final do intervalo de integração e $\mathbf{y}_{0}$ é o valor inicial do vetor de dimensão $\mathrm{N}$.

Em uma equação stiff prototípica apresentada por BYRNE e HINDMARSH (1987)

$y=10^{-3}[y \quad \exp (t)] \quad[\exp (t)] t_{0} \leq t \leq t_{\text {final }}$

Onde y é escalar e cuja solução exata da equação é

$y(t)=[\exp (t)] \exp \left(10^{3} t\right)$

$\mathrm{Na}$ solução, $\exp \left(10^{3} t\right)$ é o elemento que varia muito mais rapidamente em to que a outra $(\exp (t))$. A partir disto, BYRNE e HINDMARSH (1987) (2) desenvolvem a noção de stiffness. Considerando as constantes $\tau_{1}=10^{-3}$ e $\tau_{2}=1$, para o qual quando $t=\tau_{1}$, o elemento rápido da solução equivale a $\exp \left(10^{3} \tau_{1}\right)=\exp (1)$ enquando o elemento lento da solução em $\mathrm{t}=$ $\tau_{2}$ equivale ao mesmo $\exp (1)$. Para $t$ muito menor do que $\tau_{1}$, a componente rápida é a que influencia o resultado da solução. Para estes intervalos de t, não há necessidade de métodos numéricos especiais. No entanto a estabilidade não é ilimitada, fora deste intervalo o problema é stiff resultado é influenciado pela componente lenta, ainda que métodos explícitos de 
resolução sejam forçados a usar passos extremamente curtos para a integração, devido à presença do componente rápido. Em sistemas de equações químicas em que às concentrações das espécies variam em diferentes ordens de grandeza, dado as diferentes magnitudes das constantes das reações envolvidas, são associadas EDOs stiff.

Para a solução dessas EDOs stiff, principalmente abordando química atmosférica, a literatura aponta o método de Rosenbrock como eficiente, juntamente com o BDF (3). O método parte da linearização de um método Runge-Kutta diagonalmente implícito. Um método Runge-Kutta de s-estágios aplicado ao problema da EDO com valor inicial canônico, na sua forma escalar é, dado por

$$
\begin{gathered}
y_{n+1}=y_{n}+\sum_{i=1}^{s} b_{i} k_{i} i=1, \ldots, s \\
y_{n+1}=f\left(y_{n}+\sum_{j=1}^{s} a_{i j} k_{j}\right)
\end{gathered}
$$

Onde se define um método Runge-Kutta diagonalmente implícito se $a_{i j}=0$ para $\mathrm{i}>\mathrm{j}$ e quando pelo menos um valor $a_{i i} \neq 0$. Com $=t_{n+1} \quad t_{n}$ sendo o tamanho do passo e $y_{n}$, uma aproximação para $y\left(t_{n}\right)$; sendo que cada passo do método é equivalente a encontrar o zero da função $F:{ }^{m} \rightarrow{ }^{m}$ sendo $F(y)=y \quad y_{n} \quad f(y)$. Sartori (2014) (3) realizou a expansão em série de Taylor da equação (C.5) em método Runge-Kutta diagonalmente implícito em torno de $g_{i}=y_{n}+\sum_{j=1}^{i-1} a_{i j} k_{j}$ obtendo a equação linearizada

$$
k_{i}=f\left(g_{i}\right)+J_{f}\left(g_{i}\right) a_{i i} k_{i}
$$

Sendo $J_{F}\left(y_{0}\right)=\frac{\partial f}{\partial y}\left(y_{0}\right)$ a matriz jacobiana das derivadas de $F$ em relação a $y$. Dessa forma, por Rosenbrock se deriva fórmulas estáveis e trabalha diretamente com a matriz jacobiana que, fazendo substituições devidas de $g_{i}$ por $y_{n}$, obtém-se vantagens computacionais. 


\section{REFERÊNCIAS}

1 Byrne, G. D., Hindmarsh, A. C., Stiff ODE solvers: A review of current and coming attractions. Journal of Computational Physics. 70, 1-62 1987.

2 Byrne, G. D., Hinndmarsh, A. C., ArticDe tiff ODE Solvers : A Review of Corning Attractions. J. Comp. Phys. 70, 1-62 1987.

3 SARTORI, L. M., Métodos para resolução de EDOs stiff resultantes de modelos químicos atmosféricos. (2014). 99p. Dissertação (Mestre em Ciências) - Instituto de Matemática e Estatística, Universidade de São Paulo, São Paulo, (2014). 